Chary Ely Martin Marquez Batista

\title{
Análise dos mecanismos de neuroplasticidade na porção lombar da medula espinal do rato submetida à lesão isquêmica fototrombótica e tratada pela injeção local de PEDF
}

Dissertação apresentada à Faculdade de Medicina da Universidade de São Paulo para obtenção do título de Mestre em Ciências

Programa de: Neurologia

Orientador: Prof. Dr. Gerson Chadi 
Dados Internacionais de Catalogação na Publicação (CIP)

Preparada pela Biblioteca da

Faculdade de Medicina da Universidade de São Paulo

Oreprodução autorizada pelo autor

\section{Batista, Chary Ely Martin Marquez}

Análise dos mecanismos de neuroplasticidade na porção lombar da medula espinal do rato submetida à lesão isquêmica fototrombótica e tratada pela injeção local de PEDF / Chary Ely Martin Marquez Batista. -- São Paulo, 2012.

Dissertação(mestrado)--Faculdade de Medicina da Universidade de São Paulo. Programa de Neurologia.

Orientador: Gerson Chadi.

Descritores: 1.Medula espinal 2.Lesão isquêmica fototrombótica 3.PEDF 4.Sistema Eph/efrina 5.Plasticidade neuronal 6.Ratos Wistar

USP/FM/DBD-057/12 


\section{Dedicatória}

Dedico esta dissertação aos meus pais Clássio e Pepi, minhas maiores fontes de inspiração, pelos ensinamentos que formaram os alicerces da minha vida. 


\section{AGRADECIMENTOS}

Ao prof. Dr. Gerson Chadi, pela oportunidade de realizar este trabalho e pelos ensinamentos transmitidos durante esta trajetória. Obrigada por me introduzir ao "mundo da pesquisa", dando-me subsídios para a consecução deste projeto. Que este seja apenas o começo de uma longa jornada.

À pesquisadora Jessica Ruivo Maximino, pela amizade e pela ajuda indispensável na realização desse trabalho.

Ao Dr. Edmar Zanoteli, pela grande ajuda na etapa laboratorial.

Aos pós-graduandos e amigos do Lim-45, Gabriela Oliveira, Tatiana Duobles, Juliana Scorisa, Thaís Moura, Chrystian Alves, Rita Macedo, Alan Fappi, Vanessa Rizzato e Juliana Neves, por toda ajuda, pelas valiosas discussões e pelos bons momentos que passamos juntos.

Aos amigos Leonardo Bianqui, Bruno Zanon e Mauricio Ivo, que foram imprescindíveis na elaboração e execução desse projeto.

Aos funcionários do LIM-45, Sarah, Florence e Gilmar, pela grande ajuda no decorrer deste experimento.

Aos membros da banca de qualificação, Dr. Mario Augusto Taricco e Dra. Vânia Gomide, pelas sugestões que engrandeceram este trabalho.

Ao Dr. Ricardo Nitrini e ao programa de pós-graduação, pela grande oportunidade.

Aos meus irmãos Leandro e Vanessa, por todo apoio, carinho e principalmente pela nossa grande amizade. Eu me espelho em vocês.

À minha família, sinônimo de união, por todo carinho e dedicação. Um abraço especial a mi abuela Maria Luiza e a minha tia Maria del Pilar (Pili), minhas segundas mães, por terem me ajudado e apoiado em todos os momentos.

À FAPESP (2009/13248-5) e CNPq. 
"Quando uma criatura humana desperta para um grande sonho e sobre ele lança toda a força de sua alma, todo o universo conspira a seu favor". 
Esta dissertação está de acordo com as seguintes normas, em vigor no momento desta publicação:

Referências: adaptado de International Committee of Medical Journals Editors (Vancouver).

Universidade de São Paulo. Faculdade de Medicina. Divisão de Biblioteca e Documentação. Guia de apresentação de dissertações, teses e monografias. Elaborado por Anneliese Carneiro da Cunha, Maria Julia de A. L. Freddi, Maria F. Crestana, Marinalva de Souza Aragão, Suely Campos Cardoso, Valéria Vilhena. 3a ed. São Paulo: Divisão de Biblioteca e Documentação; 2011.

Abreviaturas dos títulos dos periódicos de acordo com List of Journals Indexed in Index Medicus. 


\section{SUMÁRIO}

\section{LISTA DE TABELAS}

LISTA DE FIGURAS

RESUMO

\section{ABSTRACT}

1. INTRODUÇÃO

1.1. Lesão Medular............................................................................. 2

1.2. Lesão Medular Isquêmica Fototrombótica........................................... 3

1.3. Neurodegeneração...........................................................................

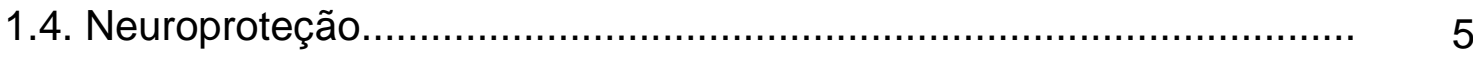

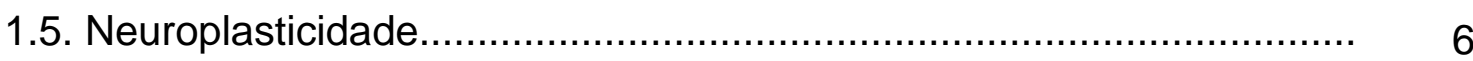

1.6. Sistema Eph/Efrina ...................................................................

1.7. Fator Derivado do Epitélio Pigmentado............................................. 12

1.8. Centro Gerador de Padrão.............................................................. 15

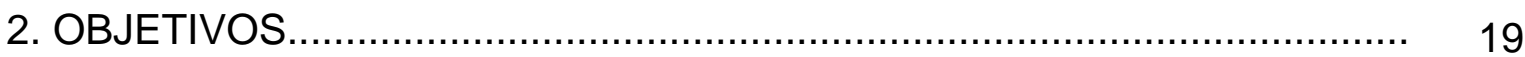

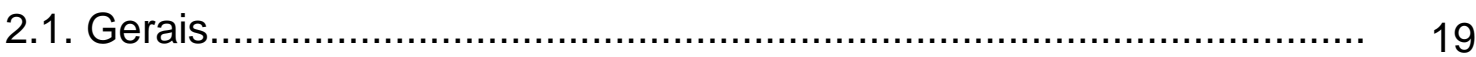

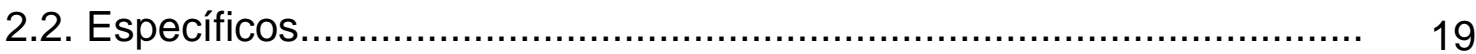

3. MATERIAIS E MÉTODOS.................................................................. 22

3.1. Lesão Medular Isquêmica Fototrombótica.......................................... 22

3.2. Injeção Local de PEDF.................................................................. 25

3.3. Grupos Experimentais................................................................ 25

3.4. Análise Comportamental.............................................................. 26

3.4.1. Índice BBB....................................................................... 26

3.4.2. Índice CBS..................................................................... 28 
3.4.3. Impressão de Pegadas.

3.5. Processamento Tecidual para a Técnica de Imunoistoquímica............ 32

3.5.1. Seccionamento e Amostragem.................................................. 33

3.5.2. Imunoperoxidase ............................................................. 33

3.5.3. Análise de Imagem.............................................................. 34

3.5.4. Imunofluorescência de Duas Cores.......................................... 35

3.6. Processamento Tecidual para as Técnicas de Western Blot e PCR em Tempo Real............................................................................ $\quad 36$

3.6.1. Western Blot........................................................................ 37

3.6.2. Extração e Quantificação de RNA Total..................................... 40

3.6.3. Reação da Polimerase em Cadeia em Tempo Real.................... 41

3.7. Análise Estatística..................................................................... 43

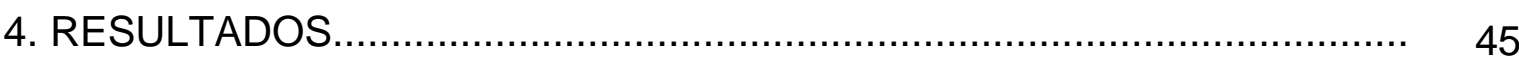

4.1. Análise Comportamental................................................................. 45

4.1.1. Análise Comportamental BBB e CBS..................................... 45

4.1.2. Análise Motora Fina - Impressão de pegadas............................ 50

4.2. Análise de Moléculas Inibidoras do Crescimento de Fibras................. 52

4.3. Análise dos Fatores Neurotróficos....................................................... 53

4.4. Análise da Angiogênese e Apoptose Local........................................... 55

4.5. Análise de Moléculas Relacionadas à Neuroplasticidade..................... 56

4.6. Análise de Moléculas do Sistema Eph/Efrina....................................... 59

4.7. Análise da Localização Celular dos Receptores Eph/Efrinas................. 65

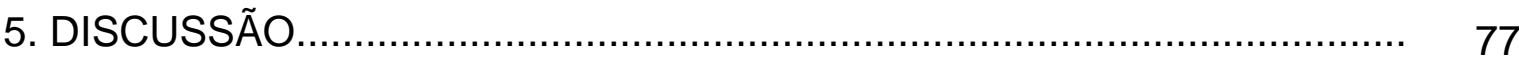

5.1. Lesão Medular Isquêmica ............................................................ 77

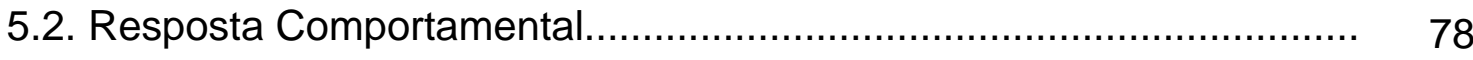


5.3. Restrição do Crescimento de Fibras......................................... 80

5.4. Trofismo Neuronal............................................................ 81

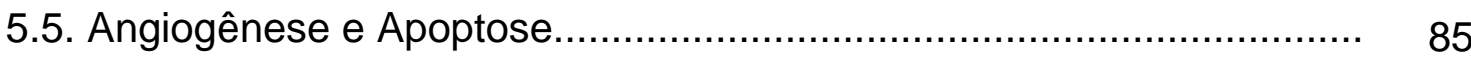

5.6. Neuroplasticidade da Medula Espinal...................................... 86

5.7. Mecanismos de Neuroplasticidade........................................... 89

5.8. Localização Celular do Sistema Eph/Efrina................................. 93

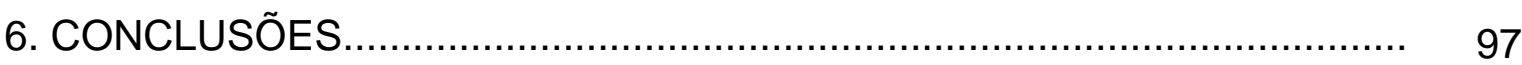

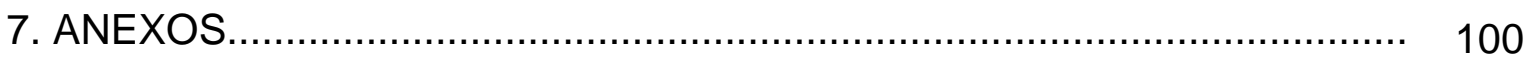

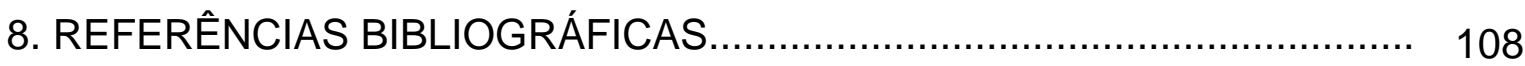




\section{LISTA DE TABELAS}

Tabela 1: Escala locomotora BBB ......................................................... 27

Tabela 2: Índice CBS...................................................................... 31

Tabela 3: Relação dos anticorpos dos receptores Eph e das efrinas e as concentrações utilizadas na técnica do western blot..................... 40

Tabela 4: Dados referentes às análises comportamentais BBB e CBS obtidos através da análise estatística ANOVA de duas vias.......... 47

Tabela 5: Dados referentes aos testes que compõem o índice CBS obtidos através da análise estatística ANOVA de duas vias....................... 48

Tabela 6: Dados referentes às avaliações que compõem 0 teste impressão de pegadas obtidos através da análise estatística ANOVA de duas vias 


\section{LISTA DE FIGURAS}

Figura 1: Características gerais das estruturas dos receptores Eph e das efrinas e o conceito de sinalização bidirecional.

Figura 2: Interações entre as diferentes classes dos receptores Eph e seus ligantes...

Figura 3: Fotografia de um animal submetido à lesão medular isquêmica fototrombótica.

Figura 4: Eletroferogramas indicando a integridade dos RNA

Figura 5: Gráficos dos índices BBB e CBS

Figura 6: Gráficos dos testes que compõem o índice CBS.

Figura 7: Gráficos das avaliações que compõem o teste impressão de pegadas.

Figura 8: Gráficos dos níveis de proteína das CSPGs.

Figura 9: Gráficos da expressão relativa de RNAm dos fatores neurotróficos NT-3,FGF-2, BDNF e GDNF.

Figura 10: Gráfico do nível de proteína do PEDF 54

Figura 11: Gráficos dos níveis de proteína da laminina e do Bcl-2. 55

Figura 12: Gráficos das áreas de imunorreatividade da MAP-2 e da GAP-43... 56

Figura 13: Fotomicrografias da imunorreatividade da MAP-2

Figura 14: Gráficos dos níveis de proteína da MAP-2, GAP-43 e sinaptofisina.. 58

Figura 15: Gráficos dos níveis de proteína dos receptores Eph do tipo A......... 60

Figura 16: Gráficos dos níveis de proteína dos receptores Eph do tipo B......... 61

Figura 17: Gráficos dos níveis de proteína das efrinas do tipo A.................... 62

Figura 18: Gráficos dos níveis de proteína das efrinas do tipo B. 
Figura 19: Gráficos da expressão relativa de RNAm dos receptores EphA6 e EphB2.

Figura 20: Gráfico da expressão relativa de RNAm da RhoA

Figura 21: Fotomicrografias da localização celular dos receptores do tipo A estudados no corno anterior da região lombar.

Figura 22: Fotomicrografias da localização celular dos receptores do tipo B estudados no corno anterior da região lombar.

Figura 23: Fotomicrografias da localização celular da efrina-A5 estudada no corno anterior da região lombar

Figura 24: Fotomicrografias da localização celular das efrinas do tipo B estudadas no corno anterior da região lombar.

Figura 25: Fotomicrografias da localização celular do receptor EphA4 estudado na raiz ventral do nervo.

Figura 26: Fotomicrografias da localização celular dos receptores do tipo A estudados no funículo posterior da região lombar.

Figura 27: Fotomicrografias da localização celular das efrinas do tipo A estudadas no funículo posterior da região lombar

Figura 28: Fotomicrografias da localização celular dos receptores do tipo A estudados no corno anterior da região onde foi aplicada a lesão......

Figura 29: Fotomicrografias da localização celular dos receptores do tipo A estudados na área da lesão.

Figura 30: Fotomicrografias da localização celular dos receptores do tipo B estudados na área da lesão. 


\section{RESUMO}

Batista, CEMM. Análise dos mecanismos de neuroplasticidade na porção lombar da medula espinal do rato submetida à lesão isquêmica fototrombótica e tratada pela injeção local de PEDF [Dissertação]. São Paulo: Faculdade de Medicina, Universidade de São Paulo; 2012.

O fator derivado do epitélio pigmentado (PEDF) é um fator neurotrófico que possui um grande potencial trófico nos neurônios motores da medula espinal, bem como é capaz de modular o microambiente da lesão. Desta forma, analisamos a capacidade do tratamento com PEDF em promover a neuroplasticidade da medula espinal após lesão isquêmica. Ratos Wistar adultos foram submetidos à lesão medular isquêmica do tipo fototrombótica, segundo o método de Rose Bengal, na altura do $11^{\circ}$ segmento torácico e foram imediatamente tratados com inoculação local de PEDF (grupo PEDF) ou solvente (grupo Salina). Ratos submetidos à cirurgia simulada (grupo Sham) receberam a injeção do solvente. Ao término do procedimento cirúrgico, os ratos foram submetidos a testes neurofuncionais durante 6 semanas. Após esse período, os animais sofreram eutanásia e o tecido medular foi dividido entre as técnicas de imunoistoquímica, western blot e PCR em tempo real. Foi analisada na região lombar anterior da medula espinal a modulação das CSPGs, a expressão dos fatores neurotróficos NT-3, GDNF, BDNF e FGF-2, bem como os níveis das moléculas associadas à angiogênese e apoptose (laminina e Bcl-2), das proteínas relacionadas à neuroplasticidade (MAP-2, GAP-43 e sinaptofisina) e do sistema Eph/efrina e a RhoA, que são capazes de modular o crescimento de fibras. Os resultados mostraram uma recuperação parcial e espontânea do comportamento sensório-motor dos animais que foram submetidos à lesão fototrombótica, onde o tratamento com PEDF foi capaz de potencializar alguns desses parâmetros. A análise da região lombar anterior da medula espinal, caudal à lesão, mostrou uma diminuição das CSPGs nos dois grupos lesados, o que pode ter favorecido os eventos de neuroplasticidade. O tratamento com PEDF foi capaz de promover a regulação dos fatores neurotróficos NT-3 e GDNF, diminuir a angiogênese local (diminuição da laminina) e potencializar o processo de neuroplasticidade (aumento da MAP-2) nessa região. A lesão medular isquêmica foi capaz de modular a expressão do receptor EphA4 e da efrina-B1 e o tratamento com PEDF possivelmente regulou o estado de ativação da efrina-A2 e da efrina-B3 e certamente modulou a ativação da efrina-B2. Ainda, os receptores Eph e as efrinas foram observados diferentemente nos neurônios e astrócitos. Nossos resultados confirmam a capacidade plástica da medula espinal após lesão e mostra que o tratamento com PEDF foi capaz de potencializar esse processo.

Descritores: Medula espinal, Lesão isquêmica fototrombótica, PEDF, Plasticidade neuronal, Sistema Eph/efrina, Ratos Wistar. 


\section{ABSTRACT}

Batista, CEMM. Analysis of neuroplasticity mechanisms in lumbar levels of the rat spinal cord submitted to photothrombotic ischemia and treated with local injection of PEDF [Dissertation]. São Paulo: Faculty of Medicine, University of São Paulo; 2012.

The pigment epithelium derived factor (PEDF) is a neurotrophic factor that has a great trophic potential in the motor neurons of the spinal cord, and is able to modulate the lesion microenvironment. We analyzed the capacity of the treatment with PEDF to promote the neuroplasticity after ischemic spinal cord injury. Adult male Wistar rats were underwent to photothrombotic ischemic spinal cord injury, according to the Rose Bengal method, at the level of $11^{\circ}$ thoracic segment, and were immediately treated with local injection of PEDF (PEDF group) or solvent (Saline group). Rats underwent to a sham surgery (Sham group) received solvent injection. At the end of surgery, the rats were submitted to neurofunctional tests during 6 weeks. After this period, the animals were euthanized, and the anterior lumbar region of the spinal cord tissue was submitted to immunohistochemistry, western blot and real-time PCR analyses. The inhibitory response of CSPGs, the expression of neurotrophic factors (NT-3, GDNF, BDNF and FGF-2), the molecules associated with angiogenisis and apoptosis (laminin and $\mathrm{Bcl}-2$ ), the proteins related to neuroplasticity (MAP-2, GAP-43 and synaptophysin), as well the Eph/ephrin system and the RhoA, which is able to modulate the fibers growth, were evaluated. The results showed a spontaneous, and parcial, recovery of the sensory motor behavior of the animals that were underwent to a photothrombotic injury, and the treatment with PEDF was able to potentiate some of these parameters. The analysis of the anterior lumbar region of the spinal cord, caudally to the lesion, showed a decrease of CSPGs, which may have favored the neuroplasticity events. The treatment with PEDF was able to promote the regulation of NT-3 and GDNF, as well the reduction of laminin and the increase of MAP-2 in that region. In relation to the Eph/ephrin system, the ischemic spinal cord injury was able to modulate the EphA4 receptor and ephrin-B1 expression, and the treatment with PEDF possibly regulated the activation state of ephrin-A2 and ephrin-B3 and certainly modulated the ephrin-B2 activation. Eph receptors and ephrins have been found specifically in neurons and astrocytes. Our results confirmed the plastic capacity of the spinal cord after injury and showed that the treatment with PEDF was able to enhance this process.

Descriptors: Spinal cord, Photothrombotic ischemic injury, PEDF, Neuronal plasticity, Eph/ephrin system, Wistar rats. 


\section{INTRODUÇÃO}




\section{INTRODUÇÃO}

\subsection{Lesão Medular}

A lesão da medula espinal, especialmente quando se instala de forma súbita, é uma das lesões mais devastadoras do ponto de vista fisiológico e psicológico, causando alterações importantes nas atividades de vida diária do paciente. A desconexão dos tratos e feixes de fibras nervosas responsáveis pela comunicação ascendente e descendente da medula espinal resulta em alterações sensório-motoras, bem como a perda do controle dos órgãos nos segmentos do corpo localizados abaixo da lesão.

Estima-se que 12.000 casos novos de lesão medular ocorram por ano nos Estados Unidos, acometendo em sua maioria homens com idade entre 16 e 30 anos, fase mais produtiva de sua vida. Os acidentes automobilísticos correspondem à causa mais importante de lesão medular (40,4\%), seguido por quedas $(27,9 \%)$, violência (15\%) e esportes (8\%) (The National Spinal Cord Injury Statistical Center, EUA, 2011). Os trabalhos epimediologicos publicados acerca da lesão medular no Brasil são escassos, não existindo estatísticas fiéis a respeito de tais incidências.

Ainda que a isquemia da medula espinal não seja a causa mais frequente de lesão medular, este é um evento clinicamente relevante, presente numa série de situações patológicas onde o fluxo sanguíneo à medula é restringido ou obstruído pós-eventos circulatórios sistêmicos ou ainda parenquimatosos. Não obstante, o componente isquêmico está sempre presente após uma lesão da medula espinal, independente da etiologia, contribuindo para os mecanismos fisiopatológicos deletérios secundários do órgão. 


\subsection{Lesão Medular Isquêmica Fototrombótica}

A despeito de sua importância, os efeitos lesivos da isquemia na lesão medular, bem como a reversão destes, têm sido pouco estudados. A observação experimental desses eventos é necessária para o entendimento das respostas celulares e bioquímicas no tecido lesado e nas áreas adjacentes a este.

A lesão fototrombótica experimental de Rose Bengal é promovida pela injeção sistêmica do corante tetracloro-tetraiodofluorosceína de dissódio, que atua como agente fotossensibilizante após iluminação específica do local onde se deseja obstruir o fluxo sanguíneo (Bunge et al., 1994). Quando iluminado por luz de comprimento de onda em torno de $560 \mathrm{~nm}$, o corante transfere grande parte da energia para moléculas oxidantes, notadamente radicais livres do oxigênio que, por meio de reações de peroxidação, lesam a célula endotelial (Watson et al., 1993), com reação trombogênico-plaquetária subsequente. Deste modo, a lesão, bem delimitada, coincide exatamente com a área que recebeu o foco de luz.

O método foi largamente utilizado no estudo da isquemia cerebral (Boquillon et al., 1992; Lippoldt, 1993; Takamatsu, 2000; Pevsner et al., 2001; Schroeter et al., 2002; Lee et al., 2007) e, recentemente, é empregado na promoção da lesão isquêmica da medula espinal. Os animais lesados apresentam alterações de motricidade e sensibilidade evidenciadas por escalas de avaliação sensório-motoras específicas (Prado et al., 1987; Gaviria et al., 2002; Scheff et al., 2002; García-Alias et al., 2006). A concentração definida do corante e o tempo de exposição à luz correlacionam-se com a profundidade da lesão desejada, que é evidenciada pelas alterações histopatológicas e neuro-comportamentais no pósoperatório. 


\subsection{Neurodegeneração}

O prognóstico da lesão medular depende do tipo e da intensidade da agressão. Ainda na fase aguda, células como os neutrófilos, linfócitos, macrófagos e as neuroglias invadem a área lesada da medula espinal (Anderson e Hall, 1993). Além disso, mudanças celulares e moleculares, tais como eventos inflamatórios, citotóxicos, vasculares e edema no local da lesão, resultam na perda progressiva do tecido espinal, provocando uma autodestruição secundária do órgão. Esta ocorrência, muitas vezes conhecida como neurodegeneração secundária, pode modificar totalmente o prognóstico do paciente ao transformar uma lesão parcial em total.

$\mathrm{Na}$ fase subaguda da lesão medular, os mecanismos de reparo e cicatrização entram em cena, formando uma cicatriz glial que é inibitória ao crescimento das fibras lesadas (Fawcett e Asher, 1999), ficando estas impedidas de encontrarem suas células-alvo de inervação (Oudega et al., 1999). Ademais, várias moléculas da matriz extracelular têm sido identificadas como capazes de restringir a regeneração do sistema nervoso central (SNC) após uma lesão, como as proteoglicanas de sulfato de condroitina (CSPGs). As CSPGs, apesar de possuirem um papel importante no desenvolvimento do cérebro e da medula espinal, por impedir o crescimento axonal para um local inapropriado, são inibitórias ao crescimento e regeneração axonal através do sítio de uma lesão. $\mathrm{O}$ aumento em sua expressão ocorre no quarto dia após a lesão na medula espinal, persistindo por semanas a meses (Lemons et al., 1999; Bradbury et al., 2002).

Era clássico o conceito de que, uma vez lesado, o SNC não possuiria ferramentas para se recompor. Esse conceito começou a ser questionado no início do século XX por Santiago Ramon y Cajal (Stahnisch e Nitsch, 2002), 
entretanto, o dogma da incapacidade regenerativa do SNC foi derrubado apenas quando Aguayo e colaboradores (1981) demonstraram a capacidade regenerativa considerável de neurônios centrais, utilizando modelos específicos de lesão, desde que condições favoráveis sejam fornecidas para tal. Entre elas, a manutenção da sobrevida dos neurônios lesados é condição essencial, o que pode ser promovido pelo controle das reações citotóxicas e inflamatórias no local da lesão, bem como pela promoção do suporte trófico dado a estas células através do suprimento local com moléculas com ação neurotrófica.

\subsection{Neuroproteção}

Os fatores neurotróficos são moléculas protéicas capazes de manter a vida dos neurônios, de estimular o crescimento axonal e de proteger os corpos celulares de neurônios agredidos, bem como induzir a neuroplasticidade nos neurônios remanescentes (Kuncl et al., 2002). Estas ações são verificadas através de estudos in vivo e in vitro (Bilak et al., 1999b; Mitsumoto e Tsuzaka, 1999; Hale et al., 2011; Hollis e Tuszynski, 2011). A despeito de alguns fatores neurotróficos terem seus efeitos amplificados por ações indiretas, como por exemplo, por modular o processo inflamatório, as reações vasculares e a formação cicatricial no microambiente da lesão, a maior expressão funcional destas moléculas é a de promover neuroplasticidade nos neurônios remanescentes na fase crônica após a lesão. Vários fatores neurotróficos mostram ações desta natureza na medula espinal. A neurotrofina-3 (NT-3) é um fator neurotrófico da família das neurotrofinas que reconhecidamente contribui para a sobrevivência e a diferenciação dos motoneurônios da medula espinal, 
assim como estimula o crescimento e a diferenciação de novos neurônios e sinapses (Maisonpierre et al., 1990; Scarisbrick et al., 1999). O fator neurotrófico derivado da glia (GDNF) é um potente fator neurotrófico que promove a sobrevivência e a diferenciação morfológica de neurônios centrais (Lin et al., 1993). Durante o desenvolvimento, o GDNF é produzido pelas células de Schwann, e seu papel principal em neurônios motores após o nascimento é a promoção da ramificação de terminais axonais e a formação sináptica (Airaksinen

e Saarma, 2002). O fator neurotrófico derivado do cérebro (BDNF) também desempenha um papel essencial na manutenção neuronal, podendo reduzir a apoptose neural e promover a regeneração de neurônios lesados (Zong et al., 2011).

Os fatores de crescimento de fibroblastos também são implicados em vários processos celulares, incluindo proliferação, migração, diferenciação e sobrevivência. Particularmente, o fator de crescimento fibroblástico-2 (FGF-2) possui propriedades neurotróficas e gliogênicas e é conhecido por regular a resposta pós-lesão no SNC, esta que inclui a transformação de astrócitos reativos, a neurogênese e a promoção de atividades neurotróficas. Estes efeitos variados do FGF-2 no SNC podem ser benéficos à recuperação funcional após a lesão da medula espinal (Fahmy e Moftah, 2010).

\subsection{Neuroplasticidade}

Outro evento importante no processo de neurorestauração é a neuroplasticidade dos neurônios remanescentes da lesão, estes que se modificam morfológica e neuroquimicamente no sentido de desenvolverem funções que antes eram atribuídas às áreas lesadas ou ainda ao crescimento de 
fibras, na tentativa de prover ao sujeito uma melhor condição comportamental e neurofuncional às deficiências sensoriais, motoras e cognitivas após lesões (Aguayo et al., 1991).

Proteínas associadas à regeneração representam um papel importante na plasticidade neuronal, entre elas destacam-se a proteína associada ao microtúbulo-2 (MAP-2) e a proteína 43 associada ao crescimento (GAP-43) (Di Giovanni et al., 2005).

A MAP-2 é uma proteína estrutural do citoesqueleto dos neurônios e também está envolvida na regulação de processos intracelulares de transdução de sinal (Sanchez et al., 1998). Sua expressão aumentada após uma lesão do tecido nervoso sugere sua participação nos fenômenos neuroplásticos, que podem interferir na recuperação motora. Por sua vez, a GAP-43 é a maior constituinte do cone de crescimento no mamífero durante o desenvolvimento inicial das projeções do SNC, e mesmo durante a regeneração do sistema nervoso periférico (SNP). Além disso, ela possui um papel chave no direcionamento do crescimento dos axônios e na modulação da formação de novas conexões (Benowitz e Routtenberg, 1997).

Outro mecanismo importante é a plasticidade sináptica (Gulino et al., 2007). A sinaptofisina, proteína associada à vesícula pré-sináptica encontrada nos axônios terminais, é um marcador do crescimento de fibras e da sinaptogênese após uma lesão do tecido nervoso (Chen et al., 1998). Essa proteína também se manifesta antes da sinaptogênese e coincide com o crescimento de fibras no desenvolvimento da medula espinal e na extensão do cone de crescimento dos neuritos, estes que são necessários para a formação sináptica. Um aumento em 
sua expressão coincide com o incremento de terminais sinápticos, apontando para um possível crescimento de axônios locais e maior efetividade da neurotransmissão sináptica (Krassioukov e Weaver, 1996).

\subsection{Sistema Eph/Efrina}

Modificações nos axônios terminais e nos dendritos são necessárias no processo de plasticidade sináptica, sendo que o sistema de sinalização bidirecional realizado pelos receptores Eph (Eph, receptor interacting proteins) e seus ligantes, as efrinas (Erythropoietin-producing hepatocellular), está particularmente adaptado para a regulação desse processo. O sistema Eph/efrina possui papel chave no direcionamento axonal durante o desenvolvimento do SNC e, apesar de suas funções não estarem totalmente claras no sistema nervoso adulto, estudos recentes apontam para esse sistema como sendo importante na plasticidade neuronal e sinaptogêne após a lesão neural (Klein, 2009; Zhao et al., 2010).

Os Eph fazem parte da família de receptores da tirosina cinase e são proteínas transmenbrânicas com domínio intra e extracelulares altamente conservados, capazes de deflagrar homo e heterodimerizações. Os receptores Eph são divididos em tipo A e B segundo a similaridade de suas sequências de domínio extracelular. Nos mamíferos, os Eph são subdivididos em nove membros do tipo A (EphA1-A8 e A10) e cinco do tipo B (EphB1-B4 e B6) (Martinez et al., 2004; Klein, 2009).

Diferenças estruturais também distinguem duas classes de efrinas, sendo que as efrinas do tipo $A$ (A1-A6) são presas à membrana plasmática por um 
ancorador GPI, enquanto as efrinas do tipo B (B1-B3) possuem uma curta cauda citoplasmática (figura 1). Em geral, os receptores de cada tipo se unem às efrinas correspondentes, ainda que existam exceções, por exemplo, o receptor EphA4 é capaz de interagir com as efrinas-B2 e B3, como mostra a figura 2 (Aoto e Chen, 2007; Arvanitis e Davy, 2008).

Os receptores Eph e suas efrinas têm atividades distintas em células neuronais e não neuronais. Após o reconhecimento e união do Eph e da efrina, localizados em superfícies celulares opostas, uma sinalização bidirecional é desencadeada entre as células de contato (um sinal para cada lado), causando três tipos de sinalizações: forward, reversa e crosstalk (Martinez et al., 2004).

$\mathrm{Na}$ sinalização forward, proporcionada nos receptores Eph, a autofosforilação deles ao se unirem aos seus ligantes promove efeitos diversos, como colapso do cone de crescimento e orientação do crescimento axonal, formação/plasticidade sináptica e morfogênese de espinhas dendríticas. A sinalização forward ocorre após a fosforilação dos receptores $A$ e $B$ e, então, sinalizações intracelulares específicas são descritas para cada um dos efeitos neuroplásticos descritos acima (Aoto e Chen, 2007). Essa ativação se traduz em reorganizações do citoesqueleto mediante a guanina trifosfatase (GTPase) da família Rho, que faz a troca molecular entre uma forma ligada do GDP inativo e outra ligada ao GTP ativo. Uma vez ativado, o GTP pode interagir com seus efetores específicos levando a uma variedade de funções biológicas. Entre as GTPases da família Rho encontradas no mamífero, a Rho, Rac e Cdc42 estão envolvidas na regulação de diferentes aspectos do desenvolvimento dendrítico (Negishi e Katoh, 2005). Um tipo em especial, a RhoA, é um regulador negativo 
do crescimento dos neuritos, pois é responsável por várias mudanças morfológicas, como o colapso do cone de crescimento, retração de neuritos e repulsão axonal (Temporin et al., 2008).

$\mathrm{Na}$ sinalização reversa, desencadeada nos ligantes, ocorre uma fosforilação de resíduos do domínio citoplasmático das efrinas-B quando estas se unem aos seus receptores. Elas influem no citoesqueleto celular mediante proteínas tais como Grb4 e FAK. Nesse tipo de sinalização, a proteína da efrina-B atua no amadurecimento sináptico para regular a transmissão sináptica e mudanças a longo prazo na força sináptica (Klein, 2009). As efrinas do tipo A também possuem um potencial de sinalização reversa e, mediante a interação com seus receptores $A$, parecem aumentar a adesão por intermédio de mecanismos dependentes da integrina $\beta 1$ (Martinez et al., 2004). No entanto, a sinalização reversa das efrinas-A ainda é pouco conhecida e deve implicar outros receptores transmembrânicos.

Um outro tipo de sinalização, crosstalk, é produzido pela interação com outras proteínas da superfície celular, permitindo uma ampla gama de interações de sistemas de sinalizações neuroplásticas. Aqui, por exemplo, a ativação do EphB2 aumenta a fosforilação do receptor NMDA mediada por Src, resultando em um incremento da entrada de $\mathrm{Ca}^{+2}$ induzida por glutamato, o que sugere uma importância funcional da interação do Eph e o NMDA para os processos de sinaptogênese e de modificação fisiológica das sinapses (Martinez et al., 2004).

Essa sinalização bidirecional é a grande novidade oferecida pelo sistema Eph/efrinas, promovendo amplas possibilidades de ativação de mensageiros intracelulares e interações intercelulares. 


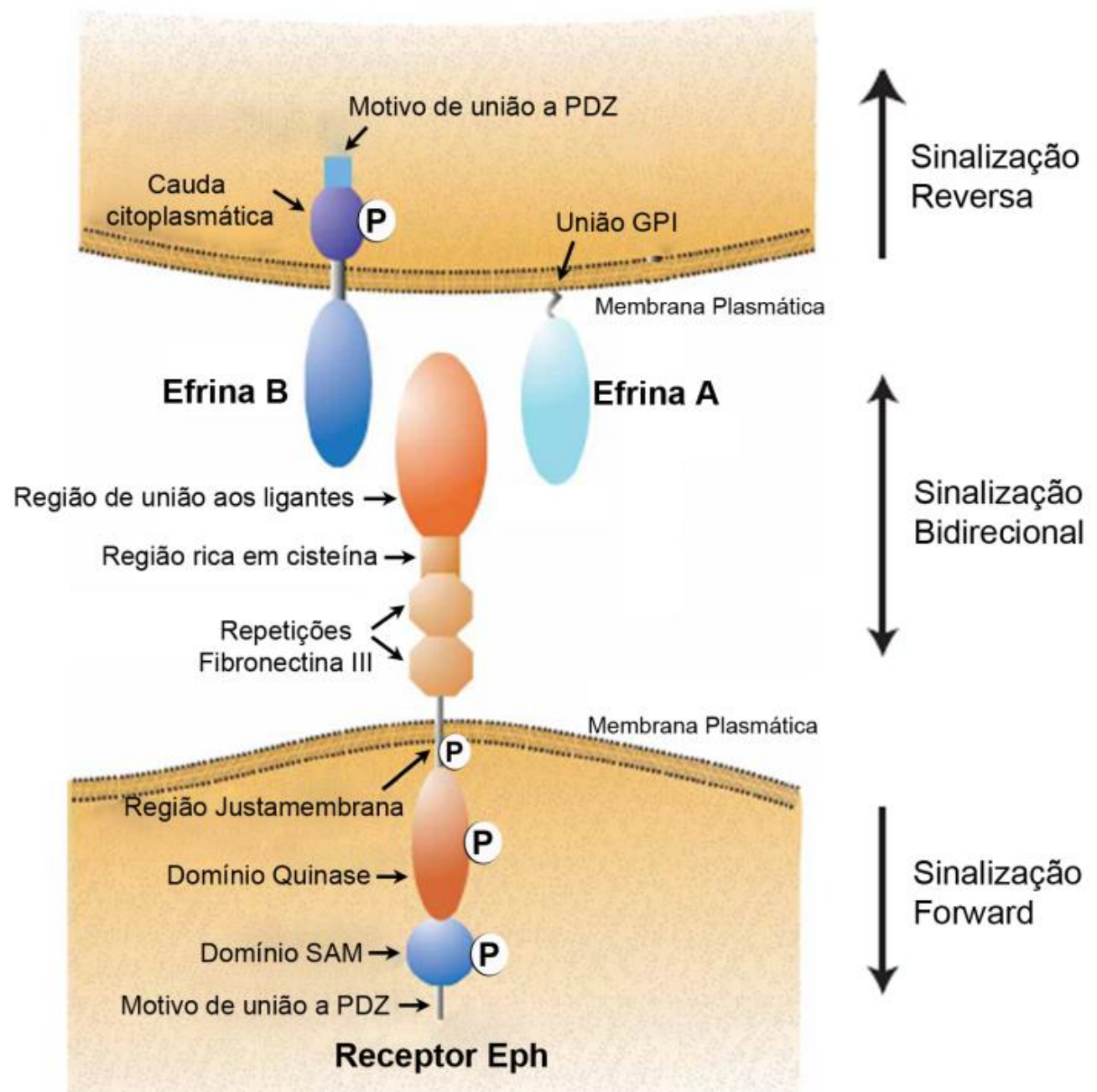

Figura 1: Características gerais da estrutura dos receptores Eph e das efrinas e o conceito de sinalização bidirecional. Proteínas da efrina-A e efrina-B são estruturalmente distintas de acordo com suas âncoras de membrana, enquanto os receptores EphA e EphB possuem domínios similares. GPI: Glycosyl Phosphatidyl Inositol; PDZ: Postsynaptic density protein/Disks large/Zona occludens; SAM: Sterile- $\alpha$-Motif. Figura modificada de Klein, 2009. 


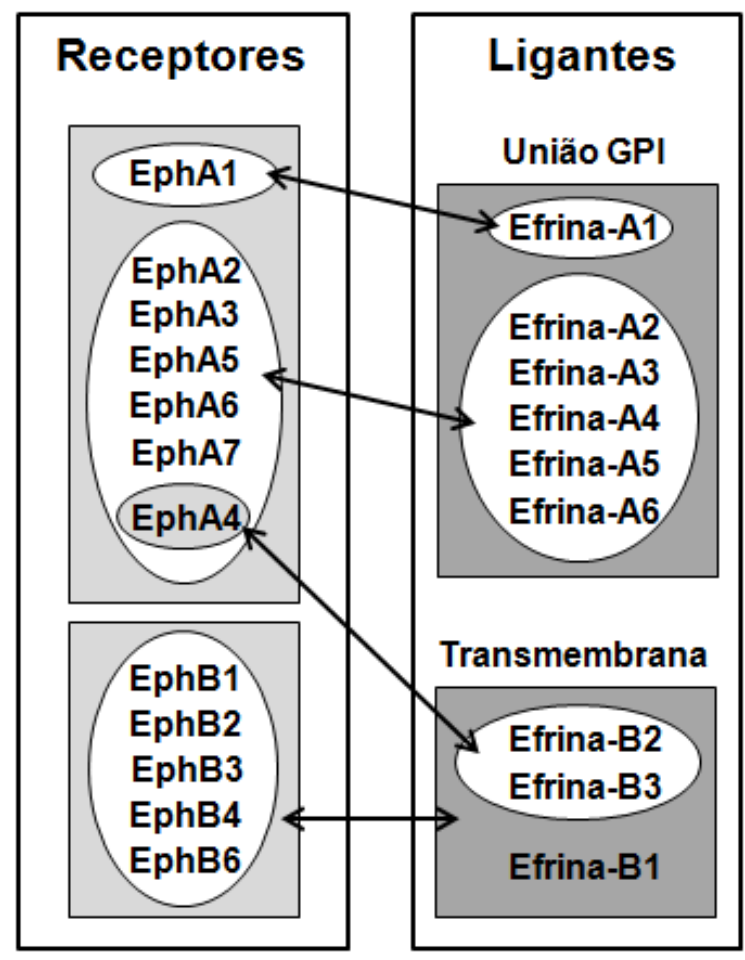

Figura 2: Interações entre as diferentes classes dos receptores Eph e seus ligantes. De modo geral, as efrinas de classe A e B unem-se de forma promiscua aos receptores EphA e EphB respectivamente, porém alguns ligantes apresentam certas especificidades de união. GPI: Glycosyl Phosphatidyl Inositol.

\subsection{Fator Derivado do Epitélio Pigmentado}

Acredita-se que a regeneração do SNC somente seja possível quando questões relacionadas à neuroproteção, crescimento de fibras e neuroplasticidade forem mais bem entendidas. A busca de uma molécula capaz de promover a neurorestauração da medula espinal por apresentar ações tróficas diretas sobre os neurônios medulares e indiretamente poder modular o microambiente da lesão nas fases de neurodegeneração, reparo/cicatrização e neuroregeneração, identificou a importância do fator derivado do epitélio pigmentado (PEDF).

O PEDF é uma glicoproteína de 50kDa da família das serfinas (Steele et al., 1993). As serfinas consistem em uma família importante de proteínas de estrutura globular, geralmente envolvidas na regulação de eventos proteolíticos 
ou no transporte hormonal (Tombran-Tink et al., 1996). Este fator neurotrófico foi identificado pela primeira vez por Tombran-Tink et al. (1989) em um meio condicionado de células epiteliais pigmentadas da retina humana. A primeira função trófica identificada deste fator foi a de aumentar a sobrevida de neurônios da retina (Becerra et al., 1997; Tombran-Tink et al., 2003).

Sabe-se agora que o PEDF é secretado pela maioria dos tecidos humanos, como o cérebro (Bilak et al., 1999a), a medula espinal, os ossos, o coração e o pulmão (Ek et al., 2006), sugerindo que este fator é capaz de exercer ações tróficas às células de origens múltiplas.

No final dos anos 90, as atividades anti-angiogênica e de restrição do edema pelo PEDF foram descritas (Dawson et al., 1999), o que de fato pode influenciar o processo regenerativo do SNC por interferir, deste modo, nos eventos de reparo e cicatrização. Como mencionado acima, estas ações são especialmente importantes no reparo da medula espinal lesada.

Do mesmo modo, é possível que o PEDF exerça efeitos tróficos nos neurônios medulares. Sabe-se hoje que o PEDF é capaz de proteger os neurônios granulares do cerebelo, os neurônios hipocampais e os neurônios motores medulares dos efeitos apoptóticos induzidos pela toxicidade glutamatérgica (Taniwaki et al., 1997; Bilak et al., 1999a; DeCoster et al., 1999). Foi descrito que as formas nativas da molécula bovina e da recombinante humana são capazes de promover a sobrevida, a diferenciação e o crescimento neurítico dos neurônios motores da medula espinal de embriões de galinha in vitro, segundo gradiente de concentração (Bilak et al. 2002). Ainda, o estudo realizado por Houenou e colaboradores (1999) ressaltou a importância do PEDF no trofismo 
dos neurônios motores periféricos, estes cujos corpos celulares estão localizados no corno anterior da medula espinal. Os resultados mostraram que o PEDF previne a morte celular e promove o crescimento de fibras dos neurônios motores periféricos medulares em modelos in vivo e in vitro. Assim, o PEDF parece exercer efeitos tróficos nos neurônios medulares, abrindo a possibilidade da sua utilização no tratamento de doenças neurodegenerativas e neurotraumáticas desta região do SNC.

Os mecanismos intracelulares de sinalização envolvidos nas ações neurotróficas do PEDF não foram descritos, mas devem utilizar receptores transmenbrânicos de alta afinidade. Bilak e colaboradores (2002) demonstraram a presença destes receptores do PEDF nos neurônios motores medulares e nas células da glia, reforçando a natureza autócrina e parácrina do fator na medula espinal. O PEDF pode proteger os neurônios por alterar a homeostase intracelular de $\mathrm{Ca}^{+2}$, como descrito pela neurotoxicidade induzida pelo glutamato (Taniwaki et al., 1997), ou por alterar a síntese ou a liberação de neurotransmissores e fatores neurotróficos (Yabe et al., 2001). É necessário dizer também que o PEDF é capaz de promover a expressão de outros fatores neurotróficos com ações na medula espinal, como o fator neurotrófico derivado da glia (GDNF), o fator de crescimento do neurônio (NGF) e o fator neurotrófico derivado do cérebro (BDNF) (Yabe et al., 2004).

Em contraste com os seus efeitos anti-apoptóticos, o PEDF age de modo oposto nas células endoteliais que formam novos vasos, sendo um inibidor potente da angiogênese/neovascularização (Dawson et al., 1999; Stellmach et al., 2001), efeitos que podem ter significado importante nos eventos neuro- 
inflamatórios pós-lesão (Stellmach et al., 2001). Estes achados ressaltam a importância do estudo das ações do PEDF no reparo da medula espinal, levando em consideração os eventos isquêmicos participantes da fisiopatologia da neurodegeneração e dos processos subsequentes de neurorestauração do órgão lesado, em particular os eventos de neuroplasticidade a longo prazo.

\subsection{Centro Gerador de Padrão}

No que diz respeito à marcha, os recursos necessários para o controle locomotor consistem de uma circuitaria espinal especializada, identificada como centro gerador de padrão (CPG), das vias descendentes, de vias neuroquímicas que liberam neuromoduladores como a noradrenalina ou a serotonina e de aferentes dos receptores periféricos de diferentes modalidades sensoriais. Tais componentes interagem dinamicamente entre si, entretanto, após uma lesão, essa interação é interrompida, tornando um componente mais proeminente que outro (Rossignol e Frigon, 2011).

Como observado na prática clínica e em animais de laboratório, após lesão medular parcial ou total, parte da recuperação sensório-motora pode ser alcançada, sendo que a reexpressão da locomoção depende de várias formas de neuroplasticidade que ocorrem no CPG, localizado notavelmente ao nível lombar da medula espinal (Butt et al., 2002; Gulino et al., 2007; Barriere et al., 2008).

O CPG é uma rede neural geneticamente programada que, apesar de ser regulado por um controle motor supra-espinal e um feedback proprioceptivo, pode operar automaticamente na ausência de tais sinais (Pinter e Dimitrijevic, 1999; Butt et al., 2002; Rybak et al., 2006). Ele gera um padrão rítmico locomotor dos 
membros inferiores, caracterizado pela alternância dos músculos flexores e extensores de um membro em uma fase oposta à do membro contralateral (Tazerart et al., 2008). Segundo estudos com estimulação elétrica, a localização mais eficiente para excitar passos mioclônicos com atividade eletromiográfica organizada e recíproca de músculos simétricos está nos segmentos L3-L4 em gatos, nos segmentos L1-L2 em roedores e nos segmentos L2-L3 em humanos (Cazalets et al., 1995; Duysens e Crommert, 1998).

O padrão básico do CPG em diferentes espécies, apesar de similar, pode diferir em sua amplitude e/ou nas funções das atividades locomotoras. A diferença entre gatos e primatas, incluindo humanos, pode ser relacionada ao aumento da importância do tracto corticoespinal dos primatas, sugerindo uma excitabilidade intrínseca bem mais fraca desse gerador rítmico. Isso é causado porque o circuito espinal em primatas é suprimido pelo sinais provenientes do córtex (dominância cortical), sendo o objetivo dessa supressão a movimentação livre das extremidades (mãos e pés) (Duysens e Crommert, 1998; Calancie, 2006).

Acredita-se que o CPG tenha um papel fundamental na reexpressão da locomoção após a lesão medular (Brustein e Rossignol, 1998; Rossignol et al., 2009), sendo que a reorganização intrínseca do CPG parece ser fundamental para a ganho neurofuncional no processo de reabilitação (Barriere, 2008).

Deste modo, o presente trabalho busca avaliar as respostas e os mecanismos neuroplásticos na porção lombar da medula espinal (região do CPG), após a lesão isquêmica aplicada no orgão e tratamento local com a injeção do PEDF. As análises bioquímica, molecular e histológica do tecido medular, bem como a avaliação do comportamento motor, poderão indicar mecanismos novos 
de neuroplasticidade do órgão e correlacionar com as melhoras neurofuncionais apresentadas pelo animal. 


\section{OBJETIVOS}




\section{OBJETIVOS}

\subsection{Gerais}

Analisar a capacidade do tratamento com o PEDF em promover, seis semanas após a injúria, a neuroplasticidade na porção ventral da região lombar da medula espinal (área adjacente e caudal ao sítio de lesão), bem como a recuperação sensório-motora em animais que foram submetidos à lesão medular isquêmica fototrombótica.

\subsection{Específicos}

I. Avaliar os déficits referentes à motricidade e a sensibilidade, bem como suas evoluções, através dos testes BBB e CBS e analisar a função motora fina dos animais pelo índice de impressão de pegadas.

II. Quantificar o nível protéico de moléculas inibitórias ao crescimento de fibras, por meio de western blot.

III. Analisar a capacidade do tratamento com o PEDF em modular a expressão de outros fatores neurotróficos na medula espinal, através da técnica PCR em tempo real, e quantificar o nível protéico do PEDF por meio de western blot.

IV. Analisar a possibilidade do tratamento com o PEDF inibir a angiogênese e a presença de moléculas relacionadas à apoptose pós-lesão, por meio de western blot. 
V. Localizar/quantificar o fenômeno de neuroplasticidade a nível celular, pelo método de imunoistoquímica, e quantificar proteínas estruturais relacionadas à neuroplasticidade, por meio de western blot.

VI. Quantificar os subtipos descritos dos receptores Eph e das efrinas através das técnicas western blot e/ou PCR em tempo real.

VII. Avaliar as alterações induzidas nos receptores Eph e nas efrinas pela lesão isquêmica e pelo tratamento com o PEDF e localizar sua presença nos neurônios e/ou células gliais na medula espinal do rato, por meio de imunofluorescência. 
MATERIAIS E MÉTODOS 


\section{MATERIAIS E MÉTODOS}

\subsection{Lesão Medular Isquêmica Fototrombótica}

Foram utilizados 48 ratos Wistar machos e adultos, pesando entre 350400g, provenientes do Biotério Central da Faculdade de Medicina da Universidade de São Paulo (FMUSP). Após a pesagem e anestesia dos animais com associação ketamina xilazina intraperitonial (ketamina - 62,5mg/kg; xilazina $10 \mathrm{mg} / \mathrm{kg}$; aplicação de 0,25 ml/100g), procedeu-se com a tricotomia e anti-sepsia com iodopovidona na área cirúrgica. Em seguida, os animais receberam uma injeção com volume de $1,6 \mathrm{ml} / \mathrm{kg}(40 \mathrm{mg} / \mathrm{kg}$ a uma concentração de $25 \mathrm{mg} / \mathrm{ml}$, diluído em solução salina) do corante tetracloro-tetraiodofluorosceína de dissódio (Rose Bengal, Aldrich Chemical Co., Milwaukee, EUA) por via endovenosa na veia dorsal do pênis.

Após a aplicação do agente fotossensibilizante, foi realizada uma incisão longitudinal mediana da pele sobre a coluna vertebral torácica-baixa e lombar. A musculatura paravertebral foi cuidadosamente afastada, evitando-se lesar a rede vascular que cerca a coluna vertebral. Quando o nível da 11ª vértebra torácica foi identificado, retirou-se a apófise espinhosa bem como a fina lamínula de osso subjacente, um processo chamado laminectomia, expondo a medula espinal sem que houvesse lesão da dura-máter subjacente. A lavagem do local com solução fisiológica foi feita para garantir que não houvesse obstáculos entre a luz e a região a ser lesada. Todo o procedimento cirúrgico não ultrapassou 10 minutos de duração, tempo suficiente para que o corante fosse distribuído pela circulação sistêmica. Após essa fase, a área da medula espinal exposta foi submetida por 20 
minutos a um feixe de luz verde com comprimento de onda específico (560 nm), direcionada por um cabo de fibra óptica flexível de $5 \mathrm{~mm}$ de diâmetro, fixado ao aparelho estereotáxico e mantido a $2 \mathrm{~mm}$ de distância da medula espinal exposta para garantir que não houvesse compressão (figura 3). A luz foi produzida por um equipamento específico (Schott KL 1500, Mainz, Alemanha) e garantiu a excitação necessária do Rose Bengal para a lesão medular fototrombótica.

Um grupo de animais submetido à cirurgia simulada (Sham) não recebeu injeção venosa do corante e, então, foi submetido ao procedimento microcirúrgico e à exposição da luz descritos acima. 


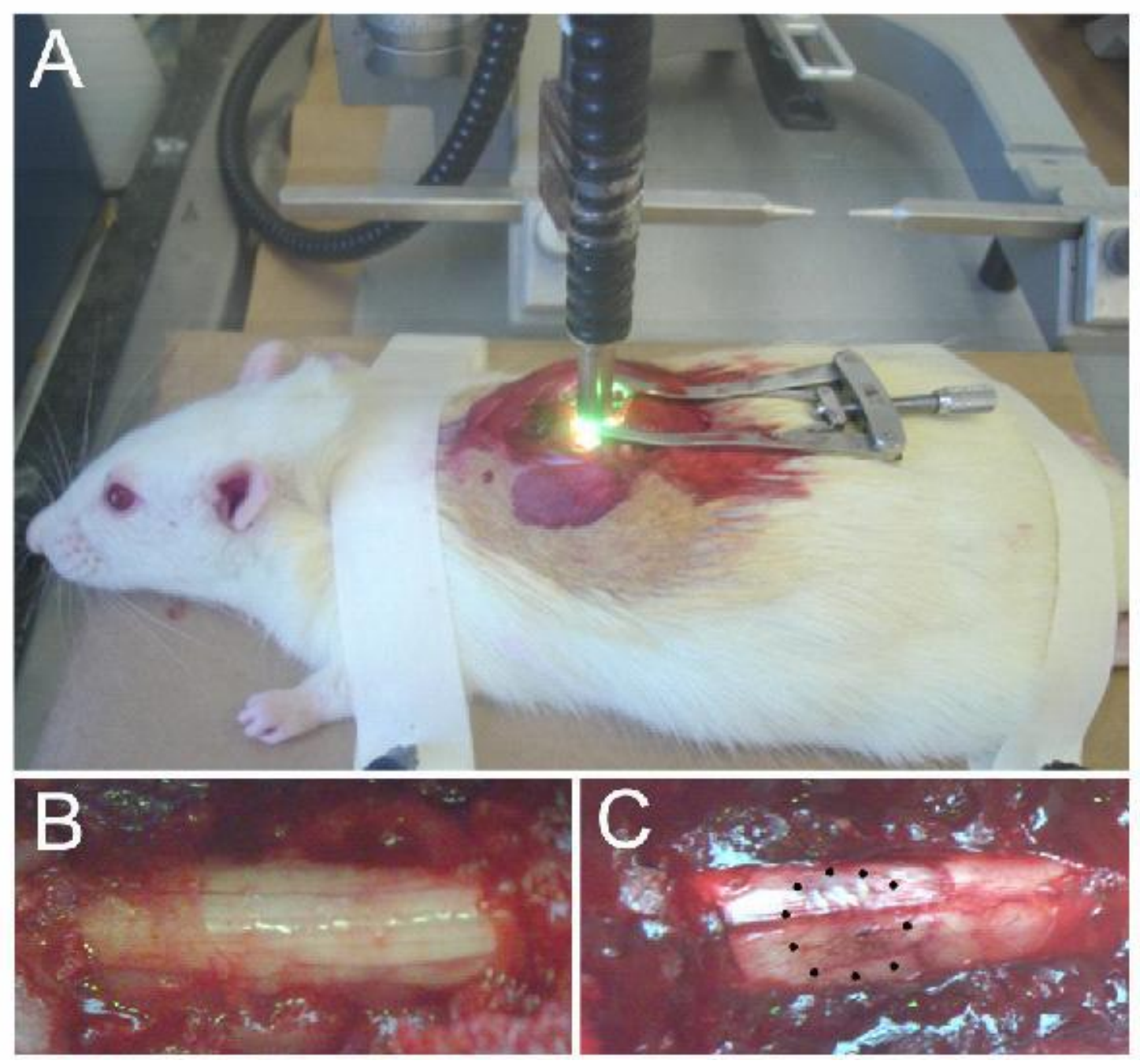

Figura 3: Para promover a lesão fototrombótica, uma fibra óptica de $5 \mathrm{~mm}$ ligada a um aparelho com lâmpada de xenon (Schott KL 1500, Mainz, Germany) direcionou um feixe de luz de comprimento de onda de $560 \mathrm{~nm}$ durante 20 minutos à região exposta (11ำ vértebra torácica) da medula espinal. Os ratos receberam uma injeção sistêmica do corante Rose Bengal $(40 \mathrm{mg} / \mathrm{kg}$ a uma concentração de $25 \mathrm{mg} / \mathrm{ml}$ ) antes da exposição à luz. (A) A fibra óptica foi fixada em um aparelho estereotáxico (Kopf, USA) e os animais foram imobilizados em uma plataforma na tentativa de manter uma distância de $2 \mathrm{~mm}$ entre a fibra óptica e a região exposta da medula. Os animais Sham foram submetidos à iluminação sem a injeção sistêmica do corante. Os painéis $\mathrm{B}$ e C mostram a superfície dorsal da medula espinal dos animais Sham e dos que receberam a injeção de Rose Bengal, respectivamente, logo após o período de iluminação. A superfície da medula espinal dos animais que sofreram lesão adquire uma região bem definida de coloração avermelhada (envolta por pontos), que corresponde ao diâmetro da fibra óptica imediatamente após o procedimento de iluminação, o que não acontece com os animais do grupo Sham. 


\subsection{Injeção Local de PEDF}

Imediatamente após a realização da isquemia medular ou cirurgia Sham, os animais receberam uma injeção estereotáxica do fator neurotrófico PEDF $(10 \mu \mathrm{l}, 100 \mathrm{ng} / \mathrm{ml})$ ou do solvente (solução salina tamponada em tampão fosfato, $\mathrm{pH} 7,4)$ no epicentro da lesão. Durante este procedimento, os animais foram submetidos à anestesia titulada com halotano por via inalatória. As injeções medulares foram feitas com agulhas de vidro de $100 \mu \mathrm{m}$ de diâmetro externo obtidas pelo puxador de pipetas (Kopf). Essas agulhas foram acopladas às seringas Hamilton de $50 \mu \mathrm{l}$ para a promoção da injeção, esta que teve duração de 3 a 5 minutos.

\subsection{Grupos experimentais}

Desta forma, foram obtidos três grupos experimentais:

- Sham (controle): cirurgia simulada e injeção local de $10 \mu$ l do solvente do $\operatorname{PEDF}(n=16)$.

- Salina (isquêmico não tratado): lesão isquêmica e injeção local de $10 \mu$ l do solvente do PEDF $(n=16)$.

- PEDF (isquêmico tratado): lesão isquêmica e injeção local de $10 \mu$ do $\operatorname{PEDF}(n=16)$.

Ao término dos procedimentos, a sutura no plano muscular foi realizada, assim como o fechamento da pele do animal. Em seguida, os ratos foram realocados para as respectivas caixas, onde receberam água e ração sem restrição. Os animais foram colocados em salas com temperatura controlada, sob 
ciclo claro/escuro de 12 horas. O esvaziamento vesical foi realizado diariamente até o retorno da função, e então foram submetidos à análise do comportamento motor durante 6 semanas. Durante 10 dias do período pós-cirúrgico todos os animais receberam antibioticoterapia preventiva (ceftriaxona sódica na proporção de $40 \mathrm{mg} / \mathrm{kg} / \mathrm{dia}$, por via intramuscular; i.m.).

\subsection{Análise Comportamental}

Após a lesão, os déficits referentes à motricidade e à sensibilidade, assim como suas evoluções, foram analisados segundo os testes BBB e CBS. Além disso, foram avaliados os parâmetros da recuperação motora fina dos animais, analisados quantitativamente pelos índices da impressão de pegadas. Os testes foram realizados nos animais 24, 48 e 72 horas após a cirurgia, e em seguida semanalmente até o término das 6 semanas.

\subsection{1. Índice BBB}

O índice BBB (Basso et al., 1996) avalia a movimentação dos membros posteriores de animais submetidos a lesão medular. Sua pontuação varia de 0 a 21 (tabela 1) e divide-se em três momentos:

- 0 a 7: corresponde aos movimentos das articulações dos membros posteriores nos estágios iniciais de recuperação.

- 8 a 13: avalia os passos e a coordenação na fase intermediária de recuperação.

- 14 a 21: avalia a movimentação fina das patas durante a locomoção. 


\section{Tabela 1: Escala locomotora BBB.}

S Sem movimento do membro posterior

1 Movimento perceptível de uma ou duas articulações, geralmente quadril e/ou joelho

2 Movimento amplo de uma articulação ou movimento amplo de uma articulação e movimento perceptível de outra

3 Movimento amplo de duas articulações

4 Movimento perceptível de todas as três articulações do membro posterior (quadril, joelho e tornozelo)

5 Movimento perceptível de duas articulações e movimento amplo da terceira

6 Movimento amplo de duas articulações e movimento perceptível da terceira

7 Movimento amplo de todas as três articulações do membro posterior

8 Arrasta sem suporte de peso ou colocação plantar da pata sem suporte de peso

9 Colocação da pata com suporte de peso somente quando parado (em posição estática) ou passos com apoio dorsal e suporte de peso ocasionais, freqüentes ou consistentes e sem passos com apoio plantar

10 Passos com apoio plantar e suporte de peso ocasionais, sem coordenação do membro anterior e membro posterior (MA e MP)

11 Passos com apoio plantar e suporte de peso frequentes ou consistentes e sem coordenação MA-MP

12 Passos com apoio plantar e suporte de peso frequentes ou consistentes e coordenação MA-MP ocasional

13 Passos com apoio plantar e suporte de peso consistentes e coordenação MA-MP frequente

14 Passos com apoio plantar e suporte de peso consistentes, coordenação MA-MP consistente e posição predominante da pata durante locomoção é em rotação ou passos com apoio plantar freqüentes, coordenação MA-MP consistente e passos com apoio dorsal ocasionais

15 Coordenação MA-MP consistente e arrasta dedos ao longo do passo

16 Coordenação MA-MP consistente durante a marcha e frequentemente não arrasta os dedos; a posição predominante da pata é paralela no contato inicial do passo e rodada na fase de retirada.

17 Coordenação MA-MP consistente durante a marcha e frequentemente não arrasta os dedos; a posição predominante da pata é paralela no contato inicial do passo e na fase de retirada

18 Coordenação MA-MP consistente durante a marcha e consistentemente não arrasta os dedos; a posição predominante da pata é paralela no contato inicial do passo e rodada na fase de retirada

19 Coordenação MA-MP consistente durante a marcha e consistentemente não arrasta os dedos; a posição predominante da pata é paralela no contato inicial do passo e na fase de retirada e cauda para baixo parte do tempo

20 Marcha coordenada consistente, consistentemente não arrasta os dedos; a posição predominante da pata é paralela no contato inicial do passo e na fase de retirada mas há instabilidade do tronco e cauda para cima consistentemente

21 Marcha coordenada consistente, consistentemente não arrasta os dedos; a posição predominante da pata é paralela no contato inicial do passo e na fase de retirada, tronco estável e cauda para cima consistentemente

Escala desenvolvida por Basso, Beattie e Bresnahan (índice BBB) para avaliação locomotora de ratos com lesão medular. A escala varia de 0 a 21 pontos, onde em zero a funcionalidade dos membros posteriores é nula e em 21 é normal. 


\subsection{2. Índice CBS}

As análises comportamentais sensório-motoras também foram testadas pelo Índice de Análise Comportamental Combinada, do inglês "Combined Behavioral Score" (CBS). Esse protocolo é eficiente na avaliação e mensuração percentual do déficit funcional em ratos após a lesão experimental da medula espinal. Os testes que compõem o CBS e suas respectivas graduações seguem abaixo.

a) Escala de Tarlov (modificada segundo Gale et al., 1985): baseia-se na atividade motora espontânea. Cada membro posterior é observado individualmente e classificado segundo a escala abaixo:

\begin{tabular}{|c|l|}
\hline Pontos & Comportamento \\
\hline 0 & Sem movimentos dos membros posteriores, não fica de pé \\
\hline 1 & Apenas movimentos perceptíveis dos membros posteriores, não fica de pé \\
\hline 2 & Frequente e/ou rigoroso movimento dos membros posteriores, não fica de pé \\
\hline 3 & Pode ficar de pé e dar um ou dois passos \\
\hline 4 & Deambula com leve déficit \\
\hline 5 & Deambula normalmente \\
\hline
\end{tabular}

b) Reflexo de Extensão dos Dedos dos Pés: reflexo presente quando elevamos o rato pelo corpo e os membros ficam livres.

\begin{tabular}{|c|l|}
\hline Pontos & Comportamento \\
\hline 0 & Sem extensão dos dedos dos pés \\
\hline 1 & Leve extensão dos dedos \\
\hline 2 & Extensão normal dos dedos \\
\hline
\end{tabular}


c) Reflexo de Colocação Visual: o animal é sustentado pelo tronco e os membros pélvicos ficam livres. O reflexo consiste na colocação dos pés em uma borda estreita.

\begin{tabular}{|c|l|}
\hline Pontos & Comportamento \\
\hline 0 & Sem tentativa de colocação dos pés \\
\hline 1 & Leve tentativa de colocação dos pés \\
\hline 2 & Colocação dos pés \\
\hline
\end{tabular}

\section{d) Reflexos de Retirada em Resposta à:}

- Extensão: reflexo de flexão dos membros posteriores após extensão.

- Dor: reflexo de retirada após beliscar a pata posterior com um prendedor de roupas. O estimulo aplicado não é suficientemente forte e prolongado para causar lesão.

- Pressão: reflexo de retirada após pressionar a região entre o hálux e segundo dedo dos membros posteriores.

Cada reflexo é codificado seguindo:

\begin{tabular}{|c|l|}
\hline Pontos & Comportamento \\
\hline 0 & Sem retirada \\
\hline 1 & Leve retirada \\
\hline 2 & Reflexo de retirada normal \\
\hline 3 & Reflexo de retirada hiperativo \\
\hline
\end{tabular}

e) Reflexo de Endireitamento: o rato em decúbito dorsal na mesa.

\begin{tabular}{|c|l|}
\hline Pontos & Comportamento \\
\hline 0 & Sem tentativa de endireitar-se \\
\hline 1 & Tentativa leve ou lenta de rolar em direção ao endireitamento \\
\hline 2 & Reflexo de endireitamento normal \\
\hline
\end{tabular}


f) Plano Inclinado: o animal é colocado com a cabeça para baixo em um plano emborrachado. O ângulo do plano é aumentado de zero grau até o ponto em que o rato não possa se manter na posição por 5 segundos. São realizadas duas mensurações para cada animal, sendo que ratos normais mantêm-se no plano com uma inclinação de 50 a 60 graus (Rivlin e Tator, 1977).

O CBS originalmente descrito é composto por mais dois testes: resposta ao calor e natação. Não realizamos estes testes por não considerarmos os mesmos convenientes aos animais no período pós-operatório imediato.

A confecção do índice CBS é feita através de um sistema de pontuação (tabela 2), onde os pontos são atribuídos para as anormalidades de função, de modo que uma maior pontuação indica um maior déficit funcional. O CBS varia de 0 para um rato completamente normal a 100 para um rato completamente paralisado. Entretanto, a graduação dada por nós não chega a 100\% de déficit, e $\operatorname{sim} 90 \%$, já que os dois testes excluídos correspondem a $10 \%$ da graduação total. 
Tabela 2: Índice CBS.

\begin{tabular}{lcc}
\hline \multicolumn{3}{c}{ Déficit percentual avaliado pelo CBS } \\
\hline Teste & Nota & Pontuação do CBS \\
\hline Tarlov & 0 & 45 \\
& 1 & 40 \\
& 2 & 25 \\
& 3 & 15 \\
Extensão dos dedos & 0 ou 1 & 5 \\
Colocação & 0 ou 1 & 0 \\
Reflexos de retirada & 0 ou 1 & 5 \\
& 3 & 5 \\
Endireitamento & 0 ou 1 & $15^{\star}$ \\
Plano Inclinado & $<30^{\circ}$ & 15 \\
& $35^{\circ}$ ou $40^{\circ}$ & 5 \\
& $40^{\circ}$ & 15 \\
& $45^{\circ}$ & 10 \\
\hline
\end{tabular}

O índice do CBS é a soma dos pontos de cada teste, neste caso, máximo de 90 (90\% de déficit). Quando os membros posteriores (direito e esquerdo) diferem entre si, o menor déficit foi utilizado para atribuir pontos no CBS. * Após a $3^{\circ}$ semana de avaliação, apenas 5 pontos foram atribuídos nas graduações 0 ou 1.

Neste experimento, também foi realizada uma análise individual de cada teste que compõe o índice. Para isso, conversões na pontuação original foram necessárias para avaliar os reflexos de retirada, os quais se encontram na tabela abaixo.

\begin{tabular}{|c|l|c|}
\hline Pontos & Comportamento & Conversão para análise em separado \\
\hline 0 & Sem retirada & 1 \\
\hline 1 & Leve retirada & 2 \\
\hline 2 & Reflexo de retirada normal & 3 \\
\hline 2 & Reflexo de retirada hiperativo & 0 \\
\hline
\end{tabular}




\subsubsection{Impressão de Pegadas}

A análise motora fina pela impressão de pegadas, do inglês "foot print", foi realizada nos animais semanalmente até a $6^{\circ}$ semana após a cirurgia. Para a análise das impressões de pegadas, os animais foram colocados em um corredor de madeira $(60 \mathrm{~cm} \times 11 \mathrm{~cm})$ com um abrigo escuro na extremidade (Maeda et al., 1999). A todos os animais foram permitidos dois testes condicionados nos quais eles podiam parar e explorar o corredor antes de finalmente entrarem na caixa escura. Foi colocado no fundo do corredor um papel branco cortado em dimensão apropriada. A região dorsal das patas traseiras dos ratos foi pintada com tinta nanquim e, em seguida, o animal foi induzido a andar pelo corredor deixando a impressão de suas pegadas no papel (Dijkstra et al., 2000).

Várias medidas foram analisadas de tais impressões bilateralmente: o comprimento da passada, a distância entre o calcanhar e o terceiro dedo, a distância entre o primeiro e o quinto dedo e a distância entre o segundo e o quarto dedo (Meek et al., 1999; Varejão et al., 2001). No comprimento da passada, a mensuração foi realizada duas vezes de cada lado (direito/esquerdo), excluindo a primeira e a última passada; já nas medidas restantes, foi escolhida a melhor pata de cada lado para mensuração.

\subsection{Processamento Tecidual para a Técnica de Imunoistoquímica}

Para o procedimento de imunoistoquímica, metade dos animais de cada grupo $(\mathrm{n}=8)$ sofreram eutanásia após o período de 6 semanas do pós-operatório, através de uma perfusão transcardíaca de solução salina (0,9\%, Merck), seguida de solução fixadora, modificada de De Martino e Zamboni (1967), que consiste de 
4\% de paraformaldeído diluído em tampão fosfato $(0,1 \mathrm{M} ; \mathrm{pH} 7,4)$. Após a perfusão, um segmento de $2,5 \mathrm{~cm}$ foi retirado da medula espinal, incluindo a área da lesão e a intumescência lombar (foi cortado $1,0 \mathrm{~cm}$ acima e 1,5 cm abaixo do epicentro da lesão). O tecido foi pós-fixado na mesma solução fixadora por 90 minutos e lavado em uma solução de sacarose (10\%) dissolvida em tampão fosfato por 48 horas para então ser congelado em isopentano (Sigma, Milwaukee) e gelo seco $\left(-45^{\circ} \mathrm{C}\right)$ e mantido no freezer a $-70^{\circ} \mathrm{C}$ até o seccionamento.

\subsubsection{Seccionamento e Amostragem}

Cortes seriados de $14 \mu \mathrm{m}$ foram obtidos com a utilização de um criostato (Leica, CM3000) de todo segmento medular, incluindo o epicentro da lesão. Quando seccionada a região da lesão, as secções obtidas foram cuidadosamente avaliadas pela visualização do tecido lesado, e as secções mais caudais à lesão foram previamente marcadas.

As secções da região da lesão e da região lombar foram amostradas sistematicamente, de modo a obter-se 10 séries amostradas a cada 100 secções. Desta forma, séries em ordem crânio-caudal foram obtidas.

\subsubsection{Imunoperoxidase}

A imunorreatividade foi detectada pelo sistema de imunoperoxidase indireta empregando a avidina-biotina (Rodrigues et al., 2001; Gomide e Chadi, 2005). As secções foram lavadas 2 vezes de 10 minutos cada em tampão fosfato (PBS) e 
incubadas em uma solução de $5 \%$ de soro normal de ovelha por 30 minutos a temperatura ambiente.

As secções obtidas foram incubadas por 24 horas em câmaras umidificadas a $4^{\circ} \mathrm{C}$ com um dos marcadores descritos a seguir: anticorpo monoclonal anti-MAP-2 feito em camundongo diluído na concentração de 1/2.500 (Sigma) e anticorpo monoclonal anti-GAP-43 feito em camundongo diluído na concentração de 1/1.000 (Sigma). Os anticorpos foram diluídos em PBS contendo 0,5\% Triton X-100. Numa terceira incubação, a avidina e uma peroxidase biotinilada foram introduzidas (Vectastain, Vector, EUA; ambas diluídas 1/100) durante 45 minutos. A reação foi completada com 0,03\% de DAB (Sigma) como cromógeno e $\mathrm{H}_{2} \mathrm{O}_{2}$ (Sigma) durante 8 minutos. Os procedimentos imunoistoquímicos foram uniformizados. Assim, foi considerado o ponto de saturação de DAB, a diluição do anticorpo primário longe do tempo de saturação e um tempo de incubação ajustado de tal modo que os elementos mais escuros das secções medulares estivessem inferiores a saturação (Zoli et al., 1990).

\subsubsection{Análise de Imagem}

A análise semi-quantitativa morfométrica e microdensitométrica das imunorreatividades da MAP-2 e GAP-43, estudadas na porção lombar da medula espinal foram feitas em duas secções por animal. A média aritmética das análises nas secções foi realizada. As medidas foram feitas nas secções da região lombar da medula espinal, precisamente no corno anterior, o qual apresentou uma morfologia totalmente preservada. A análise de imagem foi realizada num analisador de imagem KS400 (Kontrol-Zeiss, Alemanha) acoplada a uma câmera 
montada em um microscópio Zeiss, como foi descrito anteriormente (Chadi et al., 1993b; Gomide e Chadi, 2005; do Carmo Cunha et al., 2007; Andrade et al., 2008; Guzen et al., 2009). A imagem das secções foi obtida através da câmera e projetada em um monitor. Campos de área definida foram amostrados de regiões específicas das secções, dependendo da imunorreatividade quantificada. Após a correção do sombreamento, alguns procedimentos de discriminação foram realizados: os valores médios de tons cinza (MGV), assim como o erro padrão da média (s.e.m.) dos valores médios dos tons de cinza obtidos em áreas desprovidas de marcação específica [background (bg)] de acordo com cada imunorreatividade formam medidos. Valores de tons de cinza, mais escuros que o bgMGV foram considerados como marcação específica e, deste modo, discriminados. Os MGV específicos (spMGV) foram definidos como a diferença entre os bg MGV dos perfis discriminados. Os MGV da lâmina foram mantidos constantes em 200. Este procedimento foi repetido para cada secção, no intuito de corrigir as medidas de cada marcação específica em relação aos valores do seu próprio "background" (Chadi et al., 1993a; 1993b). A área total dos campos e a média dos spMGV dos perfis imunorreativos foram obtidos dentro dos campos de quantificação. A medida morfométrica (spMGV) indicou a quantidade de perfis imunopositivos e a intensidade de imunomarcação, respectivamente.

\subsubsection{Imunofluorescência de Duas Cores}

A técnica de imunofluorescência de duas cores detecta marcações simultâneas utilizando dois anticorpos. Inicialmente, as lâminas foram lavadas 3 vezes com PBS durante 10 minutos e incubadas com os anticorpos primários dos 
subtipos dos receptores Eph e suas respectivas efrinas-A e B, em uma concentração de 1/250 (a descrição dos anticorpos utilizados encontram-se na tabela 3). A análise da localização celular dos receptores Eph/efrinas foi realizada através da dupla marcação com o anticorpo monoclonal NF-200 (1/200, Sigma) ou com o anticorpo policlonal anti-GFAP, feito em coelho (1/400, Dako) ou em cabra (1/50, Dako). Os anticorpos primários foram incubados durante 48 horas. Em seguida, as lâminas foram lavadas 2 vezes de 10 minutos com PBS e incubadas, durante 2 horas no escuro, com a mistura de anticorpos secundários produzidos contra as espécies hospedeiras que produziram os anticorpos primários e conjugados aos fluoróforos vermelho do Texas (fluorescência em vermelho) e fluoresceína (FITC, fluorescência em verde), na concentração de 1/40. As lâminas puderam ser visualizadas no microscópio de fluorescência AX70 (Olympus) e as imagens foram capturadas utilizando-se o sistema DP72 de fotodocumentação (Olympus).

\subsection{Processamento Tecidual para as Técnicas de Western Blot e PCR em Tempo Real}

Para a análise protéica através do western blot e do RNA mensageiro (RNAm) através da reação em cadeia pela polimerase em tempo real (RT-PCR), a outra metade dos animais (cada grupo $n=8$ ) foi submetida à eutanásia por meio de decaptação, após o término de 6 semanas do pós operatório. Um fragmento de $0,8 \mathrm{~cm}$ foi retirado da medula espinal no nível da intumescência lombar, sendo que a porção ventral (motora) do seguimento lombar foi cuidadosamente separada da porção dorsal (sensorial). Em seguida, a porção ventral (utilizada no 
presente trabalho) foi subdividida, onde a região mais caudal foi destinada à técnica de western blot e a porção mais cranial à técnica de RT-PCR. Os materiais foram congelados em gelo seco e armazenados no freezer $-70^{\circ} \mathrm{C}$ até sua utilização.

\subsubsection{Western Blot}

Para a realização da técnica de western blot, o fragmento retirado da

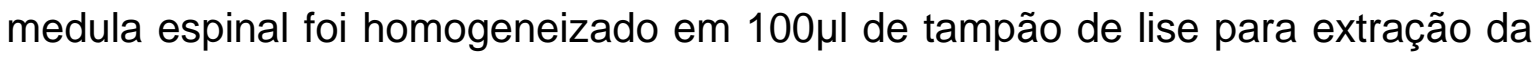
proteína total, constituído de NP40 (1\%, Sigma), deoxicolato de sódio $(0,5 \%$, Sigma), SDS (1\%, Bio-Rad), EDTA (1 mmol/L, Sigma), EGTA (1 mmol/L, Sigma) e coquetel inibidor de proteases (1\%, Sigma) diluídos em PBS. Após incubação por 30 minutos em gelo, os tubos foram centrifugados a 14.000 rpm durante 20 minutos a $4^{\circ} \mathrm{C}$, e o sobrenadante foi transferido para um novo microtúbulo. A concentração de proteína foi determinada pelo método de Bradford (Bradford, 1976).

Resumidamente, as amostras foram diluídas em tampão de lise a fim de se obter uma quantidade de $60 \mu \mathrm{g}$ em $10 \mu \mathrm{l}$ que foram desnaturadas a $100^{\circ} \mathrm{C}$ durante 3 minutos e aplicadas às canaletas do gel de poliacrilamida a $10 \%$ para fracionamento. Em um dos poçinhos foi aplicado $5 \mu \mathrm{l}$ de marcador de peso molecular (Kaleidoscope, pré-corado, Bio-Rad, EUA). O tampão de corrida foi preparado com trisma (25mol/L, Sigma), glicina (0,2mol/L, Bio-Rad) e SDS $(0,1 \%$, Bio-Rad), as proteínas foram fracionadas através da aplicação de 100 volts durante 1 hora. Após a corrida, as proteínas foram transferidas para membranas 
de PVDF (Bio-Rad) utilizando tampão de transferência gelado contêndo trisma (25mmol/L), glicina $(0,2 \mathrm{~mol} / \mathrm{L})$ e metanol $(10 \%)$ durante 1 hora a $100 \mathrm{~V}$.

As membranas foram bloqueadas por 30 minutos em leite $10 \%$, diluído em TBS-T (Chadi et al., 2008), e incubadas por 20 horas com os respectivos anticorpos primários: anticorpo monoclonal anti-CSPG (1/500, Millipore), anticorpo policlonal anti-PEDF feito em coelho (1/600, doação da Dra. Tombran Tink, Faculdade Missouri - Kansas, EUA, descobridora do PEDF), anticorpo monoclonal anti-MAP-2 (1/1.000, Novus Biologicals), anticorpo policlonal antiGAP-43 feito em coelho (1/1.000, Chemicon), anticorpo monoclonal antisinaptofisina (1/2.000, Novo Castra), anticorpo policlonal anti-laminina feito em coelho (1/1.000, Sigma), anticorpo policlonal anti-Bcl-2 feito em coelho (1/1.000, Santa Cruz). Para as marcações específicas com os subtipos A e B dos receptores Eph e das efrinas, foram utilizados $120 \mu \mathrm{g}$ de proteínas; as concentrações utilizadas e as características dos anticorpos estão na tabela 3. Os anticorpos foram diluídos em leite 3\% / TBS-T.

As membranas foram retiradas do anticorpo primário e lavadas 2 vezes de 10 minutos com TBS-T, em seguida, foram incubadas por 1 hora a temperatura ambiente com o anticorpo secundário anti-camundongo (1/6.000, GE), anti-coelho (1/10.000, GE) ou anti-cabra (1/2.000, GE), diluído em TBS-T. Após a incubação com o anticorpo secundário, as membranas foram lavadas por 2 vezes com TBST e uma vez com TBS durante 10 minutos cada. A reação aconteceu através da incubação com reagente quimioluminescente (Western Lightning Chemiluminescence Reagent Plus, ECL kit, Perkinelmer, EUA) durante 2 minutos. As membranas foram expostas ao filme sensível a quimioluminescência 
(Hyperfilm ECL, AmerSham Biosciences) durante 30 segundos a 3 minutos, dependendo do anticorpo, e revelados conforme indicado pelo fabricante.

Após revelação dos filmes, as membranas foram lavadas e submetidas a uma nova marcação, a fim de normalizar os valores protéicos. Para isso, as membranas foram incubadas durante 1 hora em temperatura ambiente com 0 anticorpo primário monoclonal anti-alfa-tubulina (1/30.000, Sigma) diluído em TBS-T contêndo BSA a 1\%, seguido de 2 lavagens com TBS-T por 10 minutos cada e de incubação, por 45 minutos em temperatura ambiente, com o anticorpo secundário anti-camundongo (1/10.000, GE) diluído em TBS-T com BSA 1\%. Após estas incubações, as membranas foram lavadas como descrito anteriormente seguidas da reação e revelação do filme. Os filmes foram quantificados através de densitometria óptica, usando um sistema de análise de imagens, como descrito por Chadi et al. (2008). 
Tabela 3: Relação dos anticorpos dos receptores Eph e das efrinas e as concentrações utilizadas na técnica do western blot.

\begin{tabular}{llll}
\hline Anticorpos & Características & Marca & Diluição \\
\hline EphA1 & Policlonal feito em coelho & Santa Cruz & $* * *$ \\
EphA2 & Policlonal feito em coelho & Santa Cruz & $1 / 200$ \\
EphA3 & Policlonal feito em coelho & Abcam & $1 / 1.000$ \\
EphA4 & Policlonal feito em coelho & Santa Cruz & $1 / 1.000$ \\
EphA5 & Policlonal feito em coelho & Santa Cruz & $1 / 1.000$ \\
EphA6 & Policlonal feito em coelho & Santa Cruz & $* * *$ \\
EphA7 & Policlonal feito em coelho & Santa Cruz & $1 / 400$ \\
EphA8 & Policlonal feito em coelho & Santa Cruz & $* * *$ \\
EphA10 & Policlonal feito em coelho & Santa Cruz & $* * *$ \\
EphB1 & Policlonal feito em coelho & Santa Cruz & $1 / 100$ \\
EphB2 & Policlonal feito em cabra & Santa Cruz & $* * *$ \\
EphB3 & Policlonal feito em coelho & Santa Cruz & $* * *$ \\
EphB4 & Policlonal feito em coelho & Santa Cruz & $1 / 1.000$ \\
EphB6 & Policlonal feito em coelho & Abcam & $1 / 200$ \\
Efrina-A1 & Policlonal feito em coelho & Abcam & $1 / 100$ \\
Efrina-A2 & Policlonal feito em coelho & Santa Cruz & $1 / 100$ \\
Efrina-A3 & Policlonal feito em coelho & Santa Cruz & $1 / 100$ \\
Efrina-A4 & Policlonal feito em coelho & Santa Cruz & $1 / 100$ \\
Efrina-A5 & Policlonal feito em coelho & Santa Cruz & $1 / 300$ \\
Efrina-B1 & Policlonal feito em coelho & Santa Cruz & $1 / 100$ \\
Efrina-B2 & Policlonal feito em cabra & Santa Cruz & $1 / 100$ \\
Efrina-B3 & Policlonal feito em cabra & Santa Cruz & $1 / 100$ \\
\hline
\end{tabular}

As ${ }^{* * *}$ indicam os anticorpos que não apresentaram marcações específicas no western blot, após várias concentrações testadas.

\subsubsection{Extração e Quantificação de RNA Total}

Inicialmente, o ambiente de trabalho foi limpo utilizando-se solução descontaminante de RNAse (RNAse ZAP, Ambion). Também foram utilizados tubos, ponteiras e soluções livres de RNAses. O RNA total dos fragmentos retirados da medula espinal (descrito anteriormente) foram extraídos com RNAspin Mini Kit (GE Healthcare, UK) de acordo com as recomendações do fabricante. O RNA foi quantificado pelo espectrofotômetro (Nanodrop 1000). Após a determinação da concentração de RNA, as amostras foram diluídas 10 vezes 
para verificar a sua integridade (Bioanalyzer 2100, RNA6000 LabChip Pico; Agilent, Palo Alto, CA). Foram usadas para as próximas fases apenas amostras com RIN (do inglês, RNA integrity number) maior do que 7, que representa um sinal de integridade de RNA excelente.

\subsubsection{Reação da Polimerase em Cadeia em Tempo Real}

Após a extração e teste de integridade do RNA (figura 4), foi feita a transformação do mesmo em cDNA, através de transcrição reversa com primers randômicos. Para isso, foi usado $1 \mu \mathrm{g}$ de RNA total e o kit de transcrição reversa TaqMan® Reverse Transcription Reagents (Applied Biosystems). Além dos tubos experimentais, outros 2 tubos controles foram inseridos no ensaio: um sem a enzima transcriptase reversa e outro sem o RNA. Os tubos foram colocados em um termociclador com o seguinte protocolo: 10 minutos de incubação a $25^{\circ} \mathrm{C}$ seguidos de 30 minutos de transcrição a $48^{\circ} \mathrm{C}$ e 5 minutos a 95ำ para inativação da enzima. Ao final do procedimento, o cDNA foi estocado em freezer a $-20^{\circ} \mathrm{C}$ até sua utilização para quantificação gênica através da RT-PCR. Os ensaios (mistura com os primers e a sonda) utilizados contêm um repórter $F A M^{\mathrm{TM}}$ fluorescente, que são comercialmente disponíveis através da empresa Applied Biosystems. 
A

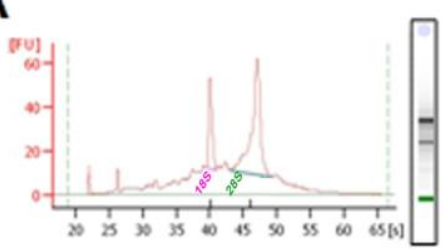

B

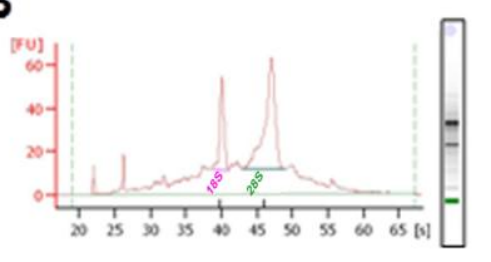

C

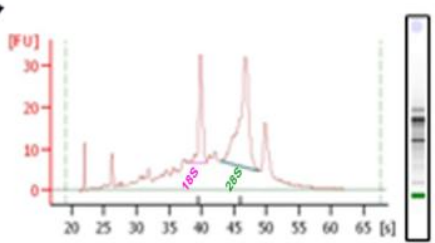

Figura 4: A figura mostra os eletroferogramas de um animal do grupo Sham (A), Salina (B) e PEDF (C), indicando claramente a integridade através dos picos de $18 \mathrm{~S}$ (em rosa) e $28 \mathrm{~S}$ (em verde) dos RNAr e nenhuma fragmentação do RNA, indicando RNA de alta qualidade (também ilustrado nas bandas) obtido pelo leitor Bionalyzer 2100 (Agilent).

Avaliou-se a expressão gênica dos fatores neurotróficos NT-3 (Rn00579280_m1), GDNF (Rn00569510_m1), BDNF (customizado - Forward 5'TGGTTATTTCATACTTCGG TTGCATGA3', Reverse 5'TGtCCGtggacGtTtgctT3', Probe 5'CtgCgccCAtgaAag3') e FGF-2 (Rn00570809_m1), dos receptores EphA6 (Rn01474859_m1) e EphB2 (Rn01181017_m1), bem como da RhoA (Rn04219610_g1). Primers e probe para RNA ribossômico (18S) foram utilizados como controle da reação, o 18 S contém o repórter $\mathrm{VIC}^{\mathrm{TM}}$ e também é comercialmente disponível (Applied Biosystems).

As soluções foram colocadas em uma placa de 96 poços com qualidade óptica (ABI Prism, Applied Biosystems, EUA), a qual também foi lacrada com adesivo com qualidade óptica (ABI Prism, Applied Biosystems, EUA) e submetida à amplificação e detecção através da RT-PCR (modelo Step One Plus, Applied Biosystems, EUA) por 40 ciclos. Os dados referentes aos RNAm de estudo foram corrigidos através da subtração dos valores referentes ao $18 \mathrm{~S}$ e comparados entre si por normalização logarítmica - método do $\Delta \Delta C T$, ou quantificação relativa (Livak e Schmittgen, 2001). 


\subsection{Análise Estatística}

Os dados dos testes comportamentais BBB, CBS e impressão de pegadas foram comparados através da análise estatística ANOVA de duas vias, seguido do pós-teste de Bonferroni. Ademais, uma segunda análise foi realizada incluindo apenas os grupos Salina e PEDF, a fim de obter dados referentes à recuperação sensório-motora dos animais lesionados. As técnicas western blot, imunoistoquímica e RT-PCR em tempo real foram analisadas através do teste ANOVA de uma via, seguido do pós-teste de Tukey. As tabelas com os resultados da média aritmética \pm erro padrão da média (e.p.m.) encontram-se em anexo. Foram aceitas como variações significativas aquelas em que a diferença entre os grupos resultou em um $\mathrm{p}$ menor ou igual a 0,05. 
RESULTADOS 


\section{RESULTADOS}

\subsection{Análise Comportamental}

\subsubsection{Análise Comportamental BBB e CBS}

Os efeitos da lesão medular isquêmica sobre os índices BBB e CBS foram avaliados segundo o teste ANOVA de duas vias, seguido do pós-teste de Bonferroni. A análise estatística mostrou efeitos do tempo e do tratamento com PEDF quando os três grupos foram analisados, bem como quando apenas os grupos Salina e PEDF foram incluídos na avaliação. Entretanto, diferenças na interação tempo/tratamento apareceram apenas quando os três grupos foram tratados conjuntamente (tabela 4). Ainda, diferenças entre o grupo Sham e os grupos Salina e PEDF foram apontadas em todos os períodos avaliados $(p<0,05)$, porém nenhuma diferença foi observada entre os grupos Salina e PEDF nestes períodos (figura 5).

Nos testes que compõem o índice CBS, a análise estatística ANOVA de duas vias realizada nos três grupos experimentais mostrou efeito do tratamento no teste de dor, efeitos do tempo e do tratamento nos testes de extensão e pressão, e, efeitos do tempo, do tratamento e da interação entre eles nos testes Tarlov, extensão dos dedos, reflexo de colocação, reflexo de endireitamento e plano inclinado. O tratamento estatístico realizado nos grupos Salina e PEDF mostrou um efeito temporal nos testes Tarlov, pressão e reflexo de colocação, efeito do tratamento com PEDF no teste reflexo de endireitamento, efeitos do tempo e do tratamento nos testes de extensão e extensão dos dedos, e por fim, 
efeitos do tempo, do tratamento e da interação entre eles no plano inclinado (tabela 5). De acordo com o pós-teste de Bonferroni, diferenças entre o grupo Sham e os grupos lesados foram observadas em todos os testes avaliados, com exceção de alguns períodos: entre a $1^{\circ}-3^{\circ}$ e a $4^{\circ}-6^{\circ}$ semana de avaliação no teste de pressão, nenhuma diferença entre os grupos Sham e Salina foi observada, e no que diz respeito à análise comparativa entre os grupos Sham e PEDF, nenhuma diferença foi observada entre a $4^{\circ}-6^{\circ}$ semana no teste de extensão, entre o $1^{\circ}-3^{\circ}$ dia e entre a $4^{\circ}-6^{\circ}$ semana no teste de dor, entre a $1^{\circ}-3^{\circ}$ e a $4^{\circ}-6^{\circ}$ semana no teste de pressão, entre a $4^{\circ}-6^{\circ}$ semana no teste extensão dos dedos e entre a $1^{\circ}-3^{\circ}$ e a $4^{\circ}-6^{\circ}$ semana no teste plano inclinado. Por fim, diferenças entre os grupos Salina e PEDF foram apontadas nos testes de extensão dos dedos e plano inclinado entre a $4^{\circ}-6^{\circ}$ semana de avaliação (figura 6). 
Tabela 4: Dados referentes às análises comportamentais BBB e CBS obtidos através da análise estatística ANOVA de duas vias.

\begin{tabular}{lcccc}
\hline \multicolumn{5}{c}{ Comparações entre os três grupos } \\
\hline Teste & Tempo & Tratamento & Interação \\
BBB & $p<0,0001 ; F=64,66$ & $p<0,0001 ; F=285,5$ & $p<0,0001 ; \quad F=4,6$ \\
CBS & $p<0,0001 ; F=62,37$ & $p<0,0001 ; F=245,9$ & $p<0,0001 ; \quad F=5,85$ \\
\hline \multicolumn{5}{c}{ Salina X PEDF } \\
\hline Teste & Tempo & Tratamento & Interação \\
BBB & $p<0,0001 ; F=76,19$ & $p=0,02 ; \quad F=5,234$ & $p>0,5 ; \quad F=0,144$ \\
CBS & $p<0,0001 ; F=68,27$ & $p=0,0003 ; F=13,21$ & $p>0,5 ; \quad F=0,257$ \\
\hline
\end{tabular}

A

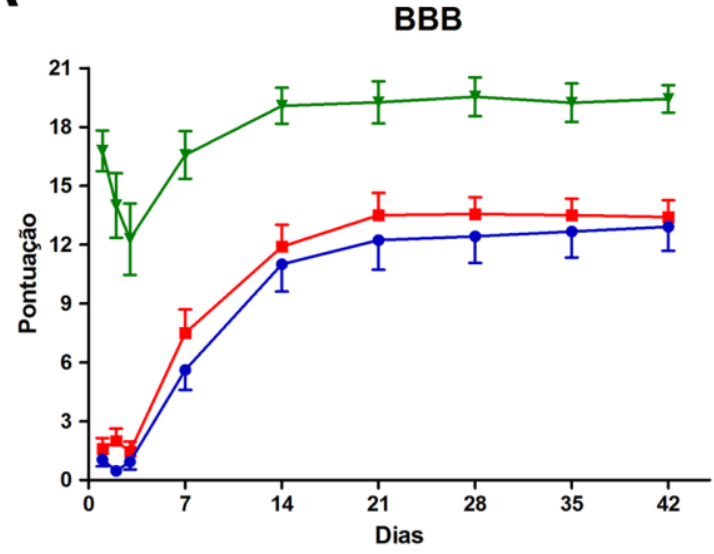

B

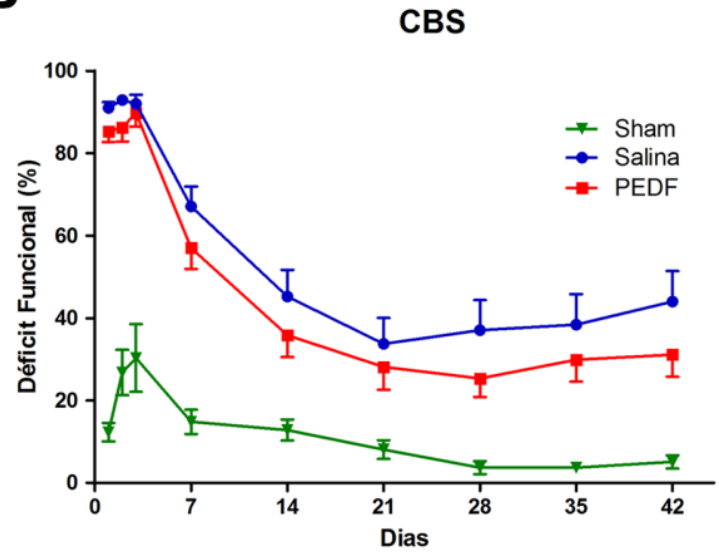

Figura 5: Os gráficos mostram as médias e os e.p.m. dos índices BBB (A) e CBS (B) e comparam ao longo do tempo a evolução do comportamento sensório-motor dos grupos experimentais Sham, Salina e PEDF. As análises foram realizadas diariamente até $03^{\circ}$ dia e depois semanalmente até o final do período de 6 semanas. A análise segundo o teste ANOVA de duas vias mostra que a melhora no padrão de recuperação sensório-motora nos animais com lesão medular isquêmica depende do tempo após a lesão $(p<0,0001)$ e do tratamento com PEDF $(p<0,05)$ para o BBB e CBS. O pós-teste de Bonferroni apontou diferenças entre o grupo Sham e os grupos Salina e PEDF em todos os períodos avaliados $(p<0,05)$ e nenhuma diferença foi vista entre os grupos Salina e PEDF. 
Tabela 5: Dados referentes aos testes que compõem o índice CBS obtidos através da análise estatística ANOVA de duas vias.

\begin{tabular}{|c|c|c|c|c|c|c|}
\hline \multicolumn{7}{|c|}{ Comparações entre os três grupos } \\
\hline Parâmetros & \multicolumn{2}{|c|}{ Tempo } & \multicolumn{2}{|c|}{ Tratamento } & \multicolumn{2}{|c|}{ Interação } \\
\hline Tarlov & $\mathrm{p}<0,0001$ & $F=87,19$ & $\mathrm{p}<0,0001$ & $F=65,92$ & $\mathrm{p}<0,0001$ & $F=9,764$ \\
\hline Extensão & $p=0,005$ & $F=5,538$ & $p<0,0001$ & $F=22,40$ & $p>0,05$ & $F=0,507$ \\
\hline Dor & $p>0,9$ & $F=0,1032$ & $p<0,0001$ & $F=13,87$ & $p>0,05$ & $F=0,0633$ \\
\hline Pressão & $p=0,0018$ & $\mathrm{~F}=6,617$ & $\mathrm{p}<0,0001$ & $F=13,50$ & $p>0,5$ & $F=0,2423$ \\
\hline Extensão dos dedos & $\mathrm{p}<0,0001$ & $F=64,63$ & $\mathrm{p}<0,0001$ & $F=70,83$ & $\mathrm{p}<0,0001$ & $F=10,67$ \\
\hline Reflexo de colocação & $p<0,0001$ & $F=91,14$ & $p<0,0001$ & $F=119,3$ & $p<0,0001$ & $F=8,453$ \\
\hline Reflexo de endireitamento & $p<0,0001$ & $F=10,88$ & $p<0,0001$ & $F=90,95$ & $p<0,0001$ & $F=9,488$ \\
\hline Plano inclinado & $\mathrm{p}<0,0001$ & $F=101,4$ & $\mathrm{p}<0,0001$ & $F=32,99$ & $\mathrm{p}<0,0001$ & $F=7,516$ \\
\hline \multicolumn{7}{|c|}{ Salina X PEDF } \\
\hline Parâmetros & \multicolumn{2}{|c|}{ Tempo } & \multicolumn{2}{|c|}{ Tratamento } & \multicolumn{2}{|c|}{ Interação } \\
\hline Tarlov & $\mathrm{p}<0,0001$ & $F=119,3$ & $p>0,05$ & $F=1,144$ & $p>0,05$ & $F=0,1416$ \\
\hline Extensão & $p=0,01$ & $F=4,106$ & $p=0,04$ & $F=4,276$ & $p>0,05$ & $F=0,1378$ \\
\hline Dor & $p>0,05$ & $F=0,1385$ & $p>0,05$ & $F=1,865$ & $p>0,05$ & $F=0,0198$ \\
\hline Pressão & $\mathrm{p}=0,005$ & $F=5,438$ & $p>0,05$ & $F=1,025$ & $p>0,05$ & $F=0,0157$ \\
\hline Extensão dos dedos & $\mathrm{p}<0,0001$ & $\mathrm{~F}=81,84$ & $p=0,001$ & $F=11,38$ & $p>0,05$ & $F=0,7145$ \\
\hline Reflexo de colocação & $\mathrm{p}<0,0001$ & $\mathrm{~F}=111,7$ & $p>0,05$ & $F=2,408$ & $p>0,05$ & $F=0,3490$ \\
\hline Reflexo de endireitamento & $p>0,05$ & $\mathrm{~F}=0,3132$ & $p=0,04$ & $F=4,244$ & $p>0,05$ & $F=0,7441$ \\
\hline Plano inclinado & $\mathrm{p}<0,0001$ & $F=99,14$ & $p=0,002$ & $F=9,543$ & $p=0,004$ & $F=5,80$ \\
\hline
\end{tabular}


A

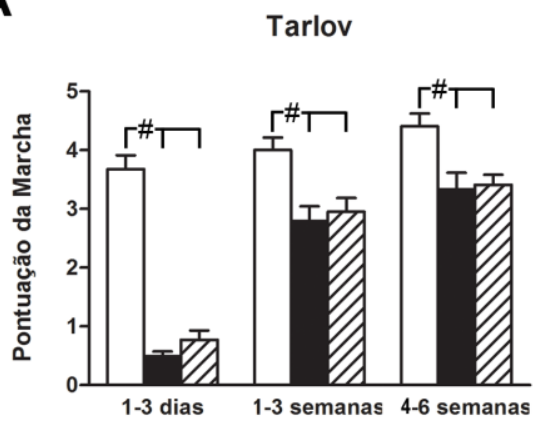

C

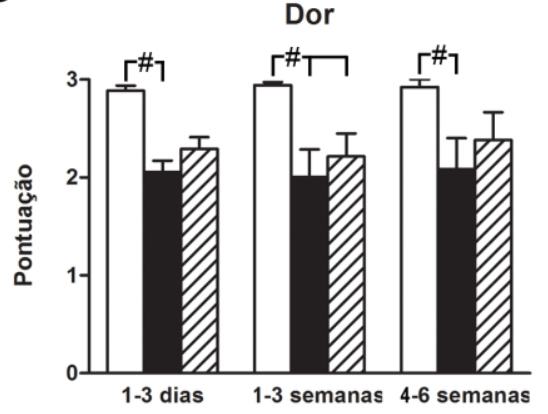

$\mathbf{E}$

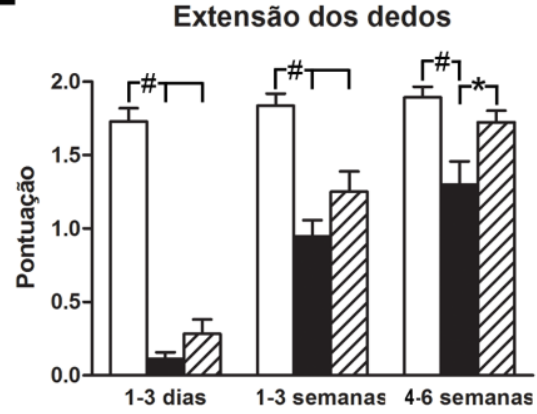

G

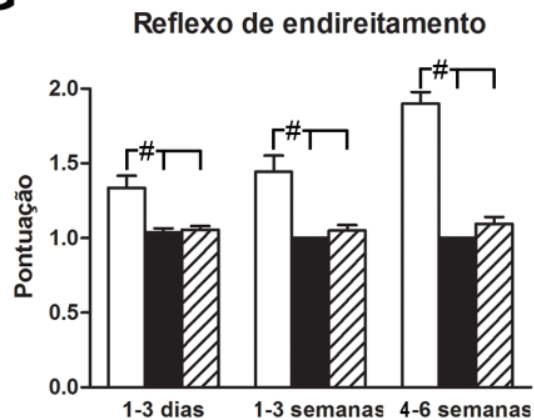

B

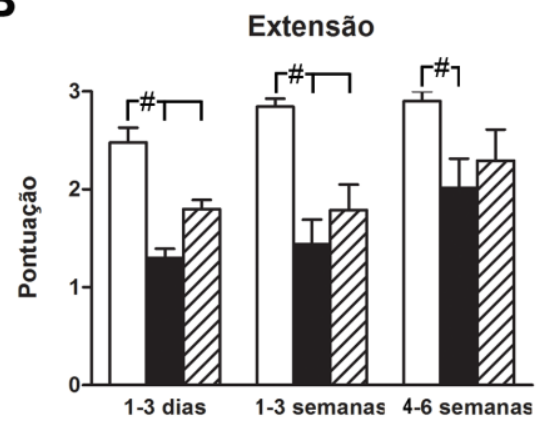

D

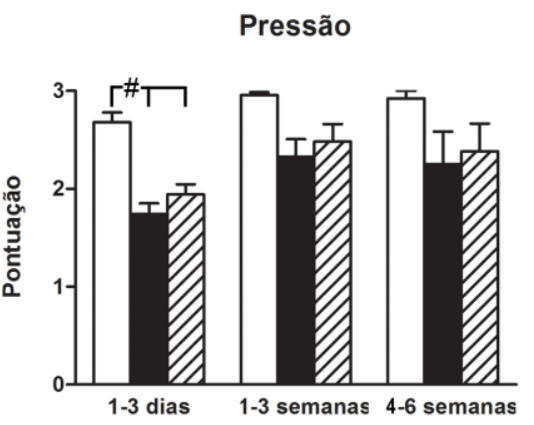

$\mathbf{F}$

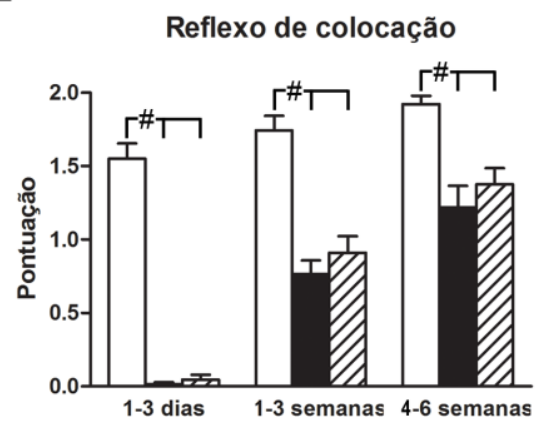

H

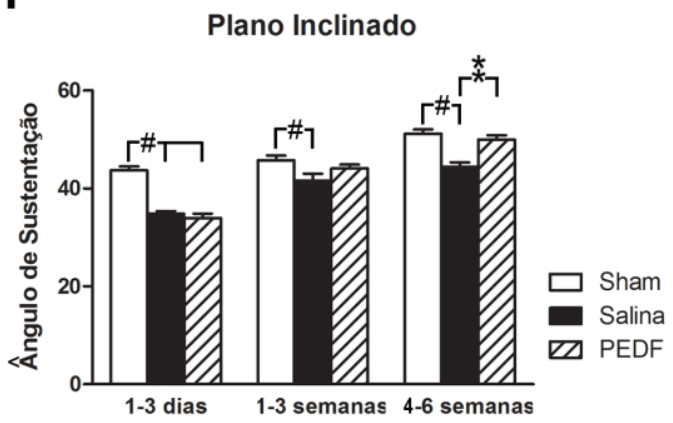

Figura 6: Os gráficos mostram as médias e os e.p.m. das avaliações que compõem o índice CBS e compara ao longo do tempo a evolução dos parâmetros sensório-motores dos grupos Sham, Salina e PEDF. Os seguintes testes foram realizados: Escala locomotora de Tarlov $(A)$, reflexos de retirada em resposta a estímulos de extensão $(B)$, dor $(C)$ e pressão $(D)$, reflexo de extensão dos dedos $(E)$, reflexo de colocação $(F)$, reflexo de endireitamento $(G)$ e plano inclinado $(H)$. Os testes foram realizados diariamente até o $3^{\circ}$ dia e depois realizados semanalmente até o final do período de 6 semanas e agrupados em três períodos, como ilustrado acima. A análise segundo o teste ANOVA de duas vias mostra que a recuperação sensório-motora nos animais com lesão medular isquêmica depende em $A, D$ e $F$ do tempo após a lesão, em G do tratamento com PEDF, em B e E do tempo e do tratamento e $\mathrm{H}$ depende do tempo, do tratamento e da interação entre eles. De acordo com o pós-teste de Bonferroni, é ilustrado " $(p<0,05)$ quando o grupo Salina e/ou PEDF difere do Sham $e^{*}(p<0,05)$ ou ** $(p<0,001)$ quando o grupo PEDF difere do Salina. 


\subsubsection{Análise Motora Fina - Impressão de Pegadas}

Os resultados da análise motora fina mostraram efeitos do tempo e do tratamento em todas as avaliações que compõem o teste impressão de pegadas, quando os três grupos foram comparados. Ainda, observou-se um efeito temporal nas avaliações comprimento da passada, distância entre o calcanhar e $03^{\circ}$ dedo e distância entre $\circ 2^{\circ}$ e $\circ 4^{\circ}$ dedo, quando apenas os grupos Salina e PEDF foram analisados, segundo o teste ANOVA de duas vias (tabela 6). O pós-teste de Bonferroni mostrou diferenças entre o grupo Sham e os grupos lesionados, entretanto, nenhuma diferença foi observada entre os grupos Salina e PEDF (figura 7).

Tabela 6: Dados referentes às avaliações que compõem o teste impressão de pegadas obtidos através da análise estatística ANOVA de duas vias.

\begin{tabular}{|c|c|c|c|c|c|c|}
\hline \multicolumn{7}{|c|}{ Comparações entre os três grupos } \\
\hline Descrição & \multicolumn{2}{|c|}{ Tempo } & \multicolumn{2}{|c|}{ Tratamento } & \multicolumn{2}{|c|}{ Interação } \\
\hline $\begin{array}{l}\text { Comprimento da passada } \\
\text { Distância entre o calcanhar e o } \\
3^{\circ} \text { dedo }\end{array}$ & $p=0,002$ & $\begin{array}{l}F=3,803 \\
F=5,261\end{array}$ & $p<0,0001$ & $\begin{array}{l}F=22,60 \\
F=26,46\end{array}$ & $p>0,05$ & $F=1,087$ \\
\hline Distância entre $\circ 1^{\circ}$ e o $5^{\circ}$ dedo & $\mathrm{p}=0,0003$ & $F=4,954$ & $p<0,0001$ & $F=43,98$ & $p>0,05$ & $F=0,657$ \\
\hline Distância entre $\circ 2^{\circ}$ e $\circ 4^{\circ}$ dedo & $\mathrm{p}=0,0009$ & $\mathrm{~F}=4,317$ & $\mathrm{p}<0,0001$ & $F=19,79$ & $p>0,05$ & $F=0,192$ \\
\hline \multicolumn{7}{|c|}{ Salina X PEDF } \\
\hline Descrição & \multicolumn{2}{|c|}{ Tempo } & \multicolumn{2}{|c|}{ Tratamento } & \multicolumn{2}{|c|}{ Interação } \\
\hline $\begin{array}{l}\text { Comprimento da passada } \\
\text { Distância entre o calcanhar e o }\end{array}$ & $p=0,001$ & $F=4,018$ & $p>0,05$ & $F=0,458$ & $p>0,05$ & $F=0,874$ \\
\hline $3^{\circ}$ dedo & $p=0,0004$ & $\mathrm{~F}=4,789$ & $p>0,05$ & $F=8,45$ & $p>0,05$ & $F=0,345$ \\
\hline Distância entre o $1^{\circ}$ e o $5^{\circ}$ dedo & $p>0,05$ & $F=1,759$ & $p>0,05$ & $F=0,230$ & $p>0,05$ & $F=0,470$ \\
\hline Distância entre $\circ 2^{\circ}$ e $\circ 4^{\circ}$ dedo & $\mathrm{p}=0,02$ & $F=2,562$ & $\mathrm{p}>0,05$ & $\mathrm{~F}=0,003$ & $\mathrm{p}>0,05$ & $F=0,234$ \\
\hline
\end{tabular}


A

\section{Comprimento da Passada}

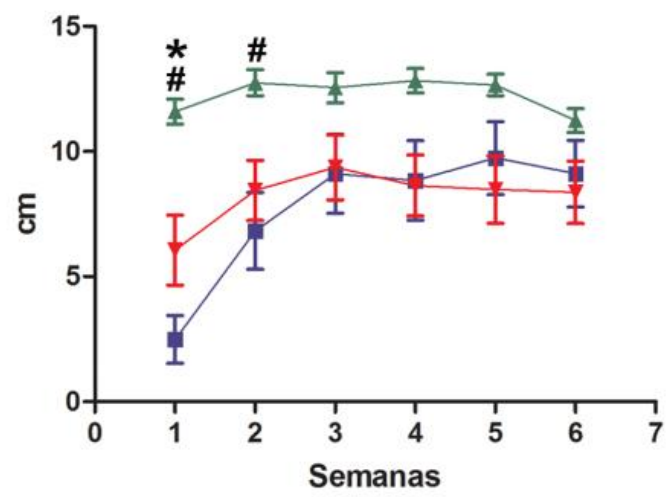

C

Distância entre o $1^{\circ}$ e o $5^{\circ}$ dedo

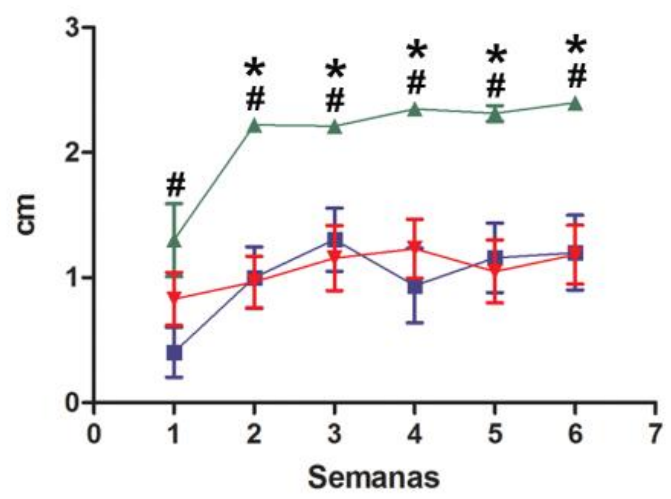

B

Distância entre o calcanhar e o $3^{\circ}$ dedo

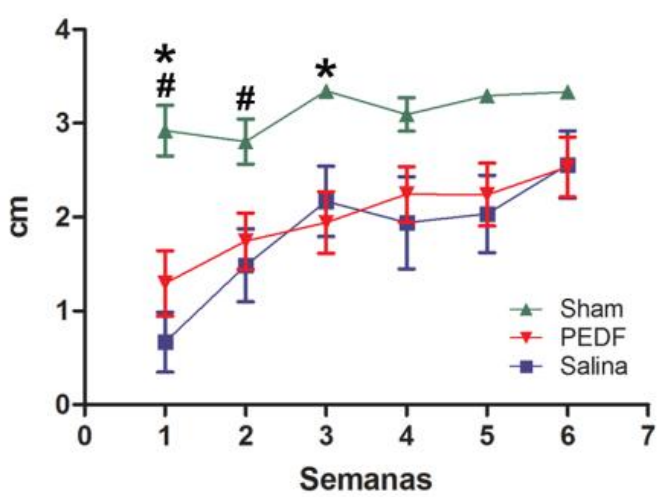

D

\section{Distância entre o $2^{\circ}$ e o $4^{\circ}$ dedo}

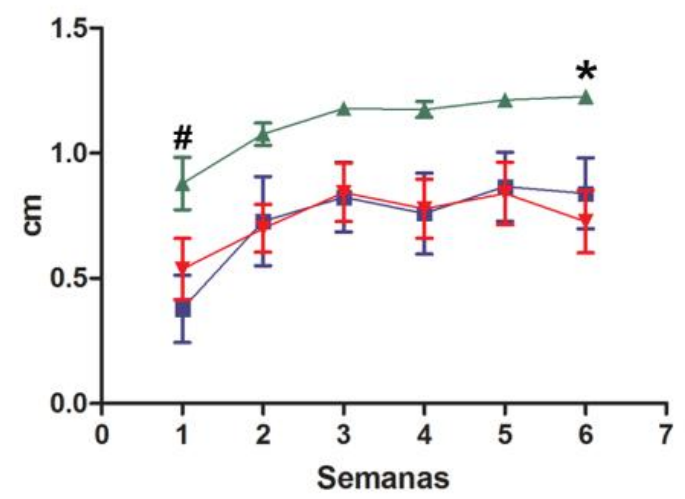

Figura 7: Os gráficos mostram as médias e os e.p.m. da análise motora fina, realizado através do teste impressão de pegadas e compara ao longo do tempo a evolução dos parâmetros motores dos grupos Sham, Salina e PEDF. Os seguintes testes foram realizados: Comprimento da

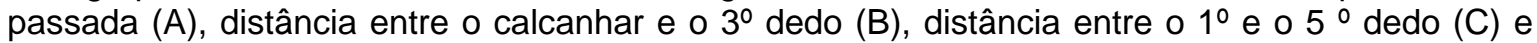
distância entre $\circ 2^{\circ}$ e $\circ 4^{\circ}$ dedo (D). Os testes foram realizados semanalmente até 0 final do período de 6 semanas, como ilustrado acima. A análise segundo o teste de variância ANOVA de duas vias mostra que a melhora no padrão de recuperação motora nos animais com lesão medular isquêmica depende, em $\mathrm{A}, \mathrm{B}$ e $\mathrm{D}$, do tempo após a lesão. De acordo com o pós-teste de Bonferroni, é ilustrado ${ }^{\#}(p<0,05)$ quando o grupo Sham difere do Salina $e^{*}(p<0,05)$ quando $o$ Sham difere do grupo PEDF. 


\subsection{Análise de Moléculas Inibidoras do Crescimento de Fibras}

A análise protéica das CSPGs, quantificadas nos homogenados colhidos na porção lombar anterior da medula espinal, por meio de western blot, mostrou duas bandas com pesos moleculares distintos. Na banda de $150 \mathrm{kDa}$, nenhuma diferença significante foi observada entre os grupos experimentais, entretanto, os dados apontam uma diminuição no nível das CSPGs na banda de 70 kDa, nos grupos Salina e PEDF em relação ao grupo Sham (figura 8).

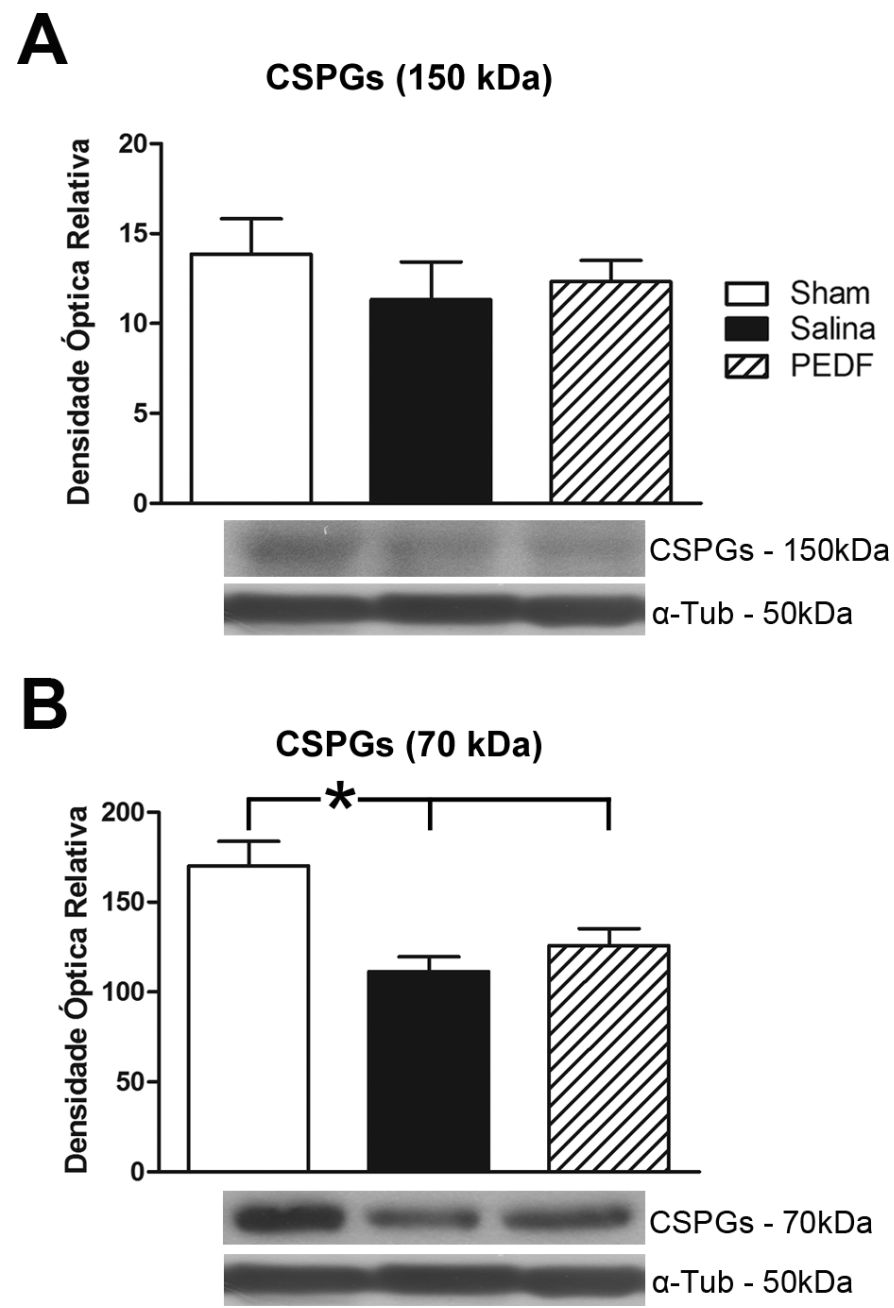

Figura 8: A figura mostra a densidade óptica relativa dos níveis de proteína das Proteoglicanas de Sulfato de Condroitina (CSPGs) de peso molecular de $150 \mathrm{kDa}(\mathrm{A})$ e $70 \mathrm{kDa}(\mathrm{B})$, na região lombar anterior da medula espinal. $\alpha$-Tubulina $(50 \mathrm{kDa})$ foi utilizada como controle. Observam-se os grupos Sham, Salina e PEDF. A análise realizada segundo o teste de variância ANOVA de uma via, seguido do pós-teste de Tukey, mostrou uma diminuição no nível das CSPGs na banda de 70 $k$ Da dos grupos Salina e PEDF em relação ao Sham $\left({ }^{*} p<0,05\right)$. 


\subsection{Análise dos Fatores Neurotróficos}

O estudo da expressão relativa de RNAm dos fatores neurotróficos NT-3, GDNF, BDNF e FGF-2 foi realizado na porção lombar anterior da medula espinal, pelo método da RT-PCR. O resultado mostrou uma diminuição na expressão do NT-3 no grupo PEDF em relação ao Sham. Em contra partida, foi observado um aumento na expressão do GDNF no grupo PEDF em relação aos grupos Sham e Salina e nenhuma diferença foi observada entre os grupos ao analisar os fatores neurotróficos BDNF e FGF-2 (figura 9).

A

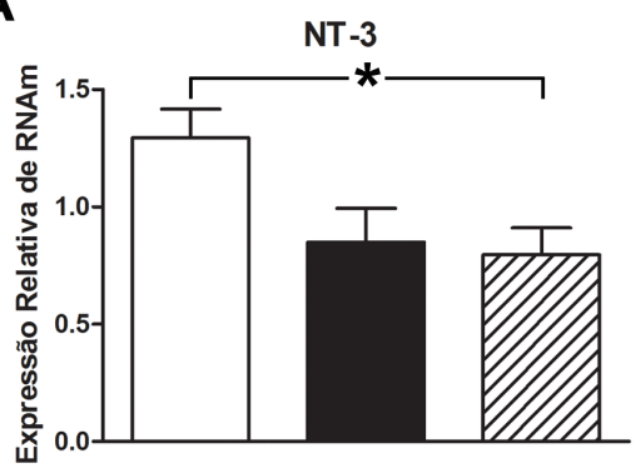

C

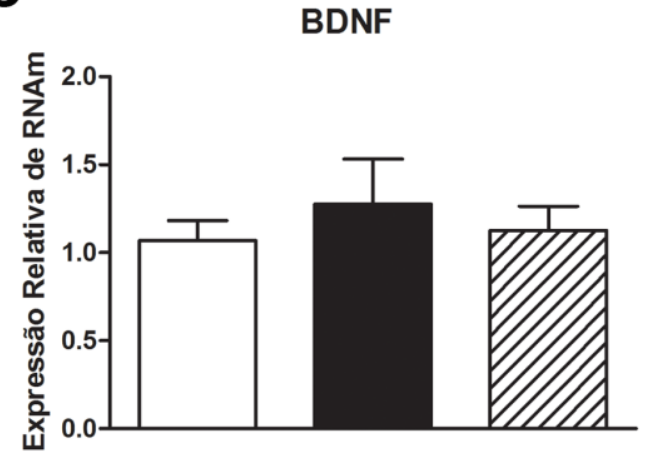

B

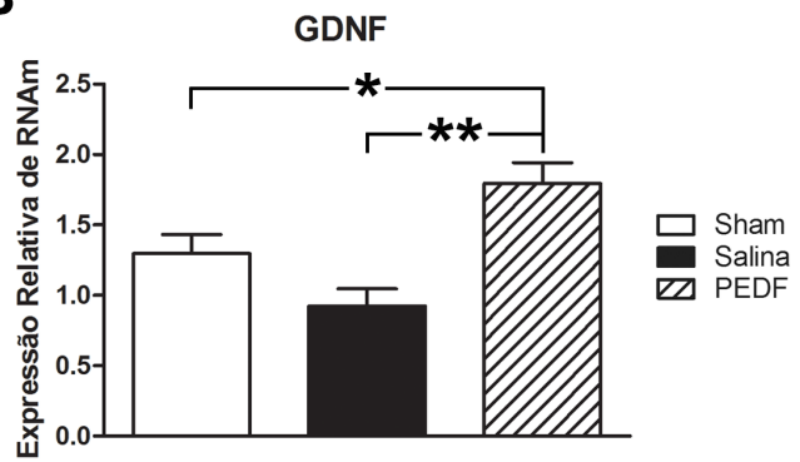

D

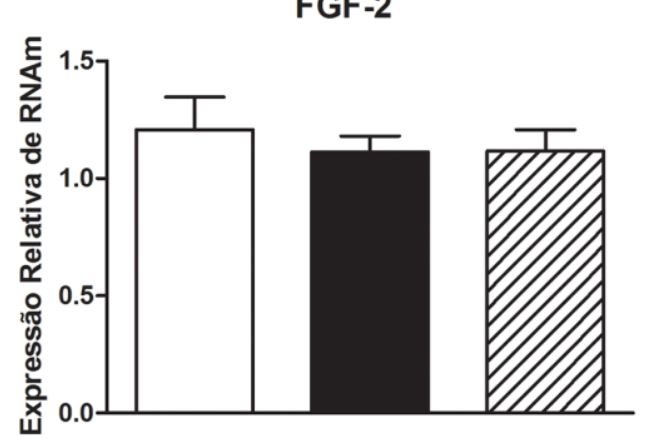

Figura 9: A figura mostra a expressão relativa de RNAm dos fatores neurotróficos NT-3 (A), FGF2 (B), BDNF (C) e GDNF (D), na região lombar anterior da medula espinal. Observam-se os grupos Sham, Salina e PEDF. A análise segundo o teste de variância ANOVA de uma via, seguido do pós-teste de Tukey, mostra uma diminuição da expressão gênica do NT-3 no grupo PEDF em relação ao Sham $\left({ }^{*} p<0,05\right)$ e um aumento da expressão gênica do GDNF no grupo PEDF em relação aos grupos Sham e Salina $\left({ }^{*} p<0,05 ;{ }^{* *} p<0,01\right)$. 
Em relação à quantificação protéica do PEDF realizada na mesma região, todavia pela técnica de western blot, nenhuma diferença foi observada entre os grupos experimentais no período do pós-operatório escolhido neste estudo (figura 10).

\section{PEDF}

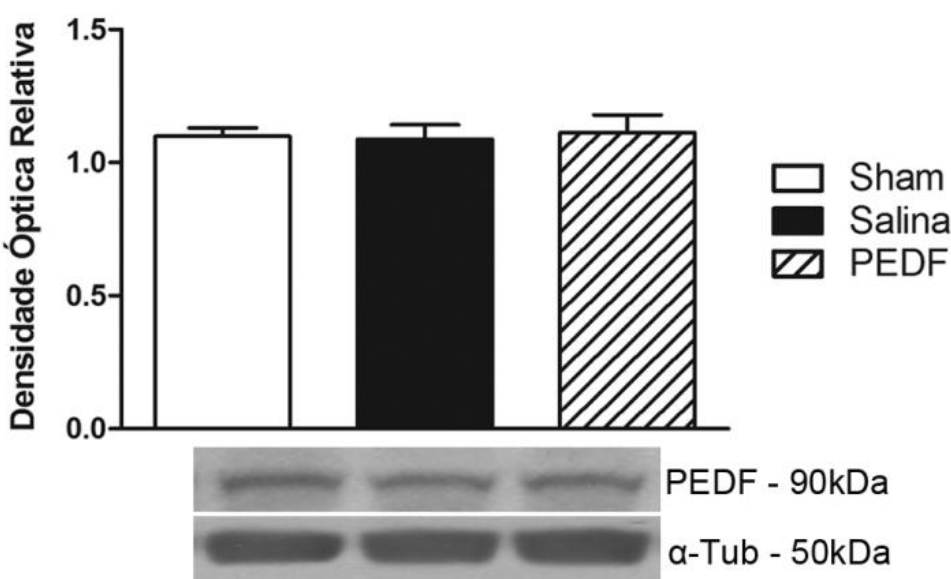

Figura 10: A figura mostra a densidade óptica relativa do nível de proteína do PEDF (90kDa) na região lombar anterior da medula espinal. $\alpha$-Tubulina $(50 \mathrm{kDa})$ foi utilizada como controle. Observam-se os grupos Sham, Salina e PEDF. A análise foi realizada segundo o teste de variância ANOVA de uma via, seguido do pós-teste de Tukey. 


\subsection{Análise da Angiogênese e Apoptose Local}

De acordo com a quantificação protéica da laminina e do Bcl- 2 efetuada na região lombar anterior da medula espinal, por meio do Western Blot, os resultados mostraram um aumento no nível da laminina no grupo Salina quando comparado com o Sham e uma diminuição do grupo PEDF em relação ao Salina. Em relação ao $\mathrm{Bcl}-2$, nenhuma alteração foi demonstrada entre os grupos no período do pósoperatório estudado (figura 11).

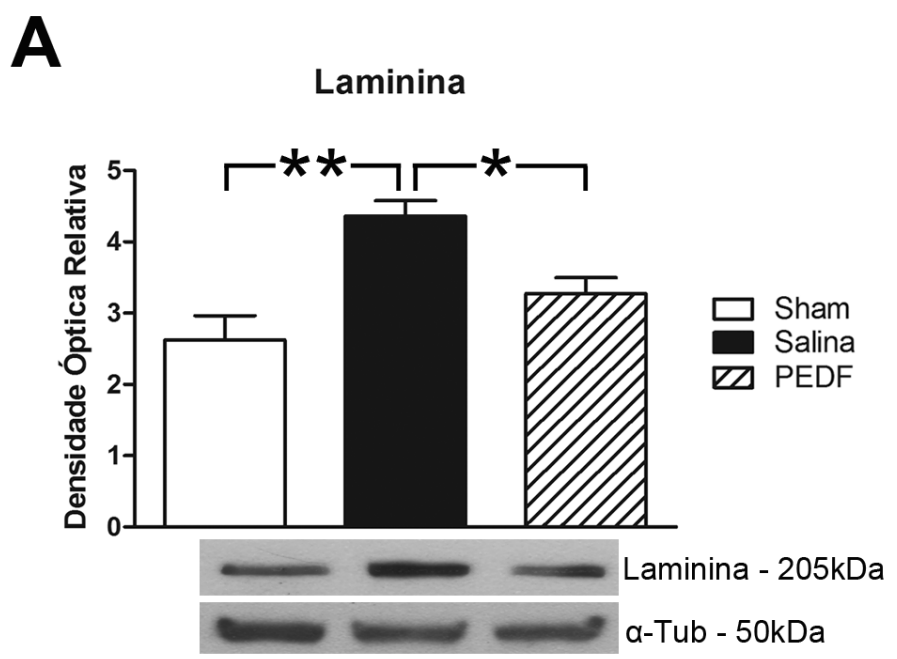

B

$\mathrm{Bcl}-2$

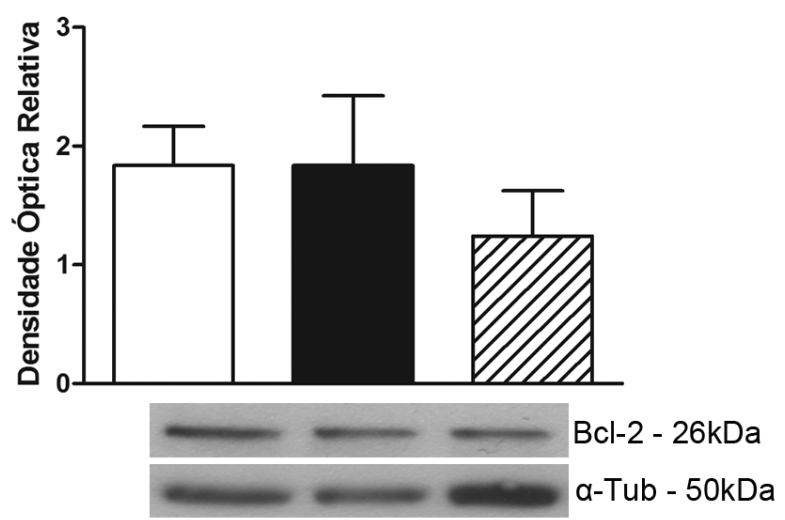

Figura 11: A figura mostra a densidade óptica relativa dos níveis de proteína da laminina $(A)$, de $205 \mathrm{kDa}$, e do Bcl-2 (B), de $26 \mathrm{kDa}$, na região lombar anterior da medula espinal. a-Tubulina $(50 \mathrm{kDa})$ foi utilizada como controle. Observam-se os grupos Sham, Salina e PEDF. A análise realizada segundo o teste de variância ANOVA de uma via, seguido do pós-teste de Tukey, mostrou um aumento no nível da laminina no grupo Salina quando comparado com os outros grupos $\left({ }^{*} p<0,05 e^{* *} p<0,01\right)$. 


\subsection{Análise de Moléculas Relacionadas à Neuroplasticidade}

A análise da imunorreatividade da MAP-2 foi realizada através da imunoperoxidase, a qual mostrou um aumento significativo de sua expressão no corno anterior da região lombar da medula espinal lesada e tratada com PEDF, quando comparada com os grupos Sham e Salina (figuras 12 e 13). Contudo, a análise da imunorreatividade da GAP-43 não mostrou alterações significativas quando os grupos foram comparados (figura 12).

A

Área - MAP-2

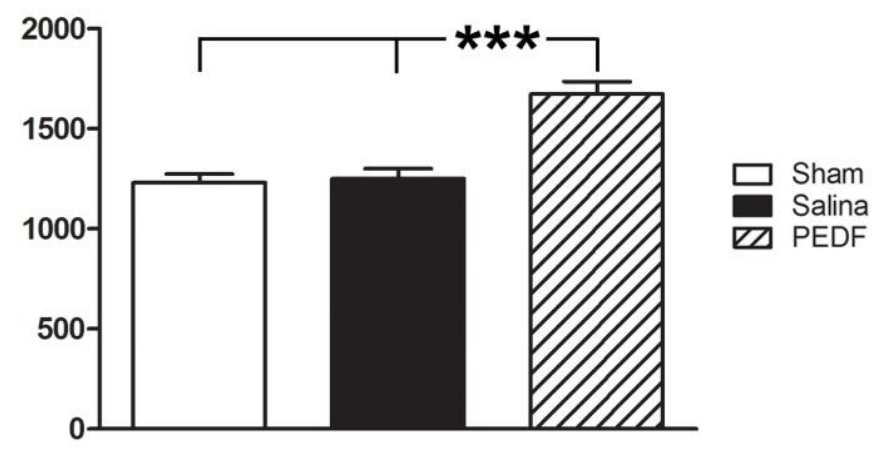

B

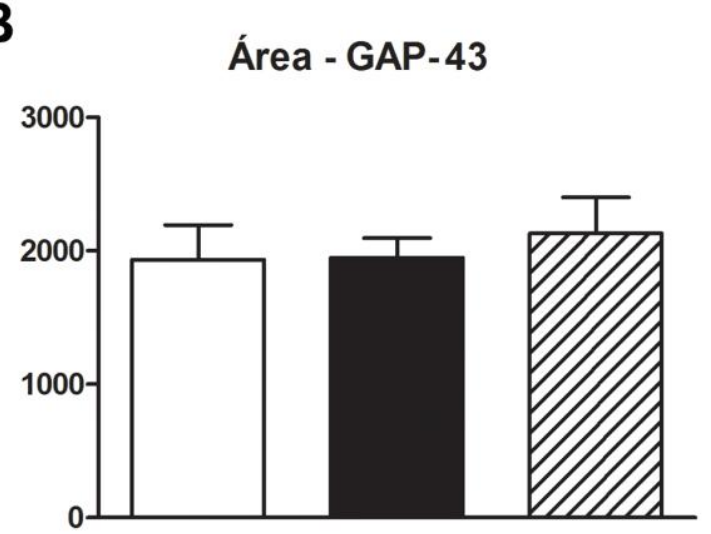

Figura 12: Os gráficos mostram as médias e os e.p.m. das áreas da imunorreatividade da MAP-2 (A) e da GAP-43 (B), no corno anterior da medula espinal em um segmento da intumescência lombar, caudal à lesão, obtidas por análise morfométrica e microdensitométrica dos animais Sham, Salina e PEDF. A análise realizada segundo o teste de variância ANOVA de uma via, seguido do pós teste de Tukey, mostrou alterações na área da imunorreatividade da MAP-2 quando comparados os grupos Sham e Salina com o grupo PEDF $\left({ }^{* * *} p<0,001\right)$. 

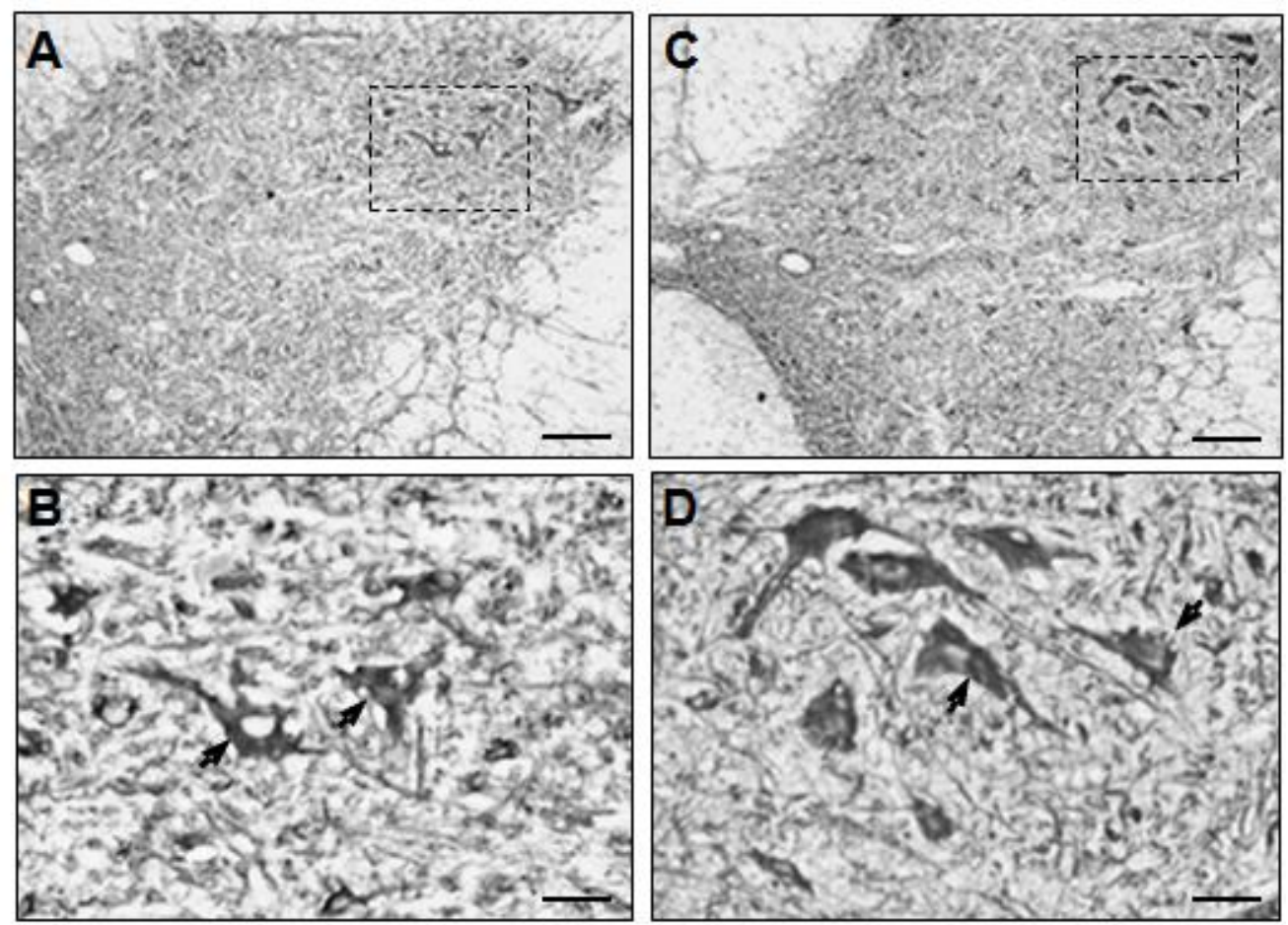

Figura 13: Fotomicrografias ilustrando o padrão de marcação da imunorreatividade à MAP-2 no corno anterior da medula espinal em um segmento da intumescência lombar de ratos que sofreram a cirurgia simulada (A, B) ou lesão isquêmica fototrombótica e tratados com PEDF (C, D) após 6 semanas da cirurgia. As setas indicam neurônios e pode-se observar a arborização dendrítica. Barra $=100 \mu \mathrm{m}(\mathrm{A}, \mathrm{C})$ e $30 \mu \mathrm{m} \mathrm{B}, \mathrm{D}$. 
Ao quantificar as proteínas estruturais MAP-2, GAP-43 e sinaptofisina na região lombar anterior da medula espinal, por meio do western blot, os dados confirmaram o aumento no nível da MAP-2 nos animais tratados com PEDF em relação ao Sham e nenhuma alteração significativa foi demonstrada no nível da GAP-43 e da sinaptofisina no período de pós-operatório definido neste estudo (figura 14).

A

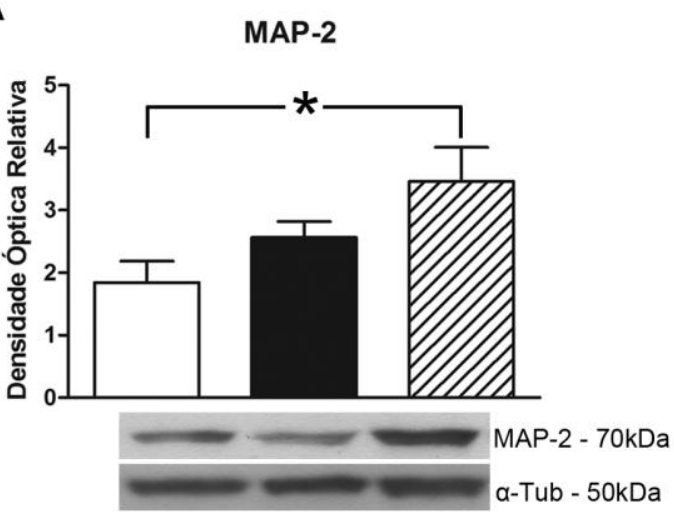

B

GAP-43

C
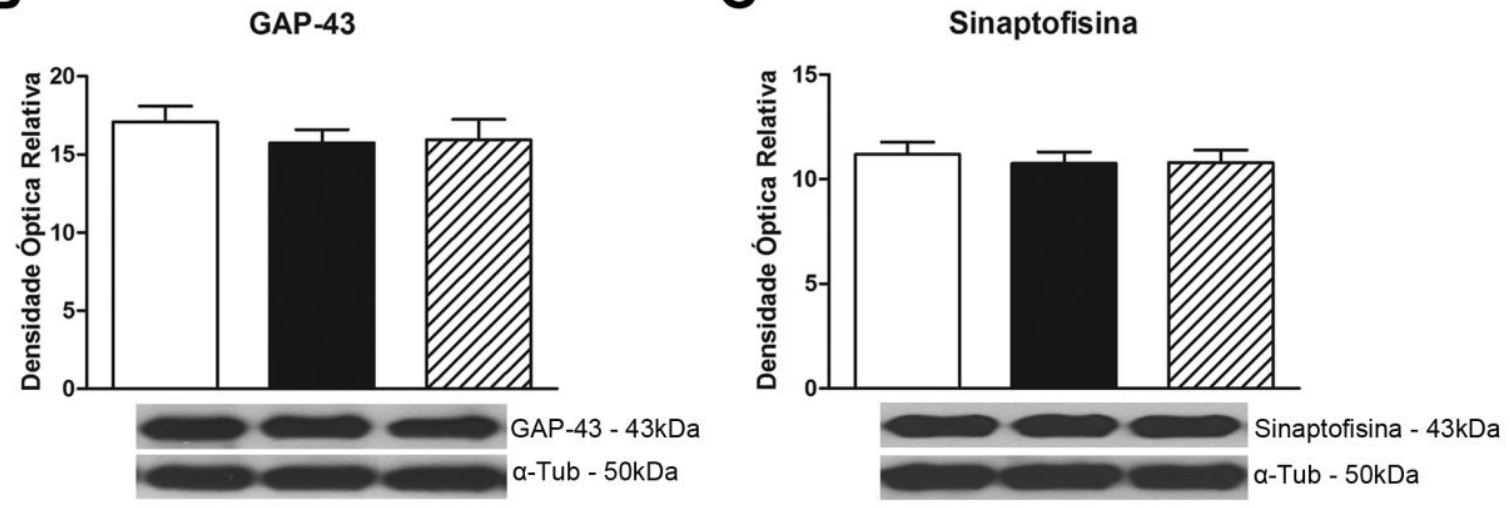

Figura 14: A figura mostra a densidade óptica relativa dos níveis de proteína dos marcadores estruturais MAP-2 (A), de $70 \mathrm{kDa}, \mathrm{GAP}-43$ (B), de 43kDa, e Sinaptofisina (C), de 43kDa, na região lombar anterior da medula espinal. $\alpha$-Tubulina $(50 \mathrm{kDa})$ foi utilizada como controle. Observam-se os grupos Sham, Salina e PEDF. A análise realizada segundo o teste de variância ANOVA de uma via, seguido do pós-teste de Tukey, mostrou um aumento no nível da MAP-2 no grupo PEDF quando comparado com o grupo Sham $\left({ }^{*} p<0,05\right)$. 


\subsection{Análise de Moléculas do Sistema Eph/Efrina}

Os níveis protéicos dos subtipos A e B dos receptores Eph, bem como das efrinas, foram quantificados por meio de western blot na porção lombar anterior da medula espinal.

Os resultados evidenciaram um aumento no nível do receptor EphA4 nos grupos Salina e PEDF quando comparados com o Sham, sem alteração nos níveis protéicos dos receptores EphA2, A3, A5 e A7 (figura 15). Nos receptores do tipo $B$, nenhuma diferença foi observada entre os grupos, como mostra a figura 16. Em relação às efrinas do tipo $A$, observou-se um aumento no nível da efrina-A2 no grupo PEDF em relação ao Sham, sem alteração nos níveis das efrinas A1, A3, A4 e A5 com os tratamentos aplicados (figura 17). Diferenças também foram encontradas nas efrinas do tipo B, onde um aumento na expressão da efrina-B1 foi observado nos grupos Salina e PEDF em relação ao Sham, um aumento no nível da efrina-B2 foi vista no grupo PEDF em relação aos grupos Sham e Salina, bem como houve um aumento no nível da efrina-B3 no grupo PEDF em relação ao Sham (figura 18).

Alguns subtipos de receptores Eph estudados, particularmente os EphA1, A6, A8, A10, B2 e B3, tiveram marcações inespecíficas ou ausentes quando analisados através do western blot, mesmo após testes utilizando protocolos com diferentes concentrações de proteína e anticorpo. 


\section{A}

Receptor EphA2

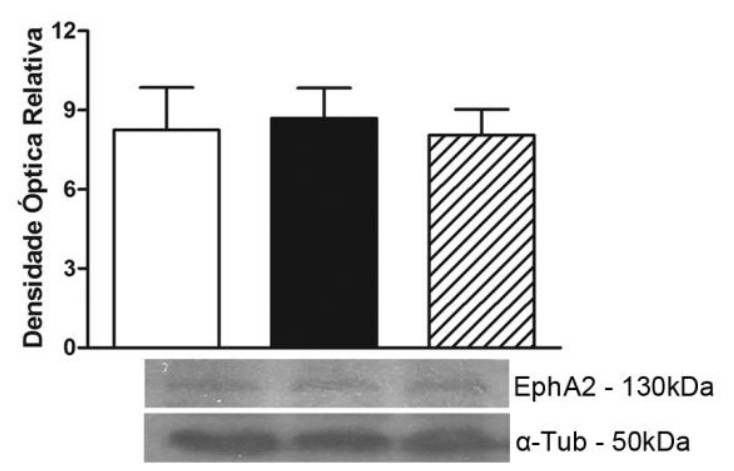

B

Receptor EphA3

C
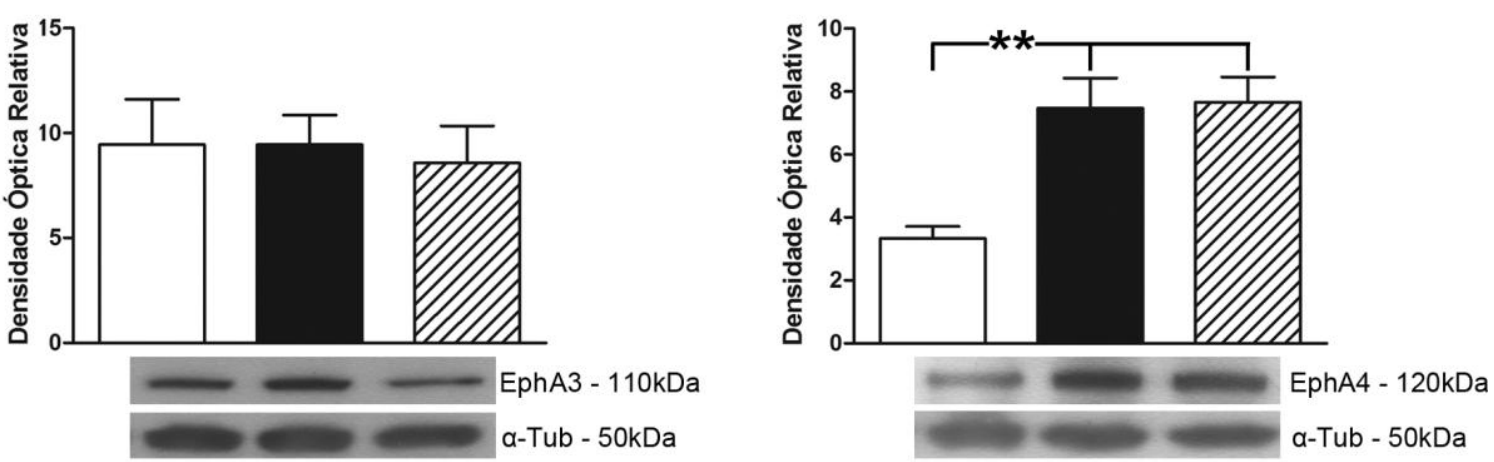

D

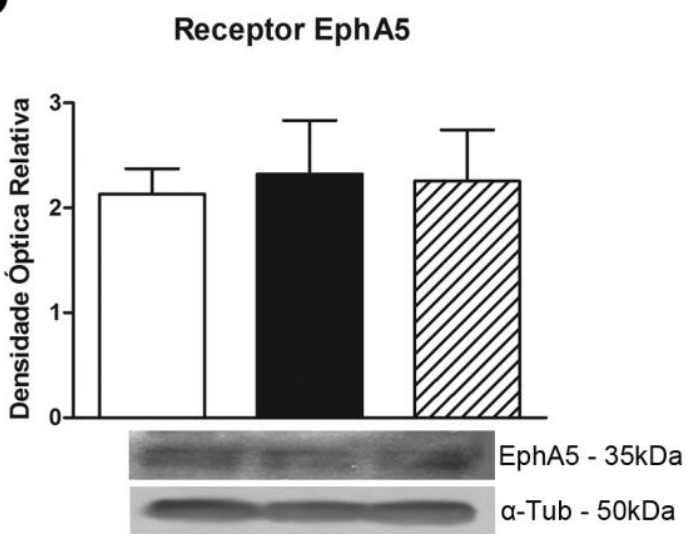

E

Receptor EphA7

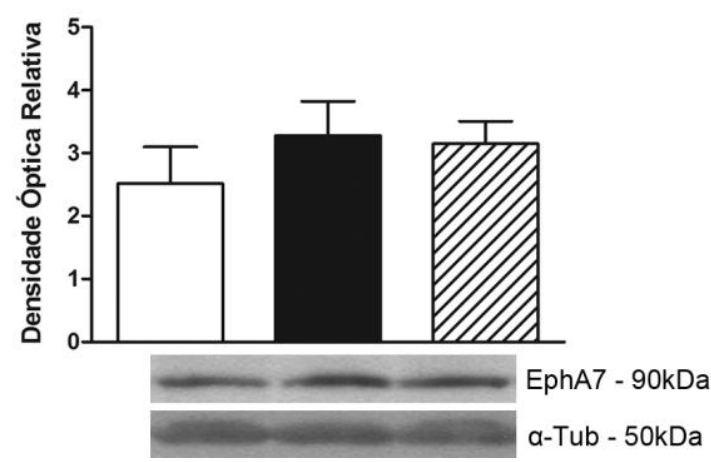

Figura 15: A figura mostra a densidade óptica relativa dos níveis de proteína dos receptores EphA2 (A), de 130kDa, EphA3 (B), de 110kDa, EphA4 (C), de 120kDa, EphA5 (D), de 35kDa, e EphA7 (E), de $90 \mathrm{kDa}$, na região lombar anterior da medula espinal. $\alpha$-Tubulina $(50 \mathrm{kDa})$ foi utilizada como controle. Observam-se os grupos Sham, Salina e PEDF. A análise realizada segundo o teste de variância ANOVA de uma via, seguido do pós-teste de Tukey, mostra um aumento no nível do receptor EphA4 $\left({ }^{*} p<0,05\right)$ nos grupos Salina e PEDF em relação ao Sham. 


\section{A}

Receptor EphB1

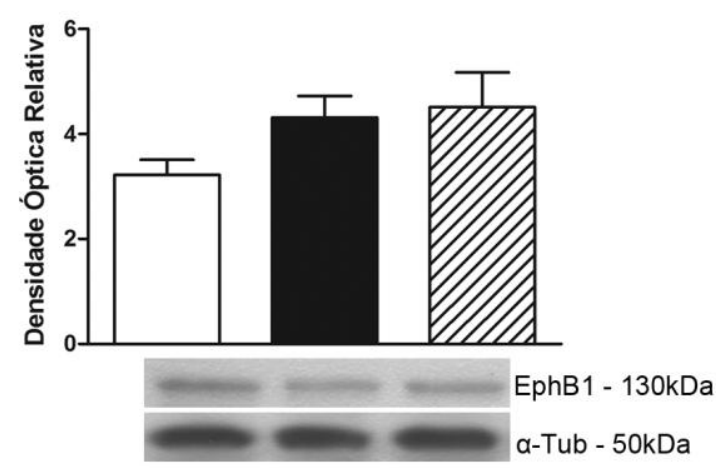

B

Receptor EphB4

C

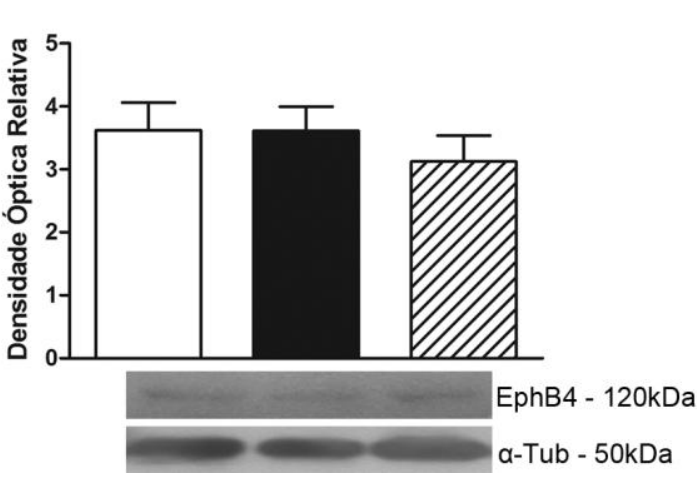

Receptor EphB6

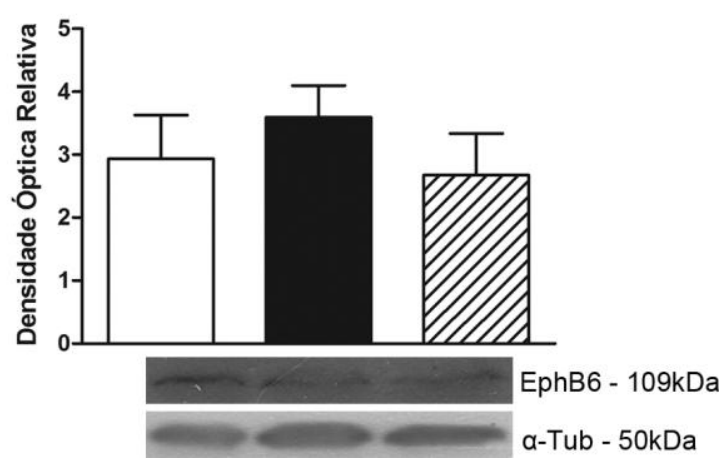

Figura 16: A figura mostra a densidade óptica relativa dos níveis de proteína dos receptores EphB1 (A), de 130kDa, EphB4 (B), de 120kDa, e EphB6 (C), de 109kDa, na região lombar anterior da medula espinal. $\alpha$-Tubulina $(50 \mathrm{kDa})$ foi utilizada como controle. Observam-se os grupos Sham, Salina e PEDF. A análise foi realizada segundo o teste de variância ANOVA de uma via, seguido do pós-teste de Tukey. 
$\mathbf{A}$

Efrina-A1

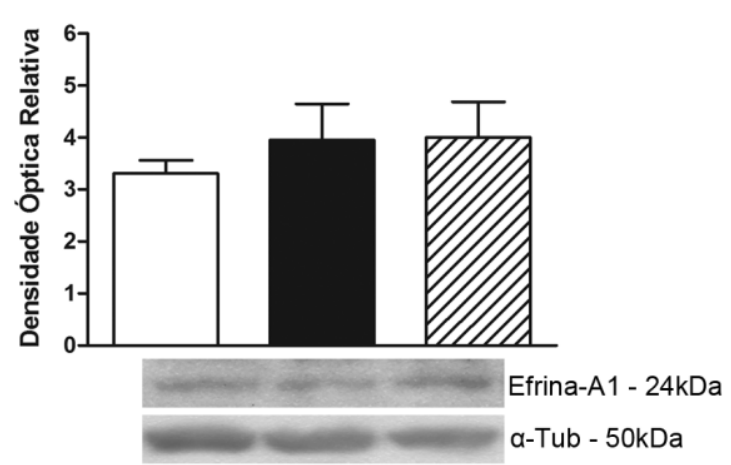

B

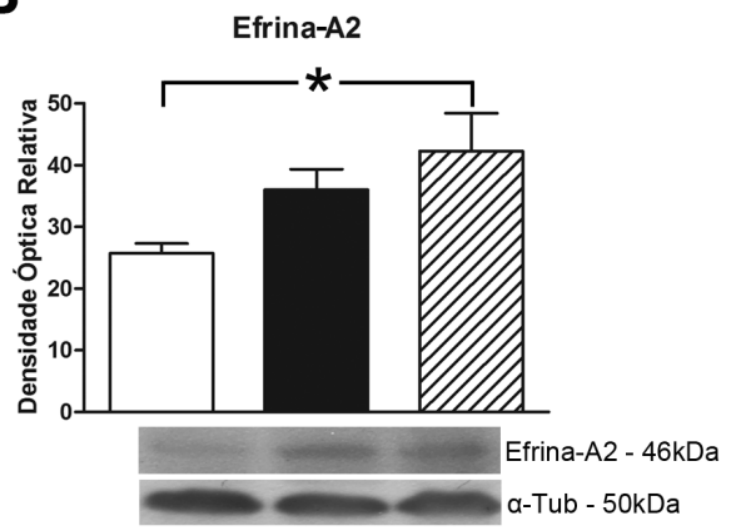

C

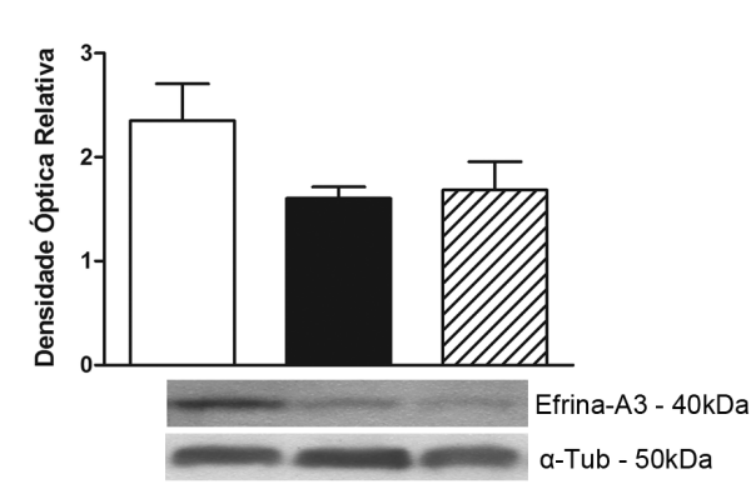

D

Efrina-A4

E

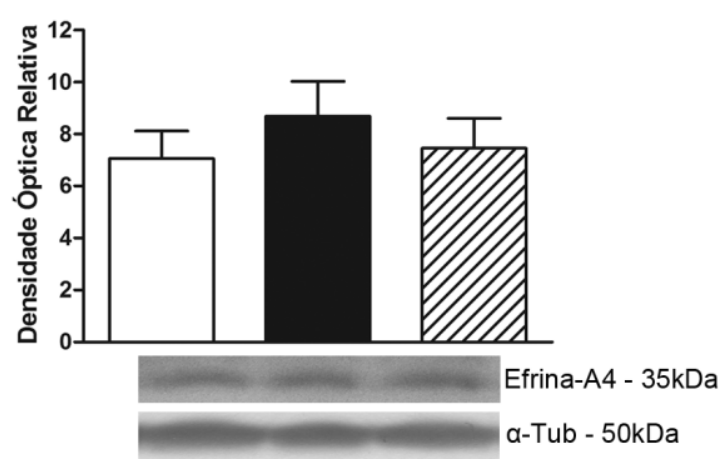

\section{Sham \\ Salina}

Z7 PEDF

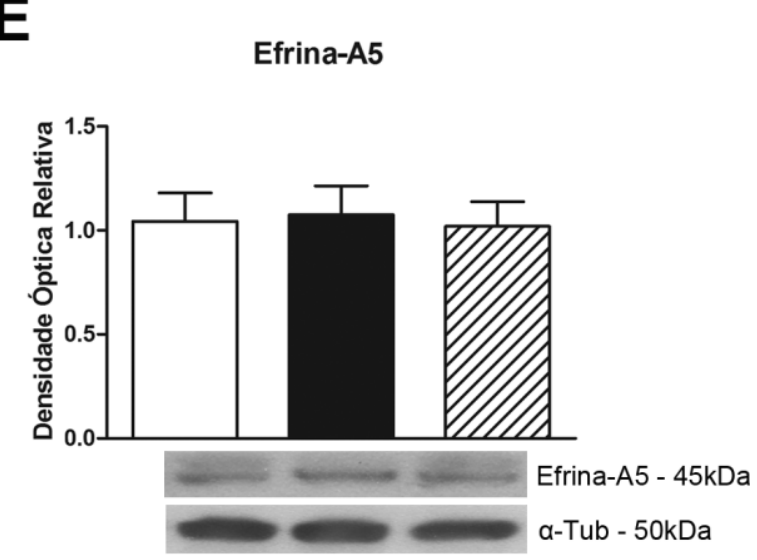

Figura 17: A figura mostra a densidade óptica relativa dos níveis de proteína das efrinas-A1 (A), de $24 \mathrm{kDa}, \mathrm{A} 2(\mathrm{~B})$, de $46 \mathrm{kDa}, \mathrm{A} 3(\mathrm{C})$, de $40 \mathrm{kDa}, \mathrm{A} 4(\mathrm{D})$, de $35 \mathrm{kDa}$, e $\mathrm{A} 5(\mathrm{E})$, de $45 \mathrm{kDa}$, na região lombar anterior da medula espinal. $\alpha$-Tubulina $(50 \mathrm{kDa})$ foi utilizada como controle. Observam-se os grupos Sham, Salina e PEDF. A análise realizada segundo o teste de variância ANOVA de uma via, seguido do pós-teste de Tukey, mostra um aumento no nível da proteína efrina-A2 no grupo PEDF em relação ao grupo Sham $\left({ }^{*} p<0,05\right)$. 


\section{A}

Efrina-B1

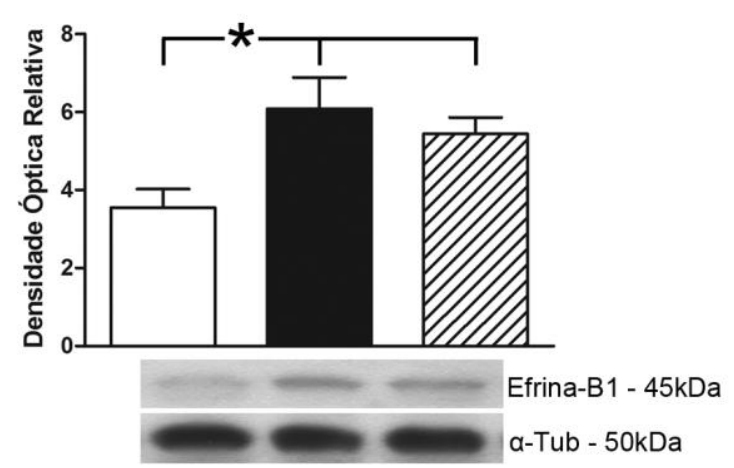

B

Efrina-B2

C

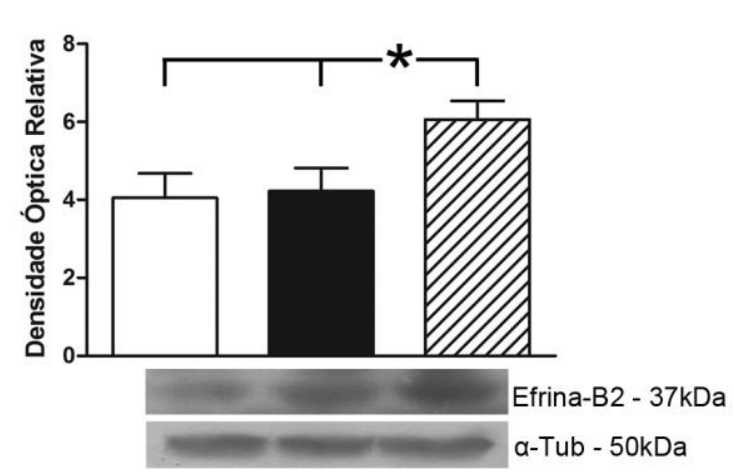

Figura 18: A figura mostra a densidade óptica relativa dos níveis de proteína das efrinas-B1 $(A)$, de $45 \mathrm{kDa}$, B2 (B), de $37 \mathrm{kDa}$, e B3 (C), de $43 \mathrm{kDa}$, na região lombar anterior da medula espinal. $\alpha$ Tubulina $(50 \mathrm{kDa})$ foi utilizada como controle. Observam-se os grupos Sham, Salina e PEDF. A análise realizada segundo o teste de variância ANOVA de uma via, seguido do pós-teste de Tukey, mostra um aumento no nível da proteína efrina-B1 nos grupos Salina e PEDF em relação ao Sham, um aumento no nível da efrina-B2 no grupo PEDF em relação aos grupos Sham e Salina e um aumento no nível da efrina-B3 no grupo PEDF em relação ao Sham ( $\left.{ }^{*} p<0,05\right)$. 
Ainda, a análise da expressão relativa de RNAm dos receptores EphA6 e EphB2, realizada pela técnica de RT-PCR na mesma região, não demonstrou nenhuma diferença na expressão gênica entre os grupos (figura 19). De forma similar, não foi observado nenhuma diferença entre os grupos experimentais na análise da expressão de RNAm da RhoA (figura 20).

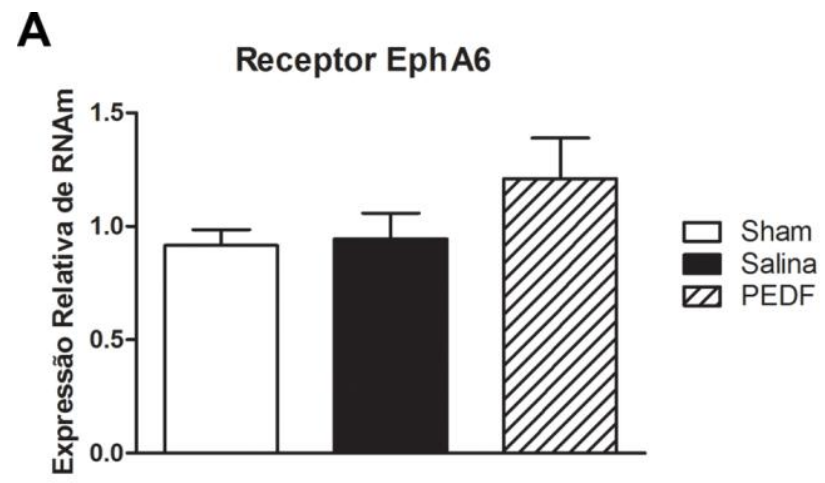

B

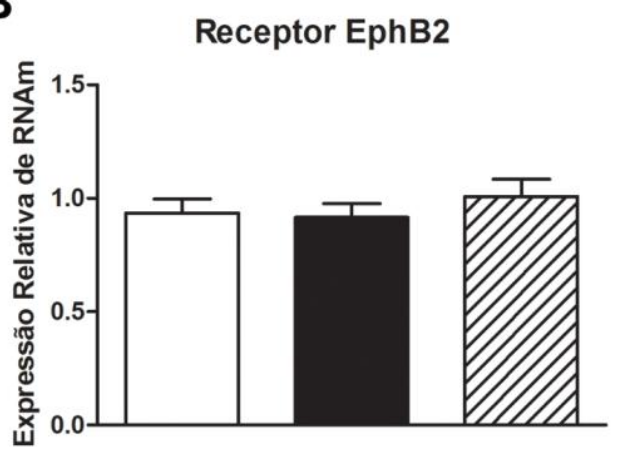

Figura 19: A figura mostra a expressão relativa de RNAm dos receptores EphA6 (A) e EphB2 (B) na porção ventral da medula espinal caudal à lesão. Observam-se os grupos Sham, Salina e PEDF. A análise foi realizada segundo o teste de variância ANOVA de uma via, seguido do pósteste de Tukey.

RhoA

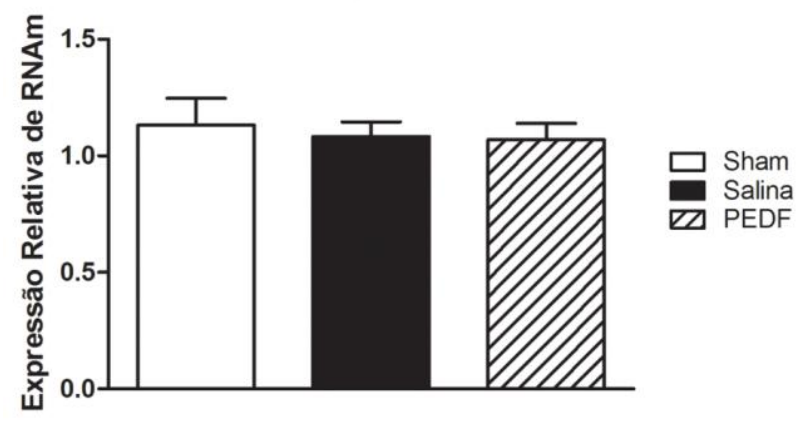

Figura 20: A figura mostra a expressão relativa de RNAm da RhoA na porção ventral da medula espinal caudal à lesão. Observam-se os grupos Sham, Salina e PEDF. A análise foi realizada segundo o teste de variância ANOVA de uma via, seguido do pós-teste de Tukey. 


\subsection{Análise da Localização Celular dos Receptores Eph/Efrinas}

A localização celular dos subtipos dos receptores Eph e das efrinas foi avaliada através da técnica de imunofluorescência de duas cores. Para isso, as imunorreatividades de receptores e efrinas foram marcadas simultaneamente com as imunorreatividades do GFAP (marcador astrocitário) ou NF-200 (marcador neuronal). No corno anterior da região lombar da medula espinal, receptores do tipo A, EphA2 e EphA7 (figura 21), do tipo B, EphB1, EphB4 e EphB6 (figura 22), bem como a efrina-A5 (figura 23), foram colocalizados com o NF-200, portanto em neurônios. As efrinas B1, B2 e B3 foram por sua vez colocalizadas com a imunorreatividade do GFAP, portanto em astrócitos da região avaliada (figura 24).

Receptores Eph e efrinas que não tiveram marcações específicas (sinal de marcação muito fraca ou ausente) no corno anterior foram analisados em outras áreas da mesma secção. A imunorreatividade do receptor EphA4, colocalizado com o NF-200, foi observada na raiz ventral do nervo (figura 25). No funículo posterior da região lombar, foram avaliados os receptores EphA3 e EphA5 (figura 26), duplamente marcados com NF-200, e as efrinas A1, A2, A3 e A4, duplamente marcadas com GFAP (figura 27).

Subtipos de receptores que não puderam ser avaliados pela técnica de western blot, pois o sinal era muito fraco ou inesistente, foram marcados pela imunofluorecência no segmento onde foi realizada a lesão. A imunorreatividade dos receptores EphA1 e EphA8, duplamente marcados com NF-200, foi observada no corno anterior da medula espinal (figura 28), onde o tecido medular encontrava-se preservado. $\mathrm{Na}$ área da lesão propriamente dita (funículo 
posterior), os receptores do tipo A, EphA6 e EphA10 (figura 29), e do tipo B, EphB2 e EphB3 (figura 30), foram duplamente marcados com GFAP.
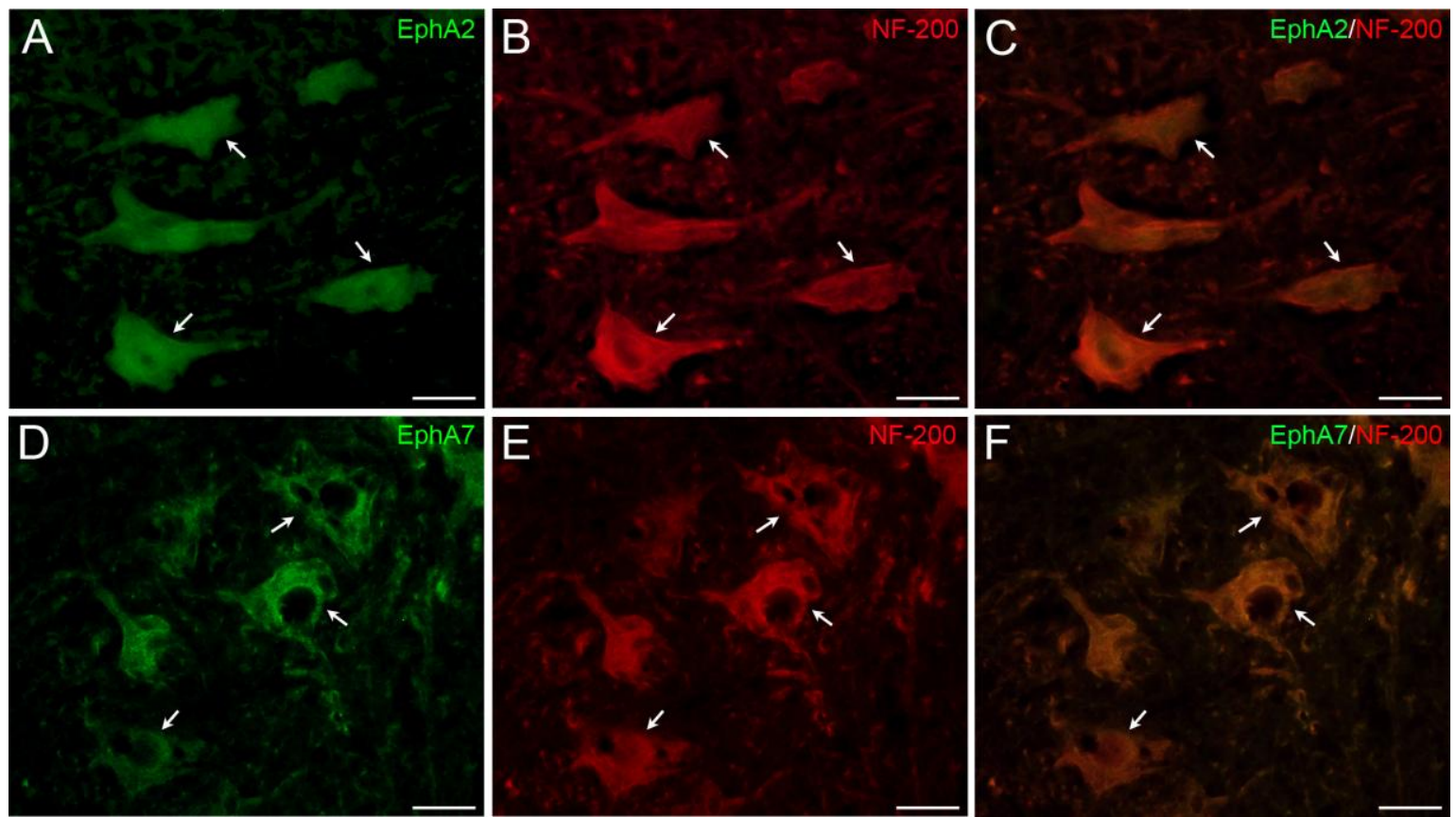

Figura 21: Fotomicrografias mostrando a localização celular dos receptores do tipo $\mathrm{A}$ estudados no corno anterior da medula espinal na região lombar do grupo PEDF. (A-C) Imunofluorescência de duas cores do receptor EphA2 (verde) com NF-200 (vermelho) e a colocalização das duas marcações. (D-F) Imunofluorescência de duas cores do receptor EphA7 (verde) com NF-200 (vermelho) e a colocalização das duas marcações. As setas indicam as colocalizações. Barras de escala $=30 \mu \mathrm{m}$. 

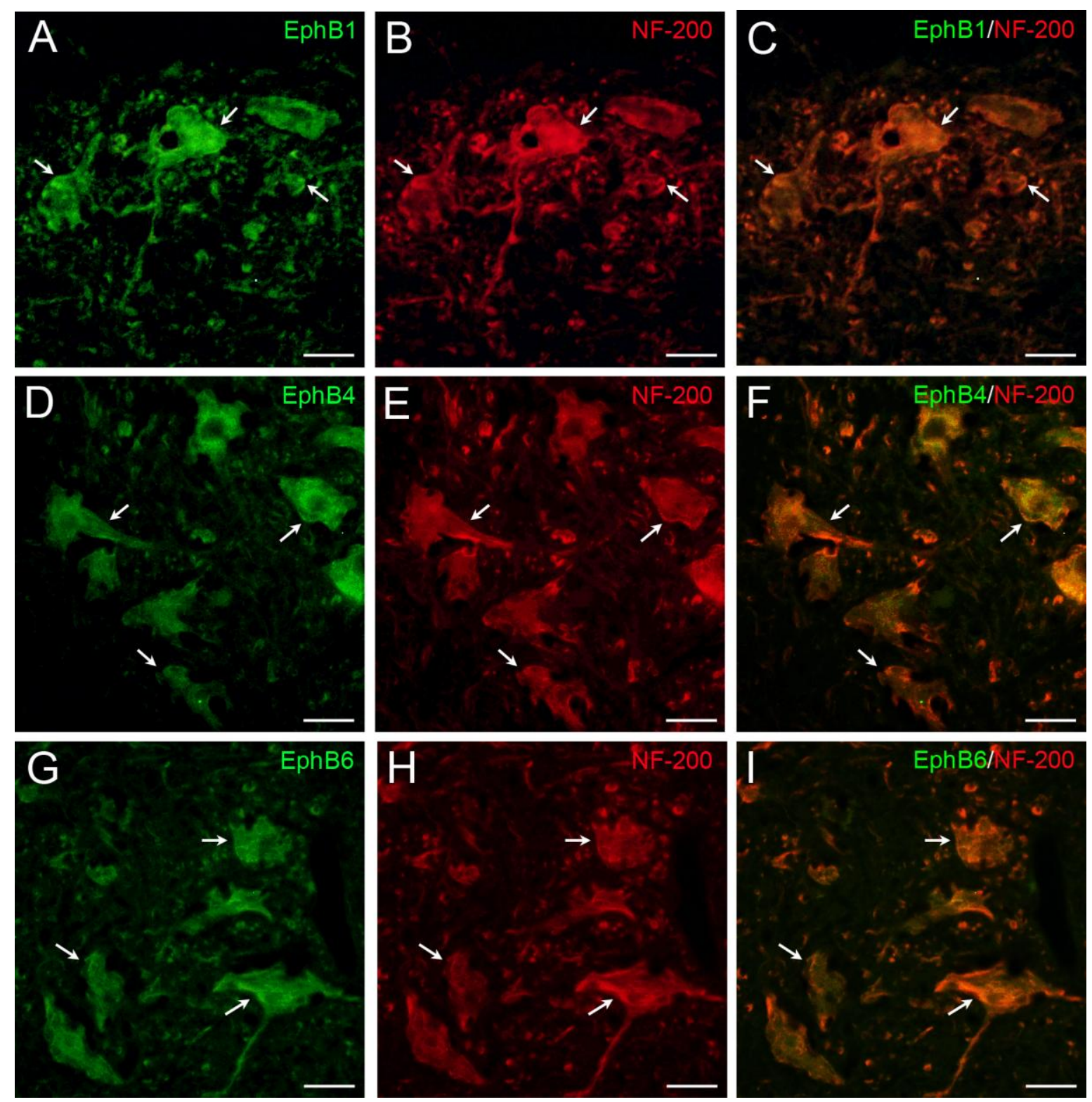

Figura 22: Fotomicrografias mostrando a localização celular dos receptores do tipo B estudados no corno anterior da medula espinal na região lombar do grupo PEDF. (A-C) Imunofluorescência de duas cores do receptor EphB1 (verde) com NF-200 (vermelho) e a colocalização das duas marcações. (D-F) Imunofluorescência de duas cores do receptor EphB4 (verde) com NF-200 (vermelho) e a colocalização das duas marcações. (G-I) Imunofluorescência de duas cores do receptor B6 (verde) com NF-200 (vermelho) e a colocalização das duas marcações. As setas indicam as colocalizações. Barras de escala $=30 \mu \mathrm{m}$. 

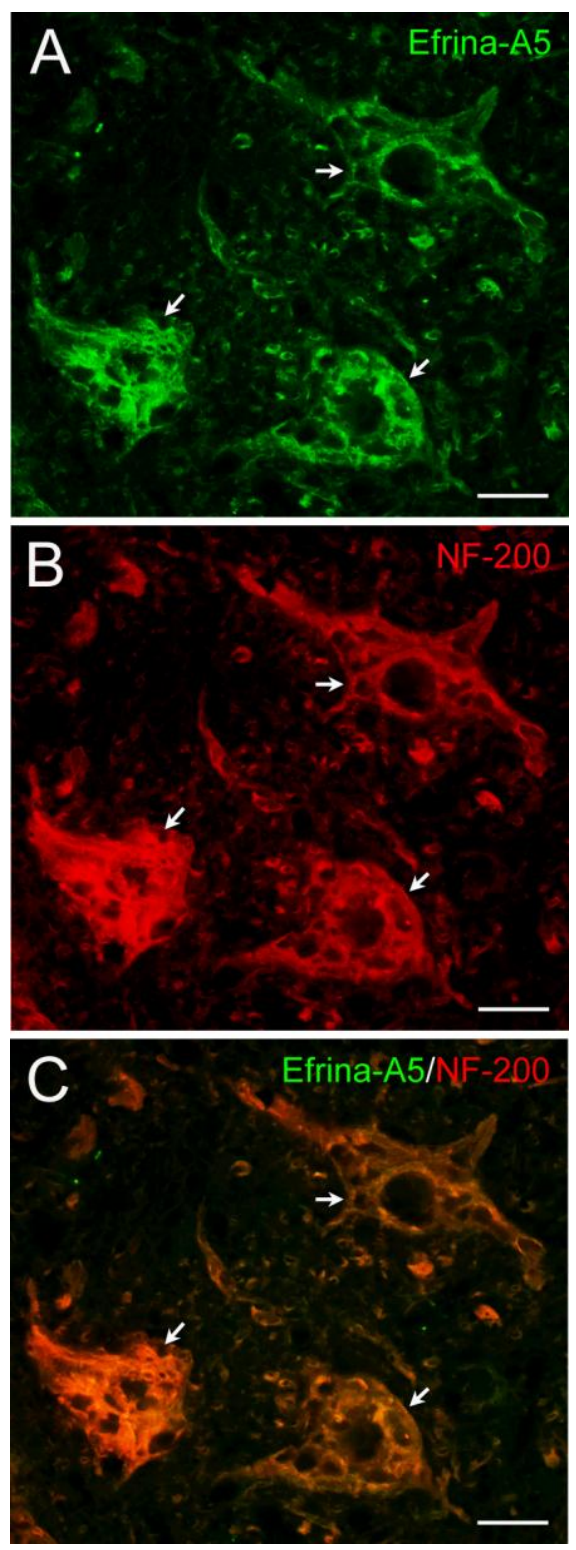

Figura 23: Fotomicrografias mostrando a localização celular da efrina-A5 estudada no corno anterior da medula espinal na região lombar do grupo PEDF. (A-C) Imunofluorescência de duas cores da efrina-A5 (verde) com NF-200 (vermelho) e a colocalização das duas marcações. As setas indicam as colocalizações. Barras de escala $=30 \mu \mathrm{m}$. 

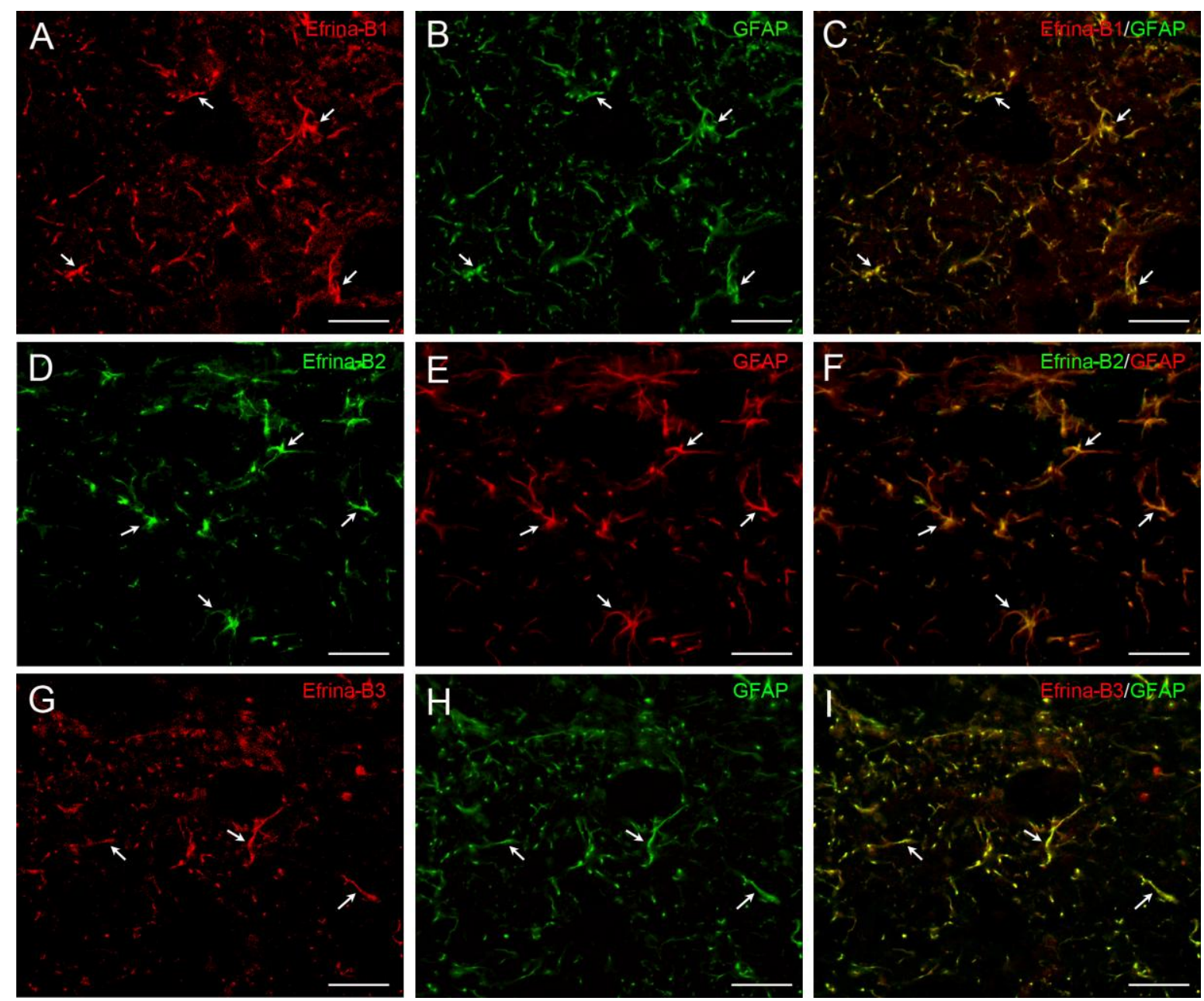

Figura 24: Fotomicrografias mostrando a localização celular das efrinas $B$ estudadas no corno anterior da medula espinal na região lombar do grupo PEDF. (A-C) Imunofluorescência de duas cores da efrina-B1 (vermelho) com GFAP (verde) e a colocalização das duas marcações. (D-F) Imunofluorescência de duas cores da efrina-B2 (verde) com GFAP (vermelho) e a colocalização das duas marcações. (G-I) Imunofluorescência de duas cores da efrina-B3 (vermelho) com GFAP (verde) e a colocalização das duas marcações. As setas indicam as colocalizações. Barras de escala $=30 \mu \mathrm{m}$. 

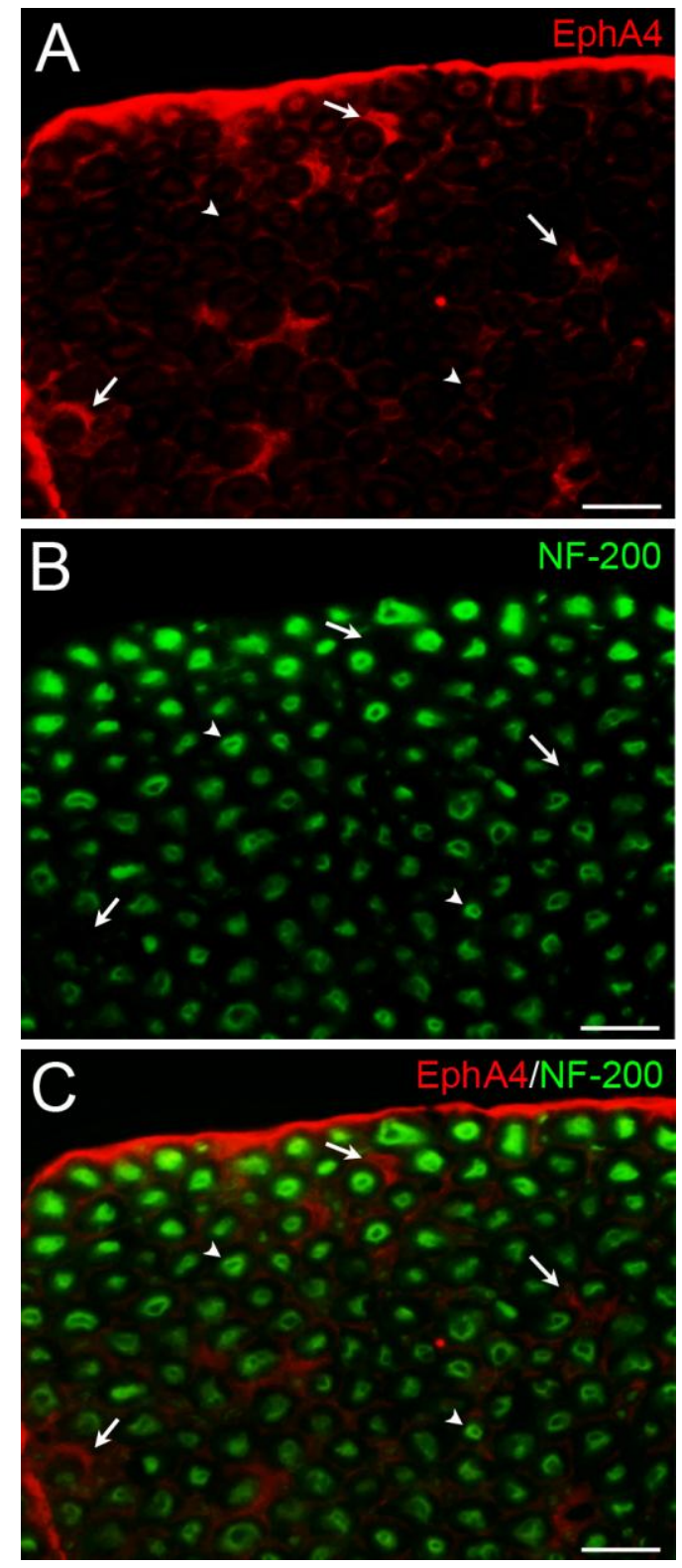

Figura 25: Fotomicrografias mostrando a localização celular do receptor EphA4 estudado na raiz ventral do nervo da medula espinal do grupo PEDF. (A-C) Imunofluorescência de duas cores do receptor EphA4 (vermelho) com NF-200 (verde) e a não colocalização das duas marcações. As setas indicam as marcações com o receptor EphA4 e as pontas de setas as marcações com NF200. Barras de escala $=20 \mu \mathrm{m}$. 

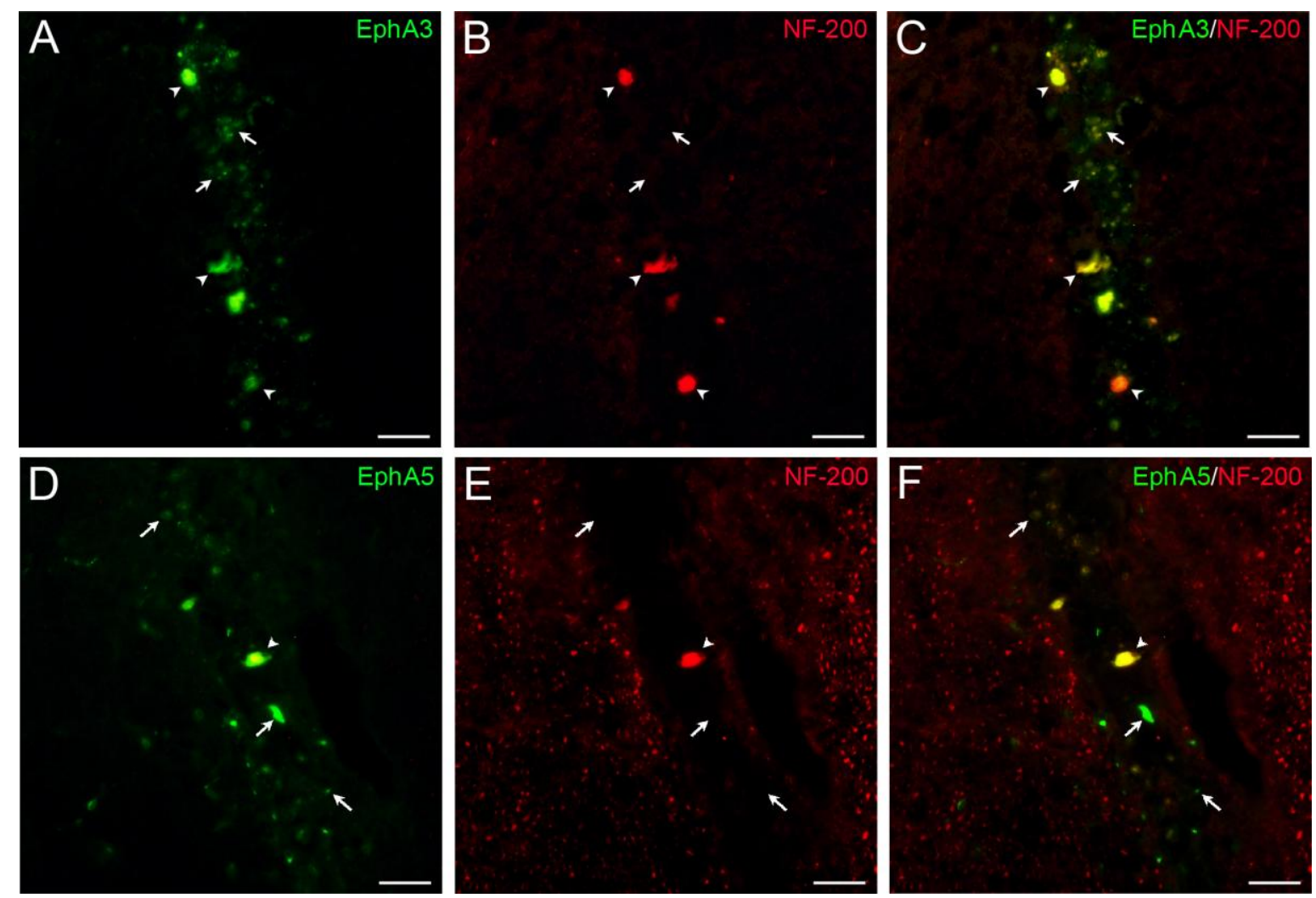

Figura 26: Fotomicrografias mostrando a localização celular dos receptores do tipo $\mathrm{A}$ estudados no funículo posterior da medula espinal na região lombar do grupo PEDF. (A-C) Imunofluorescência de duas cores do receptor EphA3 (verde) com NF-200 (vermelho) e a colocalização das duas marcações em algumas áreas. (D-F) Imunofluorescência de duas cores do receptor EphA5 (verde) com GFAP (vermelho) e a colocalização das duas marcações em algumas áreas. As setas indicam as marcações com os receptores e as pontas de setas indicam as colocalizações. Barras de escala=30 $\mu \mathrm{m}$. 


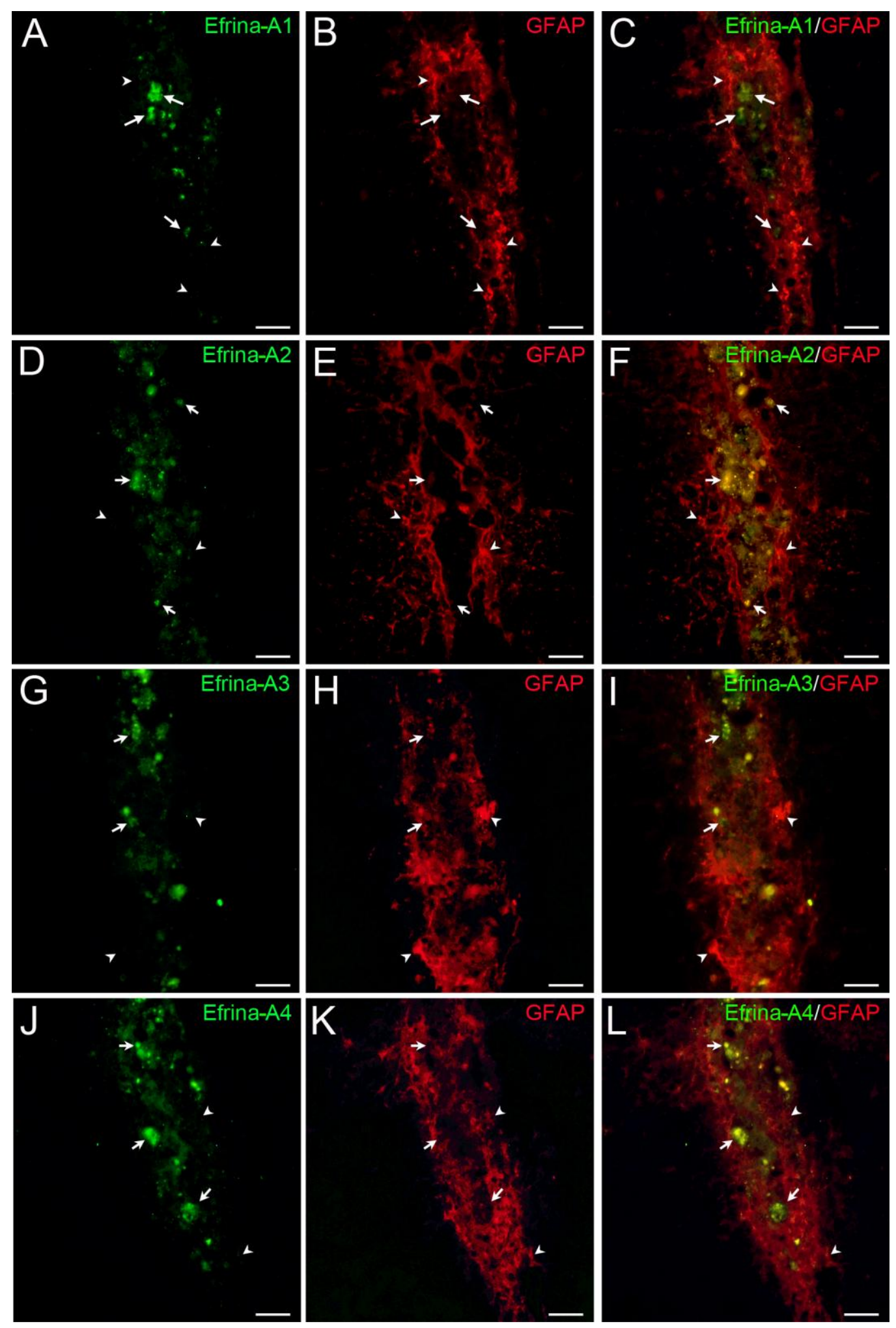

Figura 27: Fotomicrografias mostrando a localização celular das efrinas-A estudadas no funículo posterior da medula espinal na região lombar do grupo PEDF. (A-C) Imunofluorescência de duas cores da efrina-A1 (verde) com GFAP (vermelho) e a não colocalização das duas marcações. (DF) Imunofluorescência de duas cores da efrina-A3 (verde) com GFAP (vermelho) e a não colocalização das duas marcações. (G-I) Imunofluorescência de duas cores da efrina-A4 (verde) com GFAP (vermelho) e a não colocalização das duas marcações. As setas indicam as marcações com as efrinas e as pontas de setas as marcações com GFAP. Barras de escala $=30 \mu \mathrm{m}$. 

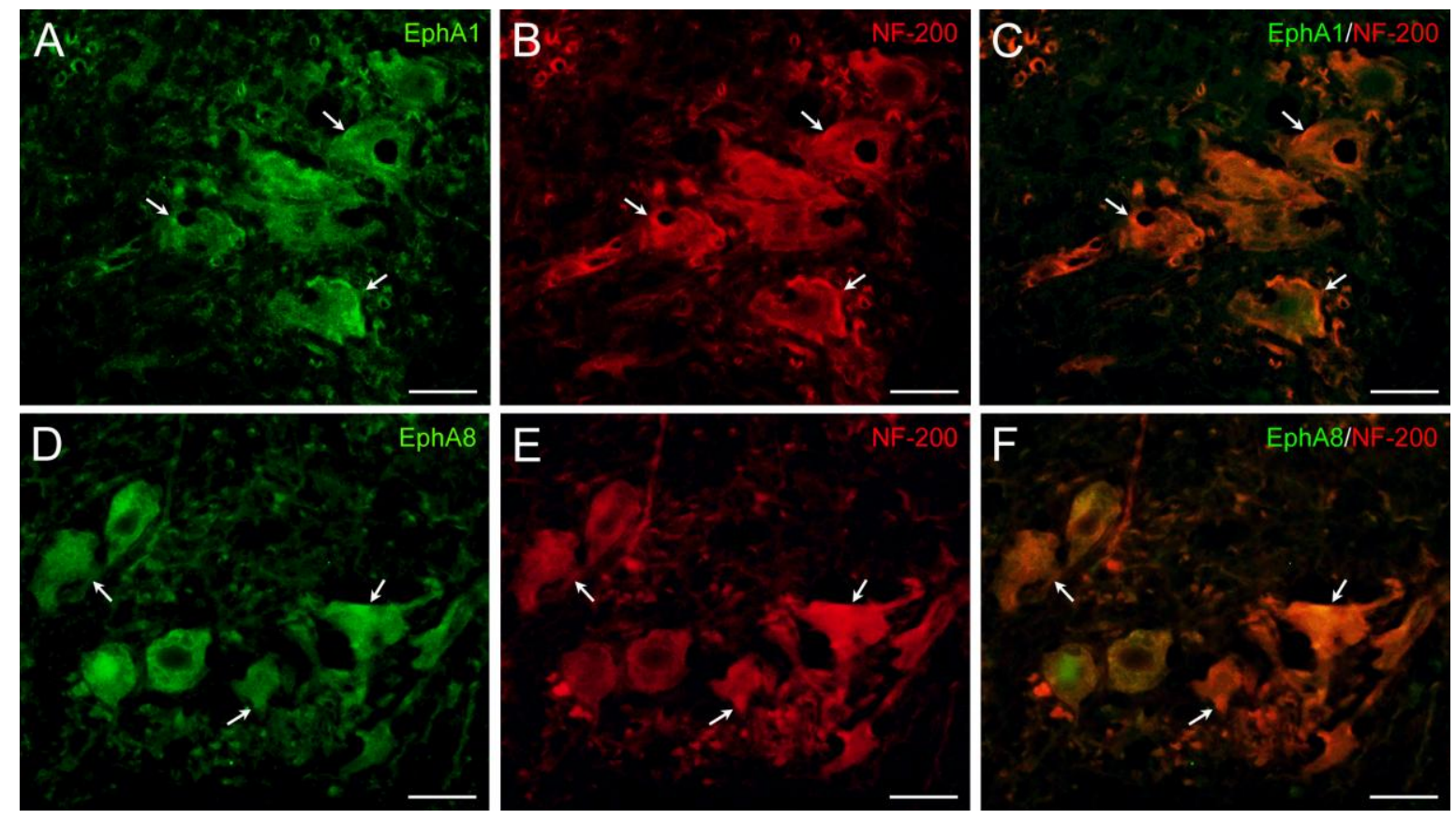

Figura 28: Fotomicrografias mostrando a localização celular dos receptores do tipo $\mathrm{A}$ estudados no corno anterior da medula espinal na região da lesão do grupo PEDF. (A-C) Imunofluorescência de duas cores do receptor EphA1 (verde) com NF-200 (vermelho) e a colocalização das duas marcações. (D-F) Imunofluorescência de duas cores do receptor EphA8 (verde) com NF-200 (vermelho) e a colocalização das duas marcações. As setas indicam as colocalizações. Barras de escala $=30 \mu \mathrm{m}$. 

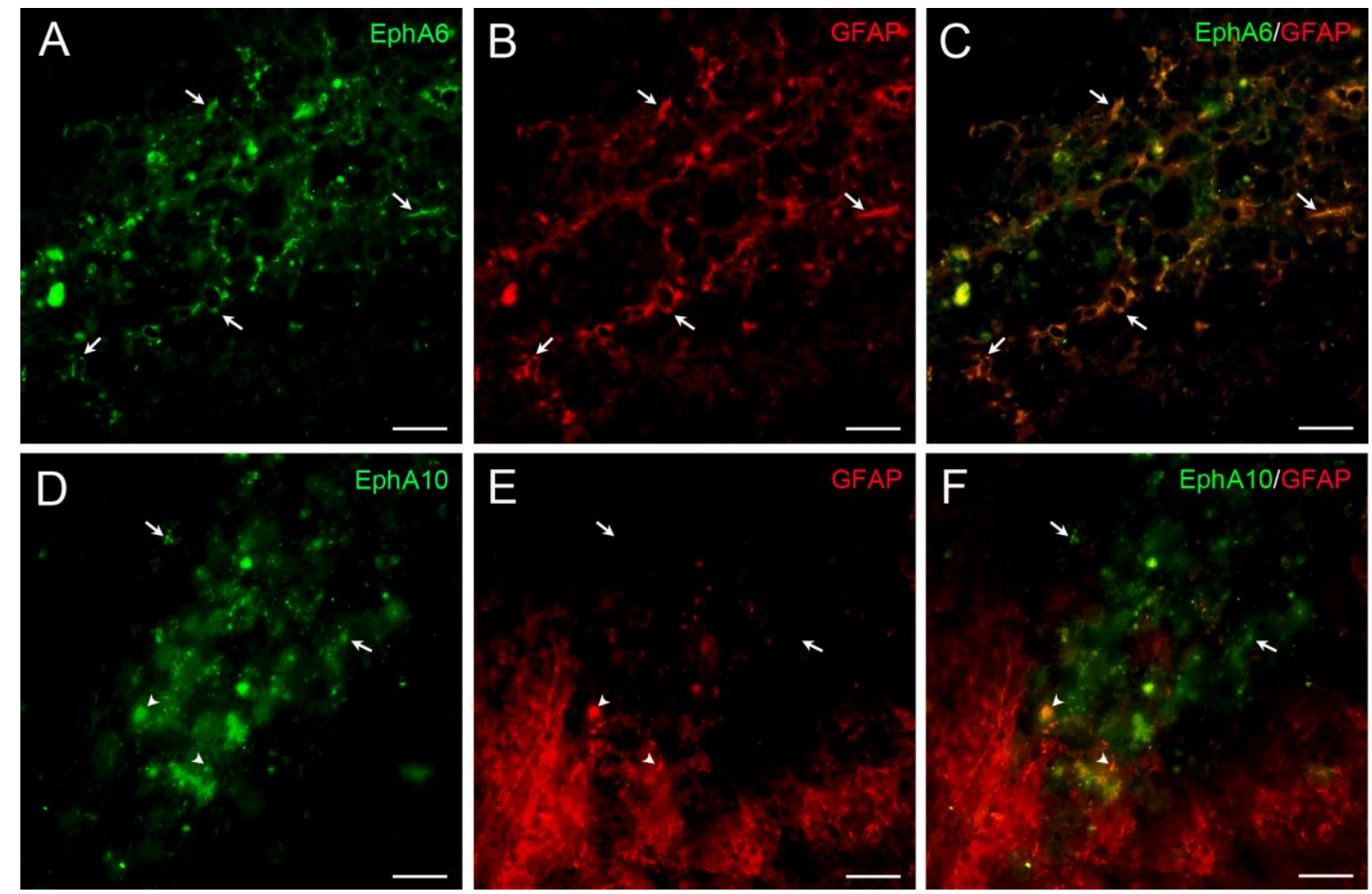

Figura 29: Fotomicrografias mostrando a localização celular dos receptores do tipo $A$ estudados na área da lesão em animais do grupo PEDF. (A-C) Imunofluorescência de duas cores do receptor EphA6 (verde) com GFAP (vermelho) e a colocalização das duas marcações. (D-F) Imunofluorescência de duas cores do receptor EphA10 (verde) com GFAP (vermelho) e a colocalização das duas marcações em algumas áreas. Em A-C as setas indicam as colocalizações, em D-F as setas indicam as marcações com o receptor EphA10 e as pontas de setas indicam as colocalizações. Barras de escala $=30 \mu \mathrm{m}$. 

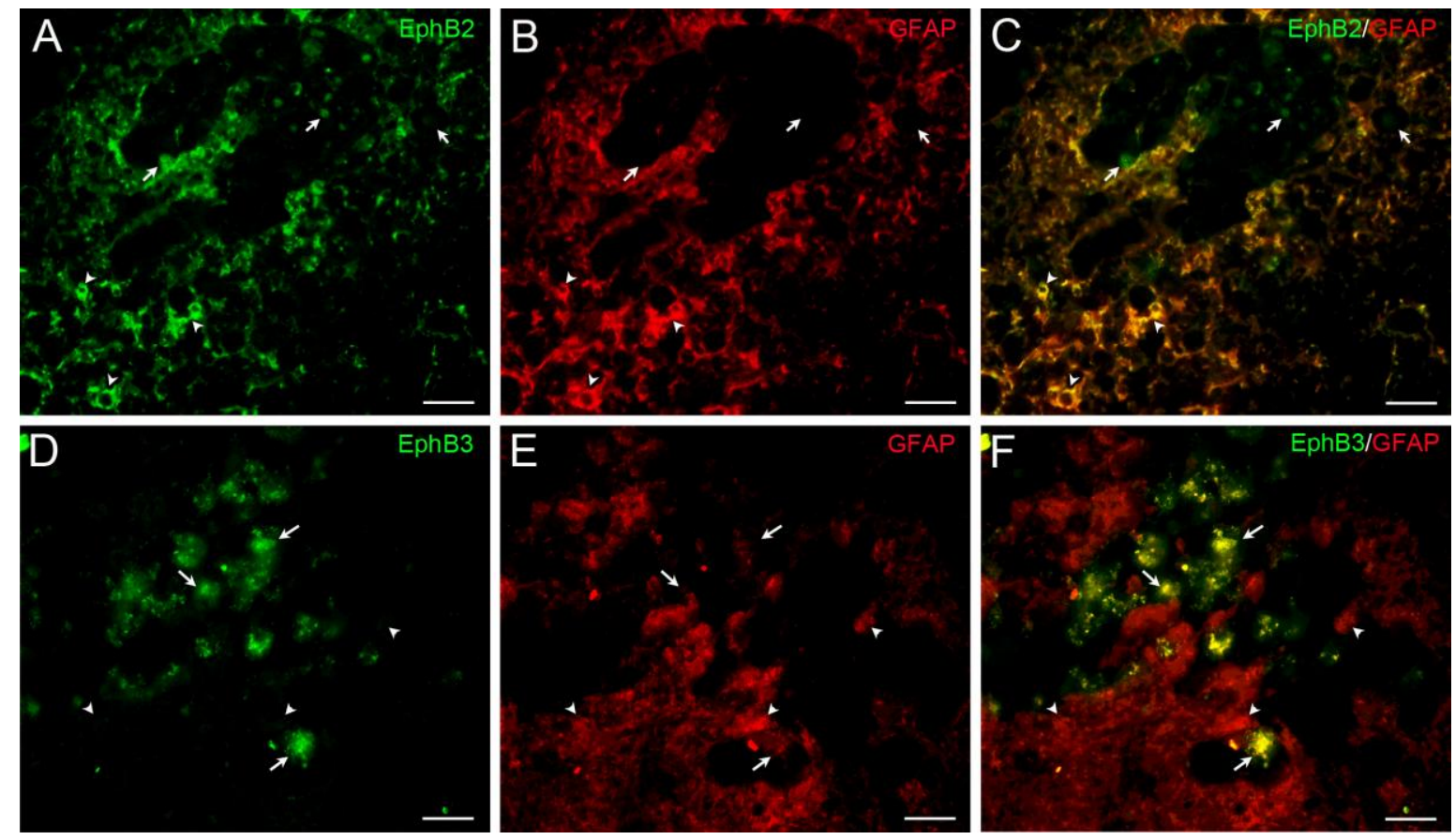

Figura 30: Fotomicrografias mostrando a localização celular dos receptores do tipo $B$ estudados na área da lesão em animais do grupo PEDF. (A-C) Imunofluorescência de duas cores do receptor EphB2 (verde) com GFAP (vermelho) e a colocalização das duas marcações em algumas áreas. (D-F) Imunofluorescência de duas cores do receptor EphB3 (verde) com GFAP (vermelho) e a não colocalização das duas marcações. Em A-C as setas indicam as marcações com o receptor EphB2 e as pontas de setas indicam as colocalizações, em D-F as setas indicam as marcações com os receptores e as pontas de setas as marcações com GFAP. Barras de escala=30 $\mu \mathrm{m}$. 
DISCUSSÃO 


\section{DISCUSSÃO}

\subsection{Lesão Medular Isquêmica}

A isquemia na medula espinal constitui um problema neurológico de importância clínica considerável e ocorre em diversas enfermidades: compressões vasculares, embolizações, aneurismas da aorta abdominal e suas cirurgias de correção, falência cardíaca, malformações arteriovenosas, bem como lesão secundária ao trauma (Cheshire et al., 1996; De la Barrera et al., 2001; Novy et al., 2006). Por conseguinte, a análise experimental da lesão medular isquêmica torna-se imperativa no intuito de estabelecer possíveis alvos terapêuticos nessa patologia.

modelo de lesão isquêmica fototrombótica induzida pelo Rose Bengal, empregado no presente trabalho para estabelecer a lesão medular nos animais, foi descrito inicialmente por Watson et al. (1986) e foi muito utilizado no estudo da isquemia cerebral. Essa metodologia produz lesões reprodutíveis em tamanho, localização e expressão comportamental, através do controle da intensidade, da concentração do corante, do tempo de exposição à luz e do local de irradiação (Ginsberg e Busto, 1989; Hunter et al., 1995; Traystman, 2003).

A realização de experimentos iniciais foi importante na adequação dessa metodologia para promover a lesão medular isquêmica. A concentração do corante foi definida conforme a profundidade de lesão desejada e o tempo de 20 minutos de exposição à irradiação de luz foi utilizado levando em conta a não recuperação do fluxo sanguíneo após esse período, como descrito por Hao e 
colaboradores (Hao et al., 1994), bem como a recuperação comportamental de ratos após períodos curtos de exposição (Prado et al., 1987).

Como este estudo propôs a avaliação das respostas neuroplásticas do tecido medular preservado, em uma área adjacente e caudal à lesão, essa metodologia apresentou mais vantagens na indução das lesões em relação ao modelo tradicional de pinçamento transitório da aorta descendente, pois permite lesões bem delimitadas.

\subsection{Resposta Comportamental}

Após a cirurgia, os déficits referentes à motricidade e a sensibilidade foram avaliados através dos testes BBB e CBS. Estes testes foram desenvolvidos para a análise comportamental de ratos submetidos à lesão medular (Gale et al., 1985; Basso et al., 1995) e dependem da observação do examinador sobre os padrões voluntários motores ou respostas reflexas obtidas após estimulação.

Um efeito temporal foi observado na análise da resposta comportamental dos animais isquemiados, segundo o BBB e o CBS, indicando uma recuperação sensório-motora parcial desses animais. Ainda, o tratamento com PEDF no epicentro da lesão foi capaz de potencializar esse efeito ao longo do tempo, auxiliando na progressão funcional dos animais tratados. Diferenças pontuais ao longo do período analisado não foram observadas entre os grupos de animais lesados, tanto no BBB quanto no CBS, indicando que, em relação a estes testes, o efeito do PEDF foi sutil.

Ao analisar individualmente os testes que compõem o índice CBS, uma melhora no reflexo de extensão dos dedos foi observada nos animais tratados 
com PEDF em relação aos do grupo Salina. A atividade reflexa pode ser um marcador da funcionalidade neuronal e possui um curso temporal com a atividade locomotora após lesão da medula espinal (Dietz et al., 2009; Hubli et al., 2011). Os animais do grupo PEDF também apresentaram uma melhora no plano inclinado quando comparados aos do grupo Salina. Este teste avalia força e resistência muscular, parâmetros necessários para manter o animal em posição estática conforme o plano aumenta o seu ângulo de inclinação (Spangenberg et al, 2005; Bowden et al., 2011).

A qualidade da marcha foi avaliada nesse trabalho, através do teste impressão de pegadas. O registro das pegadas gera dados concernentes ao controle motor fino dos animais, sendo este importante para uma boa coordenação durante a deambulação (Klapdor et. al., 1997). Os resultados mostraram que a melhora no padrão da marcha dos animais submetidos à lesão medular isquêmica depende do tempo após a lesão, neste caso, sem sofrer influência do tratamento com o PEDF. O período analisado pode influenciar diretamente na resposta da impressão de pegadas, visto que o controle da motricidade fina após uma lesão ocorre em um estágio mais tardio, conforme a melhora do desempenho sensório-motor.

Segundo estudos realizados previamente em nosso laboratório (Zanon et al., em submissão), o tratamento com o PEDF na lesão medular isquêmica fototrombótica em ratos não promoveu proteção tecidual, no que concerne o tamanho da lesão. No entanto, os animais que receberam o tratamento apresentaram melhores índices de recuperação neurofuncional, como mostrado neste trabalho, indicando a possibilidade deste efeito ser devido às respostas 
neuroplásticas, induzidas pelo PEDF, na substância cinzenta caudal à lesão. Desta forma, o presente estudo propôs a avaliação dos mecanismos de neuroplasticidade na porção ventral (motora) da região lombar da medula espinal.

\subsection{Restrição do Crescimento de Fibras}

Sabe-se hoje que o SNC possui capacidade regenerativa, a qual se encontra fortemente inibida pelo seu microambiente. A restrição do crescimento axonal não ocorre unicamente pela barreira física proporcionada pela formação da cicatriz glial, mas também pelo bloqueio químico oferecido pela expressão de diversas moléculas inibitórias, como por exemplo, as CSPGs (Cafferty et al., 2007, 2010). As CSPGs fazem parte de uma família de moléculas inibidoras da matriz extracelular e são expressas durante o desenvolvimento, período que estão envolvidas em processos de orientação axonal. No SNC maduro, as CSPGs estão presentes em níveis mais baixos, porém encontram-se concentradas em redes perineuronais, onde desempenham um papel importante para manter conexões estáveis. Sua expressão aumentada pode ter um efeito adverso após insulto do SNC, inibindo o crescimento axonal e restringindo a capacidade de regeneração. Tal regulação a princípio poderia ser funcionalmente benéfica por inibir o crescimento exagerado de fibras e evitar conexões inapropriadas, entretanto, impede o restabelecimento funcional pleno (Bartus, et al., 2011; Siebert e Osterhout, 2011).

Ao analisar a região lombar anterior da medula espinal várias semanas após a injuria, observamos uma diminuição do nível protéico das CSPGs nos animais que foram submetidos à lesão fototrombótica, quando comparados com o 
grupo Sham. A diminuição das CSPGs nessa região poderia facilitar o fenômeno de neuroplasticidade espontânea local, dando subsídios para uma melhora da recuperação funcional. De fato, apesar dos índices BBB e CBS mostrarem a evolução da recuperação comportamental muito semelhante entre os grupos Salina e PEDF, avaliações como a extensão dos dedos e o plano inclinado apontaram índices melhores para o grupo PEDF nas ultimas semanas de análise.

\subsection{Trofismo Neuronal}

A maior parte dos trabalhos atuais têm se concentrado no desenvolvimento e aplicação de estratégias visando à amplificação do potencial regenerativo dos neurônios lesados.

A escolha do tratamento com o PEDF foi em razão de suas ações diretas e indiretas na medula espinal. Dentre suas funções, destaca-se o seu potencial trófico sobre os neurônios medulares (Bilak et al., 1999a), bem como a sua capacidade de modificar o microambiente da lesão (Dawson et al., 1999), tornando-o um forte canditado para promover a neurorestauração da medula espinal.

Yabe et al. (2004) descreve que o PEDF também é capaz de modular a expressão de outros fatores neurotróficos. Essa reexpressão poderia ser benéfica após lesão da medula espinal, visto que os fatores neurotróficos permitem sobrevivência, diferenciação, manutenção e, quando possível, a regeneração axonal do SNC e periférico (Richardson et al., 1980; Halegoua et al., 1991; Cheng et al., 1996; Terenghi,1999). 
Inicialmente, os fatores neurotróficos eram considerados substâncias que regulavam o crescimento e a diferenciação neuronal durante o desenvolvimento embrionário, no entanto, sabe-se hoje que esses fatores também possuem uma função vital na plasticidade de neurônios adultos (Reichardt, 2006). Vários autores demonstraram experimentalmente que os fatores neurotróficos podem estimular o crescimento de fibras do trato córtico-espinal mesmo em estágios crônicos de lesão, além de propiciar graus variáveis de recuperação funcional (Liu et al., 2002; Lu et al., 2002; Tuszynski et al., 2003).

Os fatores neurotróficos são produzidos pelas células-alvo do neurônio, além de células de Schwann, fibroblastos e macrófagos, e cada fator parece sustentar uma determinada classe de neurônios (Scully e Otten, 1995). Eles agem através de receptores específicos e após sua ligação o complexo é internalizado por meio de endocitose e transportado retrogradamente até o corpo celular. Uma vez no soma, o DNA é ativado, promovendo o aumento de organelas citoplasmáticas, o que favorece o crescimento de dendritos e axônio (Bradshaw et al., 1990). Os fatores neurotróficos podem ser sintetizados tanto por neurônios como por células efetuadoras periféricas, podendo agir de forma parácrina e autócrina (Blottner e Baumgarten, 1994; Acheson e Lindsay, 1996; Mendell, 1996).

Diversos são os fatores neurotróficos que atuam na medula espinal, entre eles, objetivamos estudar na região lombar anterior, através da técnica de RTPCR, os fatores NT-3, GDNF, BDNF e FGF-2.

A NT-3 é bem conhecida pelo seu papel na sobrevivência neuronal, diferenciação e regeneração das fibras córtico-espinais (Grill et al., 1997; 
Tuszynski et al., 2003; Wang et al., 2011; Zhang et al., 2011). Nossos resultados mostraram uma diminuição do RNAm da NT-3 nos animais do grupo PEDF, quando comparados aos do grupo Sham. Essa diminuição poderia ser explicada por já ter ocorrido a sinalização para a produção da proteína em estágios anteriores ao período analisado. Em estágios mais tardios, como o período de seis semanas de pós-operatório escolhido no desenho experimental deste estudo, a regulação negativa poderia ocorrer para que as respostas neuroplásticas não sejam exageradas a ponto de promover o aparecimento de comportamento sensório-motor indesejado. A regulação negativa de fatores neurotróficos após lesões já foi descrito anteriormente (Gomez-Pinilla et al., 2004; Kasahara et al., 2006). De fato, a regulação negativa abriria espaço para a expressão de outros fatores neurotróficos com ações mais específicas no órgão lesado, com a função provável de levar a modulação fina da neuroplasticidade e a regulação da conectividade local, com vistas à recuperação neurofuncional. Este seria possívelmente o caso daqueles fatores neurotróficos com ações mais definidas no alvo, como é o caso do GDNF na medula espinal, fator com ações fortes aos neurônios motores desta região (Lin et al., 1993; Airaksinen e Saarma, 2002).

Em linha com o exposto acima, o tratamento com PEDF foi capaz de aumentar a expressão gênica do GDNF, observado pelo aumento desse fator neurotrófico no grupo tratado em relação aos grupos Sham e Salina pela técnica de RT-PCR. O GDNF age sobre a sobrevivência, maturação e manutenção de neurônios em desenvolvimento e lesados. Ele foi originalmente identificado por sua ação sobre os neurônios dopaminérgicos, sendo suas ações observadas posteriormente a outras populações neuronais, como é o caso dos neurônios da medula espinal (Oppenheim et al., 1995; Cheng et al., 2002). De acordo com o 
experimento realizado por lannotti et al. (2003), a co-administração de GDNF e células de Schwann após uma hemissecção da medula espinal em ratos promoveu um aumento na regeneração axonal e mielinização. Ainda, o GDNF reduziu a extensão da gliose reativa, a infiltração de macrófagos/microglia e a cavitação cística.

Corroborando com Yabe et al. (2004), nossos resultados mostraram que o tratamento com PEDF no epicentro da lesão medular foi capaz de modular a expressão do fator neurotrófico GDNF na porção anterior da região lombar, localização do CPG, favorecendo a resposta neuroplástica e a recuperação funcional parcial, como evidenciado pelos testes extensão dos dedos e plano inclinado.

Em relação à análise da expressão gênica do BDNF e do FGF-2, nenhuma diferença foi observada entre os grupos experimentais. O BDNF é capaz de reduzir a apoptose e promover a regeneração de neurôrios lesados, sendo útil na redução da lesão secundária (Kamei et al., 2007; Sasaki et al., 2009; Zong et al., 2011). Em contra partida, o FGF-2 possui propriedades gliogênicas e neurotróficas (Szebenyi e Fallon, 1999; Whittaker et al., 2011) e também está envolvido na proliferação de células progenitoras de oligodendrócito (Tripathi e McTigue, 2008). Em experimentos realizados em ratos, a regulação da expressão do FGF-2 ocorre em regiões próximas à área de lesão, entre a primeira e a quarta semana após lesão medular (Mocchetti et al.,1996; Tripathi e McTigue, 2008). Logo, a ausência de diferenças do BDNF e do FGF-2 entre os grupos pode estar relacionada ao período do estudo, fato já descrito acima no NT-3. 


\subsection{Angiogêse e Apoptose}

Sabendo que o modelo de lesão aqui estudado se baseia na isquemia tecidual e que o PEDF, utilizado como tratamento, possui um efeito antiangiogênico (Dawson et al., 1999), quantificamos a expressão da laminina, uma proteína relacionada ao endotélio vascular. Analisamos essa proteína na região lombar anterior, caudalmente à lesão, onde há uma grande quantidade de tecido preservado capaz de fornecer substratos para os eventos de neuroplasticidade que procuramos estudar. O aumento da laminina é um sinal de angiogênese local, e a diminuição de sua expressão nos ratos que receberam o tratamento com o PEDF, em relação ao grupo Salina, indica uma ação anti-angiogênica desse fator neurotrófico. Este efeito do PEDF sobre a medula lesada pode interferir indiretamente com as respostas neuroplásticas do órgão, visto sua capacidade de modificar a manutenção neuronal (DeCoster et al., 1999).

O PEDF também é descrito como um fator anti-apoptótico. A via mitocondrial da apoptose é controlada pela família das proteínas Bcl-2 (" $B$-cell lymphoma protein 2), que também controla a morte pela via extrínsica do receptor. $\mathrm{O} \mathrm{Bcl}-2$ é um proto-oncogene descoberto nos linfomas não Hodgkin humanos que produz a proteína Bcl-2 propriamente dita, cuja função biológica é a de suprimir a morte celular programada (apoptose) induzida por diversos estímulos (Hockenbery et al, 1990; Sentman et al., 1991; Jacobson et al., 1993). A eficácia do Bcl-2 é proporcional ao seu nível protéico, assim, decidimos analisar o nível dessa proteína na região lombar anterior da medula espinal. Nossos resultados não mostraram diferenças da proteína Bcl-2 entre os grupos 
experimentais, possivelmente por uma ausência de morte celular no local e/ou período avaliado.

\subsection{Neuroplasticidade da Medula Espinal}

Como observado, o SNC possui certa capacidade regenenerativa após lesão, que se traduz clinicamente através de uma melhora parcial e espontânea do comportamento sensório-motor. A melhora funcional desses animais é resultado de uma adaptação à nova condição física proporcionada pela lesão. Esta adaptação pode ser ocasionada pela capacidade de algumas estruturas preservadas do SNC desenvolverem funções que eram atribuídas às áreas lesadas, ou ainda, ao crescimento de fibras ou aumento da importância funcional das áreas preservadas. Isso caracteriza o fenômeno de neuroplasticidade presente no SNC, que pode ser tanto neuronal quanto glial (Smith et al., 1986; Aguayo et al., 1991; Shao e McCarthy, 1994).

Os efeitos da lesão fototrombótica e do tratamento com PEDF sobre a neuroplasticidade foram avaliados pelas proteínas estruturais MAP-2, GAP-43 e sinaptofisina. A seguir, faremos uma breve análise sobre cada uma delas.

A MAP-2 é uma proteína do microtúbulo que está associada à arborização dendrítica e a plasticidade sináptica (Sanchez et al., 1998). De acordo com os resultados dos experimentos pilotos realizados (Zanon et al., em submissão), a lesão isquêmica por si só leva a um aumento na expressão da MAP-2, tanto no epicentro quanto nas áreas adjacentes à lesão. Desta forma, era esperado encontrar um aumento no nível protéico da MAP-2 no corno anterior do grupo tratado com Salina em relação ao Sham, fato que não aconteceu, como visto pelo 
western blot. Isto porque nesse experimento os animais do grupo Sham também receberam a introdução da agulha na medula espinal, bem como um volume de $10 \mu l$ de solução salina, o que pode ter induzido a neuroplasticidade nesse grupo, mascarando a diferença entre o grupo Salina.

Por outro lado, o efeito da injeção intramedular do PEDF sobre os neurônios motores caudais à lesão parece ter sido grande o suficiente para aumentar a área da imunorreatividade da MAP-2, a ponto de observar uma diferença significativa no grupo tratado com PEDF em relação aos demais. Assim, o efeito de neuroplasticidade potencializada pelo PEDF, observado aqui pelo aumento da MAP-2 caudalmente ao sítio de lesão, pode estar relacionada ao aumento da arborização dendrítica e dos terminais pré-sinápticos, promovendo assim uma melhora no desempenho motor dos ratos tratados.

A proteína GAP-43 é um componente importante dos axônios e terminais pré-sinápticos e o aumento de sua expressão é visto durante o desenvolvimento neural e regeneração axonal (Benowitz e Routtenberg, 1997; Di Giovanni et al., 2005). A lesão isquêmica aqui aplicada lesou o funículo posterior da medula espinal, inclusive o tracto córtico-espinal dorsal, que nos ratos corresponde ao tracto córtico-espinal lateral, onde se encontra a maior parte das fibras motoras. Como a análise da GAP-43 foi realizada na porção ventral da medula espinal, em uma região abaixo da área de lesão, a ausência de diferenças entre os grupos experimentais pode estar relacionada com a escassez de crescimento de fibras córtico-espinais pré-sinápticas regeneradas para aquele local, visto que nesta região o tecido medular permaneceu íntegro. É possível ainda que a GAP-43 não 
tenha sido acumulada em quantidades suficientes nas fibras regeneradas neste período pós-cirúrgico de análise.

A sinaptofisina é a proteína integral de membrana mais abundante das vesículas sinápticas, sendo um marcador importante do crescimento de fibras e sinaptogênese durante o desenvolvimento da medula espinal e após lesão do tecido nervoso (Jahn et al., 1985; Navone et al., 1986; Chen et al., 1998). Um aumento em sua expressão gera o incremento de terminais sinápticos, apontando para um possível crescimento de axônios locais e maior efetividade da neurotransmissão sináptica (Krassioukov e Weaver, 1996).

Tais mudanças sinápticas não são confinadas somente ao local lesado, podendo ser estendidas aos segmentos vizinhos. Krassioukov e Weaver (1996) mostraram que após sete dias da hemisecção da medula espinal do rato, um aumento na expressão da sinaptofisina foi observado na substância cinzenta da região caudal à área de lesão. Li et al. (2004), por sua vez, mostrou que após uma lesão medular traumática em ratos, a imunorreatividade da sinaptofisina esteve diminuida na área de lesão, aumentada em segmentos craniais e sem alterações nos segmentos caudais à lesão. Segundo os estudos, a imunorreatividade da sinaptofisina em ambos os segmentos voltou a níveis basais nove dias após o trauma.

No presente trabalho, não foi observado diferenças no nível da sinaptofisina entre os animais com lesão fototrombótica, ou ainda quando comparados com o grupo Sham. A ausência de diferenças na porção ventral da medula espinal, em secções caudais à lesão, pode ter ocorrido devido ao período 
analisado, visto que as principais modificações ocorrem aproximadamente até o $10^{\circ}$ dia após a lesão (Krassioukov e Weaver, 1996; Li et al., 2004).

\subsection{Mecanismos de Neuroplasticidade}

Entre os mecanismos de neuroplasticidade do SNC, o sistema de sinalização bidirecional proporcionado pelos receptores Eph e seus ligantes, as efrinas, foi apontado recentemente como substancial na regulação desses processos. Os receptores Eph e as efrinas têm atividades distintas em células neuronais e não neuronais. Durante o desenvolvimento, possuem um papel importante no direcionamento axonal e, apesar de recentemente serem implicadas na sinaptogênese e na plasticidade neuronal, sua função não está totalmente clara no sistema nervoso adulto (Wilkinson, 2001; Klein, 2009; Zhao et al., 2010).

Em nosso estudo, a análise protéica dos subtipos dos receptores Eph e das efrinas na região lombar anterior da medula espinal, realizada pela técnica de western blot, mostrou que a lesão medular isquêmica foi capaz de modular o nível do receptor EphA4 e da efrina-B1. Ainda, o tratamento com PEDF possivelmente regulou o estado de ativação da efrina-A2 e da efrina-B3 e certamente modulou a regulação da efrina-B2.

A sinalização do receptor EphA4/efrina-B3 é referida como sendo importante na modulação neuroplástica dos circuitos espinais motores relacionados à locomoção durante o desenvolvimento (Kiehn e Butt, 2003; Beg et al., 2007). Essa sinalização bidirecional pode estar relacionada com a recuperação motora espontânea observada nos animais lesados e potencializada 
pelo tratamento com PEDF, visto que os animais isquemiados tiveram um aumento no nível do receptor EphA4 e o tratamento com PEDF aumentou o nível da efrina-B3 na região lombar anterior, onde se localiza o CPG.

Entre as moléculas do sistema Eph/efrina, o receptor EphA4 têm recebido atenção especial de diversos pesquisadores, sendo que outras funções também foram atribuídas a este receptor após lesão da medula espinal:

Quando a área da lesão foi analisada, vários autores demonstraram o aumento da expressão do receptor EphA4 em astrócitos reativos, indicando a participação desse receptor na formação da cicatriz e na possível inibição da regeneração axonal (Fabes et al., 2007; Afshari et al., 2010; Goldshmit e Bourne, 2010). Segundo experimentos de Goldshmit et al. (2004), camundongos knockout deficientes de EphA4 apresentaram uma melhora da regeneração axonal e diminuição da cicatriz glial após lesão medular. Desta forma, o tratamento com o antagonista do receptor EphA4 foi proposto como terapia para regeneração da medula espinal após lesão, resultando em uma ausência da degeneração retrógrada, aumento da regeneração axonal e melhora do comportamento motor dos animais tratados (Fabes et al., 2007; Goldshmit et al., 2011).

Entretanto, é importante salientar que esses animais knockout, ou com déficit de EphA4, apresentam vários déficit neurológios e anatômicos, o que deve ser levado em conta ao avaliar esses animais. Entre eles podemos citar o deslocamento caudal do pool motor que inerva o músculo tibial anterior (Coonan et al., 2003) e o movimento incomum da marcha devido a um defeito no CPG (Kullander et al., 2003; Niclou et al., 2006). 
As efrinas do tipo B também possuem um papel importante após lesão da medula espinal. Conforme Battaglia et al. (2003) e Song et al. (2008), o aumento na expressão das efrinas-B1 e B2, ligadas ao receptor EphB1, está relacionada com o incremento da dor neuropática, causada pela regulação da excitabilidade neuronal e neuroplasticidade a nível espinal. No presente estudo também observamos um aumento das efrinas-B1 e B2 na medula espinal após lesão isquêmica, entretanto o aumento do nível da efrina-B2 ocorreu apenas no grupo tratado com PEDF, indicando que este fator é capaz de interferir nos fenômenos de neuroplasticidade sem, no entanto, alterar o padrão de dor quando comparado com o grupo Salina, resultado este que pode ser observado através de um dos testes que compõem o CBS.

Distintas funções também são conferidas à efrina-B2 quando analisada em outras regiões da medula espinal. Na área da lesão, a efrina-B2 está expressa em astrócitos, enquanto o seu receptor EphB2 está expresso em fibroblastos. Essa sinalização bidirecional está envolvida nos processos de desenvolvimento e compartimentalização da cicatriz (Bundesen et al., 2003).

Além dos receptores Eph/efrinas citados até o momento, que apresentaram alterações neste estudo, outros subtipos de receptores também têm sido descritos após lesão da medula espinal. Os receptores EphA3 e EphB3 estão hiperegulados em astrócitos reativos no epicentro da lesão, podendo contribuir com a barreira química e bloquear o crescimento de neuritos (Willson et al., 2003; Irizarry-Ramírez et al., 2005). No SNC maduro, o receptor EphA7 está presente em neurônios de animais normais, podendo estabilizar as conexões sinápticas, 
entretanto, após uma lesão da medula espinal ele atua como um regulador da apoptose de oligodendrócitos em fases agudas (Figueroa et al., 2006).

Atentamos ao fato que diversos autores têm associado às moléculas do sistema Eph/efrina com a restrição do crescimento axonal após lesão da medula espinal, contudo, dependendo da circunstância, essa função poderia ser benéfica no processo de neuroplasticidade, ao evitar o crescimento de fibras para locais inadequados. Deste modo, propomos aqui que a regulação positiva da efrina-B2 nos animais com a medula espinal lesada e avaliada 6 semanas após a injeção local com o PEDF é um indicativo da sua participação como uma molécula reguladora das respostas neuroplásticas tardias no órgão, com benefícios à recuperação sensório-motora.

A RhoA também possui um papel importante no processo de neuroplasticidade do SNC, atuando como um regulador negativo do crescimento de neuritos mediante o colapso do cone de crescimento (Temporin et al., 2008; Gerin et al., 2011). O aumento em sua expressão ocorre na primeira semana após a lesão da medula espinal, persistindo por meses (Sung et al., 2003; Conrad et al., 2005; Erschbamer et al., 2005). No presente trabalho não foi observado diferenças na expressão gênica da RhoA entre os grupos experimentais. A ausência de diferenças no período de 6 semanas após a cirurgia pode ter ocorrido devido a região escolhida para análise, região lombar anterior da medula espinal, pois o aumento de sua expressão ocorre principalmente na área da lesão, onde os astrócitos reativos expressam altos níveis de RhoA, como demonstra Erschbamer et al. (2005). 


\subsection{Localização Celular do Sistema Eph/Efrina}

O estudo da localização celular dos receptores Eph e das efrinas foi realizado pelo método de imunofluorescência de duas cores. As imunorreatividades dos receptores e das efrinas foram duplamente marcadas com anticorpos específicos para marcação de componentes estruturais de astrócitos (GFAP) ou neurônios (NF-200).

A análise do corno anterior da região lombar da medula espinal mostrou que os receptores EphA2, EphA7, EphB1, EphB4 e EphB6, bem como a efrinaA5, estão colocalizados com os neurônios motores dessa região. Por outro lado, as efrinas do tipo B (B1, B2 e B3) estão intimamente ligadas à expressão dos astrócitos. O aumento da resposta astrocitária nessa região pode estar associado com um aumento na produção de fatores neurotróficos.

Receptores Eph e efrinas com baixa expressão no corno anterior da medula espinal foram avaliados em outras áreas da mesma secção. A localização celular do receptor EphA4, duplamente marcado com o NF-200, foi observada ao redor da raiz ventral do nervo, em animais do grupo PEDF. Esse resultado indica que a não observação desse receptor no corno anterior, bem como outros receptores/efrinas que não foram marcados, não ocorreu por uma falha técnica, mas sim pela diferença de expressão desse sistema em diferentes regiões e tecidos.

Ainda a nível lombar, alguns receptores Eph e efrinas do tipo A foram analisados no funículo posterior da medula espinal, onde uma pequena lesão causada pela neurodegeneração secundária do orgão foi observada. $\bigcirc$ resultado das duplas marcações mostrou que os receptores EphA3 e EphA5 estão 
localizados em diferentes tipos celulares, sendo que a colocalização com o NF200 nessa região pode indicar o crescimento de algumas fibras próximas à lesão. $\mathrm{Na}$ análise das efrinas $\mathrm{A} 1, \mathrm{~A} 2, \mathrm{~A} 3$ e $\mathrm{A} 4$, o resultado mostrou que estas efrinas não estão envolvidas com a resposta astrocitária local, podendo estar presentes em células da microglia ou relacionadas à inflamação.

Os receptores Eph que não puderam ser avaliados pela técnica de western blot foram estudados pela imunofluorescência em secções onde a lesão foi induzida. No corno anterior dessa região, onde o tecido medular encontrava-se preservado, observamos a colocalização dos receptores EphA6 e EphA10 com neurônios.

Os outros receptores foram estudados no funículo posterior da medula espinal, ou seja, na lesão propriamente dita. A colocalização do receptor EphA6 com os astrócitos da região pode indicar a participação desse receptor na formação da cicatriz glial e possivelmente na inibição da regeneração axonal local. Em relação ao receptor EphA10, observamos sua colocalização com astrócitos em algumas áreas, entretanto, esse receptor encontra-se localizado principalmente em outros tipos celulares. De forma similar, o receptor EphB2 também encontra-se colocalizado junto aos astrócitos, podendo participar da formação da cicatriz glial, porém também está presente em outras células. Por fim, nossos resultados mostraram que o receptor EphB3 não está colocalizado com os astrócitos, mas possivelmente em células da microglia ou inflamatória.

Como observado, os receptores Eph e as efrinas encontram-se localizados em diferentes tipos celulares, indicando sua participação na interação neurônioastrócito/microglia. Essa interação é importante no desenvolvimento e 
plasticidade de conexões sinápticas e, consequentemente em processos de plasticidade neuronal e aprendizagem (Aldskogius e Kozlova, 1998).

Os resultados encontrados nesta pesquisa confirmam a capacidade plástica da medula espinal pós-lesão. As alterações celulares encontradas são responsáveis pela recuperação neurofuncional espontânea parcial dos animais lesados; isto abre a possibilidade de se utilizar tratamentos, tais como a injeção intramedular do PEDF, para potencializar este processo. 
CONCLUSÕES 


\section{CONCLUSÕES}

I. A análise comportamental dos animais isquemiados demonstrou certo grau de recuperação nos parâmetros sensório-motores avaliados ao longo das seis semanas de avaliações, dentre eles, alguns obtiveram melhora pelo tratamento com o PEDF nas duas últimas semanas de análise.

II. A diminuição das CSPGs na região lombar anterior da medula espinal pode ter dado subsídios para que o refinamento do processo de neuroplasticidade espontânea ocorresse tardíamente nos animais que foram submetidos à lesão fototrombótica, visto que esta é uma das principais moléculas inibitórias ao crescimento de fibras.

III. A resposta neuroplástica na região lombar anterior da medula espinal pode ter sido favorecida pelo tratamento com o PEDF, uma vez que este fator foi capaz de promover a regulação da expressão de outros fatores neurotróficos, como o NT-3 e o GDNF.

IV. O aumento da laminina na região ventral da medula espinal, caudal à lesão, é um sinal de angiogênese local, o qual foi contido pelo tratamento com o PEDF. Esta ação do PEDF pode auxiliar na cicatrização das áreas adjacentes à lesão, na manutenção neuronal e, deste modo, interferindo indiretamente na resposta neuroplástica do orgão.

V. O tratamento com o PEDF no epicentro da lesão foi capaz de potencializar a neuroplasticidade na região lombar da medula espinal, como observado pelo aumento da MAP-2 nessa região. Essa habilidade do PEDF pode 
estar relacionada com a melhora da resposta comportamental desses animais observada mais tardiamente.

VI. O sistema receptor Eph/efrina modifica-se após a lesão da medula espinal e tratamento com o PEDF, em particular a efrina-B2, e pode participar das respostas tróficas/cicatriciais e neuroplásticas descritas neste trabalho.

VII. A localização dos receptores Eph e das efrinas em astrócitos e neurônios, como observado no presente estudo, apontam para esse sistema como sendo importante na interação neurônio-glia, auxiliando dessa forma na promoção de eventos relacionados à neurorestauração. 
ANEXOS 


\section{ANEXO A}

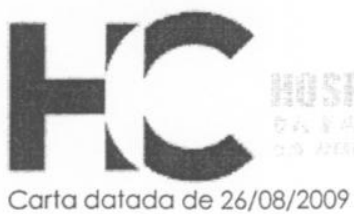

Ao

Departamento de Neurologia

A Comissão de Ética para Análise de Projetos de Pesquisa - CAPPesq da Diretoria Clínica do Hospital das Clínicas e da Faculdade de Medicina da Universidade de São Paulo, em sessão de 16/09/2009, tomou conhecimento que o Protocolo de Pesquisa $n^{\circ}$ 0542/08, intitulado: "EFEITO DA INJEÇÃO DO PEDF NO EPICENTRO DA LESÃO ISQUÊMICA FOTOTROMBÓTICA AGUDA NA EVOLUÇÃO DA RECUPERAÇÃO MOTORA, NA NEUROPROTEÇÃO E NA NEUROPLASTICIDADE DA PORÇÃO LOMBAR DA MEDULA ESPINAL DO RATO" contempla o sub-projeto intitulado: "ANÁLISE DOS MECANISMOS DE NEUROPLASTICIDADE NA PORÇÃO LOMBAR DA MEDULA ESPINHAL DO RATO SUBMETIDA À LESÃO ISQUÊMICA FOTOTROMBÓtICA AGUDA E TRATADA PELA INJEÇÃO LOCAL DE PEDF" qUe será DISSERTACCÃO DE MESTRADO da aluna CHARY ELY MARTIN MARQUEZ BATISTA, tendo como orientador O Prof. Dr. GERSON CHADI, bem como tomou ciência do Relatório de Andamento do estudo.

Pesquisador (a) Responsável: Prof. Dr. Gerson Chadi

CAPPesq, em 16 de setembro de 2009.

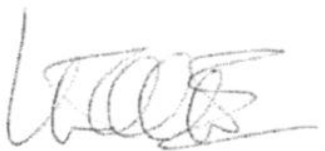

PROF. DR. CLAUDIO LEONE

Vice-Presidente da Comissão Ética para Análise de Projetos de Pesquisa

Comissão de Ética para Análise de Projetos de Pesquisa do HCFMUSP e da FMUSP Diretoria Clinica do Hospital das Clínicas da Faculdade de Medicina da Universidade de São Paulo Rua Ovídio Pires de Campos. 225, $5^{\circ}$ andar - CEP 05430010 - Săo Paulo - SP

Fone: 011 - 30696442 fax : 011 - 30696492 - e-mail : $\frac{\text { cappesq@hcnet.usp.br / secretariacappesq2@hcnet.usp.br }}{\text { hf }}$ 


\section{ANEXO B}

Dados referentes aos testes BBB e CBS dos grupos experimentais Sham, Salina e PEDF. Os valores estão apresentados como média aritmética \pm erro padrão da média.

\begin{tabular}{|c|c|c|c|c|c|c|}
\hline \multicolumn{7}{|c|}{ BBB } \\
\hline & \multicolumn{2}{|r|}{ Sham } & \multicolumn{2}{|r|}{ Salina } & \multicolumn{2}{|r|}{ PEDF } \\
\hline Dias & $n$ & Média \pm e.p.m. & $n$ & Média \pm e.p.m. & $n$ & Média \pm e.p.m. \\
\hline 1 & 14 & $16,785 \pm 1,038$ & 19 & $1,052 \pm 0,346$ & 22 & $1,590 \pm 0,549$ \\
\hline 2 & 13 & $15,000 \pm 1,414$ & 19 & $0,473 \pm 0,207$ & 20 & $2,000 \pm 0,624$ \\
\hline 3 & 11 & $15,000 \pm 1,407$ & 17 & $0,941 \pm 0,397$ & 20 & $1,450 \pm 0,499$ \\
\hline 7 & 14 & $16,571 \pm 1,212$ & 13 & $5,615 \pm 1,016$ & 20 & $7,500 \pm 1,201$ \\
\hline 14 & 13 & $19,076 \pm 0,909$ & 14 & $11,000 \pm 1,398$ & 20 & $11,900 \pm 1,104$ \\
\hline 21 & 12 & $19,250 \pm 1,066$ & 13 & $12,230 \pm 1,507$ & 16 & $13,500 \pm 1,143$ \\
\hline 28 & 12 & $20,500 \pm 0,261$ & 12 & $12,416 \pm 1,350$ & 16 & $13,562 \pm 0,856$ \\
\hline 35 & 12 & $20,166 \pm 0,297$ & 12 & $12,666 \pm 1,327$ & 16 & $13,500 \pm 0,841$ \\
\hline 42 & 14 & $19,428 \pm 0,700$ & 12 & $12,916 \pm 1,233$ & 15 & $13,400 \pm 0,855$ \\
\hline \multicolumn{7}{|c|}{ CBS } \\
\hline & \multicolumn{2}{|r|}{ Sham } & \multicolumn{2}{|r|}{ Salina } & \multicolumn{2}{|r|}{ PEDF } \\
\hline Dias & $n$ & Média \pm e.p.m. & $n$ & Média \pm e.p.m. & $n$ & Média \pm e.p.m. \\
\hline 1 & 14 & $12,302 \pm 2,268$ & 21 & $91,003 \pm 1,407$ & 20 & $85,277 \pm 2,557$ \\
\hline 2 & 11 & $26,768 \pm 5,495$ & 18 & $92,898 \pm 1,081$ & 19 & $86,256 \pm 3,434$ \\
\hline 3 & 11 & $30,303 \pm 8,217$ & 18 & $91,973 \pm 2,210$ & 19 & $89,764 \pm 3,325$ \\
\hline 7 & 12 & $14,815 \pm 2,927$ & 14 & $67,063 \pm 4,853$ & 19 & $57,016 \pm 5,095$ \\
\hline 14 & 13 & $12,821 \pm 2,546$ & 14 & $45,237 \pm 6,454$ & 20 & $35,833 \pm 5,293$ \\
\hline 21 & 11 & $8,082 \pm 2,292$ & 13 & $33,760 \pm 6,273$ & 16 & $28,125 \pm 5,519$ \\
\hline 28 & 12 & $3,705 \pm 1,579$ & 12 & $37,037 \pm 7,312$ & 16 & $25,347 \pm 4,478$ \\
\hline 35 & 12 & $3,705 \pm 1,248$ & 11 & $38,383 \pm 7,432$ & 16 & $29,862 \pm 5,291$ \\
\hline 42 & 12 & $5,094 \pm 1,597$ & 12 & $43,980 \pm 7,442$ & 16 & $31,112 \pm 5,389$ \\
\hline
\end{tabular}




\section{ANEXO C}

Dados referentes aos parâmetros que compõem o índice CBS dos grupos experimentais Sham, Salina e PEDF. Os valores estão apresentados como média aritmética \pm erro padrão da média.

\begin{tabular}{|c|c|c|c|c|c|c|}
\hline \multicolumn{7}{|c|}{ Testes que compões o índice CBS } \\
\hline & \multicolumn{2}{|c|}{ Sham } & \multicolumn{2}{|r|}{ Salina } & \multicolumn{2}{|r|}{ PEDF } \\
\hline Testes & $n$ & Média \pm e.p.m. & $n$ & Média \pm e.p.m. & $n$ & Média \pm e.p.m. \\
\hline Tarlov 1-3 dias & 14 & $3,678 \pm 0,236$ & 21 & $0,490 \pm 0,083$ & 22 & $0,772 \pm 0,159$ \\
\hline Tarlov 1-3 sem. & 14 & $4,000 \pm 0,216$ & 15 & $2,793 \pm 0,251$ & 20 & $2,950 \pm 0,234$ \\
\hline Tarlov 4-6 sem. & 13 & $4,407 \pm 0,216$ & 12 & $3,333 \pm 0,279$ & 17 & $3,411 \pm 0$ \\
\hline Extensão 1-3 dias & 14 & $2,478 \pm 0,152$ & 21 & $1,300 \pm 0,094$ & 22 & $1,800 \pm 0,090$ \\
\hline Extensão 1-3 sem. & 14 & $2,842 \pm 0,083$ & 15 & $1,440 \pm 0,250$ & 20 & $1,790 \pm 0,258$ \\
\hline Extensão 4-6 sem. & 13 & $2,900 \pm 0,099$ & 12 & $2,016 \pm 0,298$ & 17 & $2,294 \pm 0,318$ \\
\hline Dor 1-3 dias & 14 & $2,885 \pm 0,052$ & 21 & $2,057 \pm 0,113$ & 22 & $2,290 \pm 0,119$ \\
\hline Dor 1-3 sem. & 14 & $2,942 \pm 0,030$ & 15 & & 20 & \\
\hline Dor 4-6 sem. & 13 & $2,923 \pm 0,076$ & 12 & & 17 & $2,382 \pm 0,282$ \\
\hline Pressão 1-3 dias & 14 & $2,678 \pm 0,100$ & 21 & $1,742 \pm 0,107$ & 22 & $1,940 \pm 0,105$ \\
\hline Pressão 1-3 sem. & 14 & $2,957 \pm 0,0291$ & 15 & $2,326 \pm 0,179$ & 20 & $2,480 \pm 0,180$ \\
\hline Pressão 4-6 sem. & 13 & $2,923 \pm 0,0769$ & 12 & & 17 & \\
\hline & 14 & & 21 & & 22 & \\
\hline Ext. dos dedos 1-3 sem. & 14 & $1,835 \pm 0,084$ & 15 & $0,946 \pm 0,110$ & 20 & 1,25 \\
\hline Ext. dos dedos 4-6 sem. & 13 & $1,892 \pm 0,072$ & 12 & $1,300 \pm 0,157$ & 17 & $1,723 \pm 0,078$ \\
\hline Colocação 1-3 dias & 14 & $1,550 \pm 0,104$ & 21 & $0,0142 \pm 0,014$ & 22 & $0,045 \pm 0,034$ \\
\hline Colocação 1-3 sem. & 14 & $1,742 \pm 0,100$ & 15 & $0,766 \pm 0,090$ & 20 & $0,910 \pm 0,112$ \\
\hline Colocação 4-6 sem. & 13 & $1,923 \pm 0,056$ & 12 & $1,216 \pm 0,149$ & 17 & $1,376 \pm 0,109$ \\
\hline Endireitamento 1-3 dias & 14 & $1,335 \pm 0,080$ & 21 & $1,038 \pm 0,027$ & 22 & $1,054 \pm 0,025$ \\
\hline Endireitamento 1-3 sem. & 14 & $1,442 \pm 0,108$ & 15 & $1,000 \pm 0,000$ & 20 & $1,050 \pm 0,037$ \\
\hline Endireitamento 4-6 sem. & 13 & $1,900 \pm 0,078$ & 12 & $1,000 \pm 0,000$ & 17 & $1,094 \pm 0,047$ \\
\hline & 14 & $43,685 \pm 0,830$ & 21 & $34,819 \pm 0,569$ & 22 & $33,981 \pm 0,913$ \\
\hline Plano inclinado 1-3 sem. & 14 & $45,700 \pm 1,023$ & 15 & $41,620 \pm 1,410$ & 20 & $44,060 \pm 0,805$ \\
\hline Plano inclinado 4-6 sem. & 13 & $51,153 \pm 0,936$ & 12 & $44,383 \pm 0,951$ & 17 & $49,952 \pm 0,944$ \\
\hline
\end{tabular}




\section{ANEXO D}

Dados referentes ao teste Impressão de Pegadas dos grupos experimentais Sham, Salina e PEDF. Os valores estão apresentados como média aritmética \pm erro padrão da média.

\begin{tabular}{|c|c|c|c|c|c|c|}
\hline \multicolumn{7}{|c|}{ Impressão de Pegadas } \\
\hline \multicolumn{7}{|c|}{ Comprimento da passada } \\
\hline & \multicolumn{2}{|r|}{ Sham } & \multicolumn{2}{|r|}{ Salina } & \multicolumn{2}{|r|}{ PEDF } \\
\hline Semanas & $n$ & Média \pm e.p.m. & $n$ & Média \pm e.p.m. & $n$ & Média \pm e.p.m. \\
\hline 1 & 11 & $11,595 \pm 0,498$ & 13 & $2,486 \pm 0,959$ & 19 & $6,055 \pm 1,396$ \\
\hline 2 & 12 & $12,745 \pm 0,520$ & 14 & $6,821 \pm 1,533$ & 19 & $8,447 \pm 1,199$ \\
\hline 3 & 12 & $12,550 \pm 0,606$ & 12 & $9,106 \pm 1,572$ & 15 & $9,363 \pm 1,290$ \\
\hline 4 & 10 & $12,827 \pm 0,486$ & 12 & $8,843 \pm 1,591$ & 16 & $8,637 \pm 1,213$ \\
\hline 5 & 12 & $12,662 \pm 0,433$ & 12 & $9,741 \pm 1,457$ & 14 & $8,476 \pm 1,345$ \\
\hline 6 & 11 & $11,238 \pm 0,484$ & 11 & $9,115 \pm 1,333$ & 15 & $8,368 \pm 1,252$ \\
\hline \multicolumn{7}{|c|}{ Distância entre o calcanhar e o $3^{\circ}$ dedo } \\
\hline & \multicolumn{2}{|r|}{ Sham } & \multicolumn{2}{|c|}{ Salina } & \multicolumn{2}{|r|}{ PEDF } \\
\hline Semanas & $n$ & Média \pm e.p.m. & $n$ & Média \pm e.p.m. & $n$ & Média \pm e.p.m. \\
\hline 1 & 12 & $2,920 \pm 0,269$ & 14 & $0,667 \pm 0,318$ & 19 & $1,294 \pm 0,348$ \\
\hline 2 & 12 & $2,804 \pm 0,239$ & 14 & $1,485 \pm 0,387$ & 19 & $1,744 \pm 0,301$ \\
\hline 3 & 12 & $3,345 \pm 0,032$ & 12 & $2,166 \pm 0,373$ & 15 & $1,943 \pm 0,326$ \\
\hline 4 & 9 & $3,094 \pm 0,178$ & 11 & $1,940 \pm 0,491$ & 16 & $2,243 \pm 0,294$ \\
\hline 5 & 12 & $3,295 \pm 0,038$ & 12 & $2,033 \pm 0,411$ & 14 & $2,239 \pm 0,334$ \\
\hline 6 & 11 & $3,336 \pm 0,038$ & 10 & $2,560 \pm 0,358$ & 15 & $2,533 \pm 0,319$ \\
\hline \multicolumn{7}{|c|}{ Distância entre o $1^{\circ}$ e $\circ 5^{\circ}$ dedo } \\
\hline \multicolumn{7}{|c|}{ Sham $\quad$ Salina } \\
\hline Semanas & $n$ & Média \pm e.p.m. & $n$ & Média \pm e.p.m. & $n$ & Média \pm e.p.m. \\
\hline 1 & 12 & $1,300 \pm 0,290$ & 14 & $0,403 \pm 0,201$ & 19 & $0,828 \pm 0,211$ \\
\hline 2 & 12 & $2,220 \pm 0,037$ & 14 & $1,000 \pm 0,245$ & 19 & $0,965 \pm 0,205$ \\
\hline 3 & 12 & $2,212 \pm 0,045$ & 12 & $1,304 \pm 0,252$ & 15 & $1,156 \pm 0,259$ \\
\hline 4 & 10 & $2,350 \pm 0,038$ & 11 & $0,936 \pm 0,297$ & 16 & $1,231 \pm 0,235$ \\
\hline 5 & 12 & $2,312 \pm 0,063$ & 12 & $1,158 \pm 0,277$ & 14 & $1,050 \pm 0,251$ \\
\hline 6 & 11 & $2,400 \pm 0,039$ & 10 & $1,200 \pm 0,298$ & 15 & $1,183 \pm 0,235$ \\
\hline \multicolumn{7}{|c|}{ Distância entre o $2^{\circ}$ e $\circ 4^{\circ}$ dedo } \\
\hline & \multicolumn{2}{|r|}{ Sham } & \multicolumn{2}{|r|}{ Salina } & \multicolumn{2}{|r|}{ PEDF } \\
\hline Semanas & $n$ & Média \pm e.p.m. & $n$ & Média \pm e.p.m. & $n$ & Média \pm e.p.m. \\
\hline 1 & 12 & $0,879 \pm 0,104$ & 14 & $0,378 \pm 0,134$ & 19 & $0,536 \pm 0,122$ \\
\hline 2 & 12 & $1,076 \pm 0,044$ & 14 & $0,728 \pm 0,177$ & 19 & $0,700 \pm 0,096$ \\
\hline 3 & 12 & $1,179 \pm 0,027$ & 12 & $0,825 \pm 0,139$ & 15 & $0,843 \pm 0,116$ \\
\hline 4 & 10 & $1,175 \pm 0,031$ & 11 & $0,759 \pm 0,162$ & 16 & $0,778 \pm 0,118$ \\
\hline 5 & 12 & $1,212 \pm 0,024$ & 12 & $0,866 \pm 0,137$ & 14 & $0,839 \pm 0,124$ \\
\hline 6 & 11 & $1,227 \pm 0,021$ & 10 & $0,840 \pm 0,141$ & 15 & $0,726 \pm 0,125$ \\
\hline
\end{tabular}




\section{ANEXO E}

Dados referentes à área de marcação da imunorreatividade da MAP-2 e da GAP-43, por meio de Imunoperoxidase padrão. Os valores estão apresentados como média aritmética \pm erro padrão da média.

\begin{tabular}{|c|c|c|c|c|c|c|}
\hline \multicolumn{7}{|c|}{ Imunoperoxidase } \\
\hline & \multicolumn{2}{|r|}{ Sham } & \multicolumn{2}{|c|}{ Salina } & \multicolumn{2}{|r|}{ PEDF } \\
\hline Marcadores & $n$ & Média \pm e.p.m. & $n$ & Média \pm e.p.m. & $n$ & Média \pm e.p.m. \\
\hline MAP-2 & 7 & $1231 \pm 42,73$ & 7 & $1251 \pm 49,33$ & 8 & $1674 \pm 60,82$ \\
\hline GAP-43 & 7 & $1933 \pm 260,9$ & 7 & $1948 \pm 148,4$ & 8 & $2131 \pm 271,7$ \\
\hline
\end{tabular}




\section{ANEXO F}

Dados referentes à quantificação protéica dos marcadores estudados através do western blot. Os valores estão apresentados como média aritmética \pm erro padrão da média.

\begin{tabular}{|c|c|c|c|c|c|c|}
\hline \multicolumn{7}{|c|}{ Western Blotting } \\
\hline & \multicolumn{2}{|r|}{ Sham } & \multicolumn{2}{|r|}{ Salina } & \multicolumn{2}{|r|}{ PEDF } \\
\hline Marcadores & $n$ & Média \pm e.p.m. & $n$ & Média \pm e.p.m. & $n$ & Média \pm e.p.m. \\
\hline CSPGs - 150kDa & 8 & $13,86 \pm 1,956$ & 6 & $11,32 \pm 2,100$ & 8 & $12,07 \pm 1,091$ \\
\hline CSPGs - 70kDa & 6 & $170,1 \pm 13,73$ & 5 & $111,5 \pm 8,031$ & 8 & $125,9 \pm 9,289$ \\
\hline PEDF & 5 & $1,099 \pm 0,031$ & 7 & $1,088 \pm 0,054$ & 7 & $1,113 \pm 0,066$ \\
\hline MAP-2 & 5 & $1,842 \pm 0,344$ & 6 & $2,564 \pm 0,255$ & 7 & $3,459 \pm 0,547$ \\
\hline GAP-43 & 6 & $18,24 \pm 1,420$ & 7 & $17,90 \pm 2,271$ & 8 & $17,08 \pm 1,601$ \\
\hline Sinaptofisina & 6 & $11,86 \pm 0,824$ & 7 & $10,75 \pm 0,556$ & 8 & $12,44 \pm 1,719$ \\
\hline Laminina & 5 & $2,624 \pm 0,341$ & 4 & $4,362 \pm 0,213$ & 5 & $3,273 \pm 0,226$ \\
\hline $\mathrm{Bcl}-2$ & 5 & $1,837 \pm 0,328$ & 5 & $1,836 \pm 0,587$ & 5 & $1,244 \pm 0,380$ \\
\hline Receptor EphA2 & 6 & $8,256 \pm 1,596$ & 6 & $8,697 \pm 1,137$ & 8 & $8,057 \pm 0,973$ \\
\hline Receptor EphA3 & 4 & $9,445 \pm 2,157$ & 5 & $9,438 \pm 1,423$ & 8 & $8,581 \pm 1,758$ \\
\hline Receptor EphA4 & 5 & $3,362 \pm 0,300$ & 7 & $7,469 \pm 0,964$ & 6 & $7,663 \pm 0,800$ \\
\hline Receptor EphA5 & 5 & $2,130 \pm 0,245$ & 7 & $2,323 \pm 0,511$ & 5 & $2,256 \pm 0,487$ \\
\hline Receptor EphA7 & 4 & $2,513 \pm 0,587$ & 7 & $3,277 \pm 0,546$ & 8 & $3,149 \pm 0,357$ \\
\hline Receptor EphB1 & 5 & $3,224 \pm 0,282$ & 7 & $4,314 \pm 0,410$ & 8 & $4,513 \pm 0,659$ \\
\hline Receptor EphB4 & 6 & $3,617 \pm 0,442$ & 7 & $3,611 \pm 0,382$ & 8 & $3,122 \pm 0,414$ \\
\hline Receptor EphB6 & 4 & $2,935 \pm 0,691$ & 4 & $3,593 \pm 0,506$ & 5 & $2,678 \pm 0,655$ \\
\hline Efrina-A1 & 5 & $3,308 \pm 0,255$ & 7 & $3,953 \pm 0,692$ & 7 & $4,000 \pm 0,687$ \\
\hline Efrina-A2 & 5 & $25,73 \pm 1,583$ & 6 & $36,01 \pm 3,339$ & 6 & $42,27 \pm 6,154$ \\
\hline Efrina-A3 & 5 & $2,352 \pm 0,355$ & 6 & $1,603 \pm 0,112$ & 7 & $1,684 \pm 0,271$ \\
\hline Efrina-A4 & 4 & $7,055 \pm 1,060$ & 6 & $8,687 \pm 1,338$ & 5 & $7,456 \pm 1,149$ \\
\hline Efrina-A5 & 5 & $1,044 \pm 0,136$ & 7 & $1,076 \pm 0,138$ & 8 & $1,020 \pm 0,118$ \\
\hline Efrina-B1 & 5 & $3,547 \pm 0,477$ & 7 & $6,093 \pm 0,801$ & 7 & $5,445 \pm 0,417$ \\
\hline Efrina-B2 & 6 & $4,053 \pm 0,622$ & 5 & $4,226 \pm 0,593$ & 6 & $6,066 \pm 0,470$ \\
\hline Efrina-B3 & 5 & $10,44 \pm 1,183$ & 7 & $13,91 \pm 1,882$ & 6 & $19,58 \pm 2,947$ \\
\hline
\end{tabular}




\section{ANEXO G}

Dados referentes à quantificação de RNAm dos marcadores estudados através da RT-PCR. Os valores estão apresentados como média aritmética \pm erro padrão da média.

\begin{tabular}{|c|c|c|c|c|c|c|}
\hline \multicolumn{7}{|c|}{ RT-PCR } \\
\hline & \multicolumn{2}{|r|}{ Sham } & \multicolumn{2}{|r|}{ Salina } & \multicolumn{2}{|r|}{ PEDF } \\
\hline Marcadores & $n$ & Média \pm e.p.m. & $n$ & Média \pm e.p.m. & $n$ & Média \pm e.p.m. \\
\hline NT-3 & 6 & $1,295 \pm 0,121$ & 6 & $0,849 \pm 0,146$ & 6 & $0,796 \pm 0,114$ \\
\hline GDNF & 6 & $1,298 \pm 0,134$ & 5 & $0,925 \pm 0,122$ & 6 & $1,794 \pm 0,149$ \\
\hline BDNF & 6 & $1,069 \pm 0,113$ & 6 & $1,276 \pm 0,256$ & 6 & $1,126 \pm 0,138$ \\
\hline FGF-2 & 6 & $1,208 \pm 0,139$ & 4 & $1,113 \pm 0,067$ & 6 & $1,117 \pm 0,091$ \\
\hline Receptor EphA6 & 6 & $0,915 \pm 0,070$ & 5 & $0,944 \pm 0,114$ & 7 & $1,210 \pm 0,179$ \\
\hline Receptor EphB2 & 5 & $0,935 \pm 0,061$ & 4 & $0,915 \pm 0,062$ & 6 & $1,008 \pm 0,076$ \\
\hline RhoA & 5 & $1,132 \pm 0,115$ & 4 & $1,083 \pm 0,063$ & 6 & $1,070 \pm 0,070$ \\
\hline
\end{tabular}




\section{REFERÊNCIAS BIBLIOGRÁFICAS}

Acheson, A.; Lindsay, R.M. Non target-derived roles of the neurotrophins. Philos Trans $R$ Soc Lond B Biol Sci. 1996;351(1338):417-422.

Afshari, F.T.; Kwok, J.C.; Fawcett, J.W. Astrocyte-produced ephrins inhibit schwann cell migration via VAV2 signaling. J Neurosci. 2010;30(12):4246-4255.

Aguayo, A.J.; David, S.; Bray, G.M. Influences of the glial environment on the elongation of axons after injury: transplantation studies in adult rodents. J Exp Biol. 1981;95:231-240.

Aguayo, A.J.; Rasminsky, M.; Bray, G.M.; Carbonetto, S.; McKerracher, L.; Villegas-Perez, M.P.; Vidal-Sanz, M.; Carter, D.A. Degenerative and regenerative responses of injured neurons in the central nervous system of adult mammals. Philos Trans R Soc Lond B Biol Sci. 1991;331(1261):337-343.

Airaksinen, M.S.; Saarma, M. The GDNF family: signalling, biological functions and therapeutic value. Nat Rev Neurosci. 2002;3(5):383-394.

Aldskogius, H.; Kozlova, E.N. Central neuron-glial and glial-glial interactions following axon injury. Prog Neurobiol. 1998;55(1):1-26.

Anderson, D.K.; Hall, E.D. Pathophysiology of spinal cord trauma. Ann Emerg Med. 1993;22(6):987-992.

Andrade, M.S.; Hanania, F.R.; Daci, K.; Leme, R.J.; Chadi, G. Contuse lesion of the rat spinal cord of moderate intensity leads to a higher time-dependent secondary neurodegeneration than severe one. An open-window for experimental neuroprotective interventions. Tissue Cell. 2008;40(2):143-156.

Aoto, J.; Chen, L. Bidirectional ephrin/Eph signaling in synaptic functions. Brain Res. 2007;1184:72-80.

Arvanitis, D.; Davy, A. Eph/ephrin signaling: networks. Genes Dev. 2008;22(4):416-429.

Barriere, G.; Leblond, H.; Provencher, J.; Rossignol, S. Prominent role of the spinal central pattern generator in the recovery of locomotion after partial spinal cord injuries. J Neurosci. 2008;28(15):3976-3987.

Bartus, K.; James, N.D.; Bosch, K.D.; Bradbury, E.J. Chondroitin sulphate proteoglycans: Key modulators of spinal cord and brain plasticity. Exp Neurol. 2011. 
Basso, D.M.; Beattie, M.S.; Bresnahan, J.C. A sensitive and reliable locomotor rating scale for open field testing in rats. J Neurotrauma. 1995;12(1):1-21.

Basso, D.M.; Beattie, M.S.; Bresnahan, J.C.; Anderson, D.K.; Faden, A.I.; Gruner, J.A.; Holford, T.R.; Hsu, C.Y.; Noble, L.J.; Nockels, R.; Perot, P.L.; Salzman, S.K.; Young, W. MASCIS evaluation of open field locomotor scores: effects of experience and teamwork on reliability. Multicenter Animal Spinal Cord Injury Study. J Neurotrauma. 1996;13(7):343-359.

Battaglia, A.A.; Sehayek, K.; Grist, J.; McMahon, S.B.; Gavazzi, I. EphB receptors and ephrin-B ligands regulate spinal sensory connectivity and modulate pain processing. Nat Neurosci. 2003;6(4):339-340.

Becerra, S.P. Structure-function studies on PEDF. A noninhibitory serpin with neurotrophic activity. Adv Exp Med Biol. 1997;425:223-237.

Beg, A.A.; Sommer, J.E.; Martin, J.H.; Scheiffele, P. alpha2-Chimaerin is an essential EphA4 effector in the assembly of neuronal locomotor circuits. Neuron. 2007;55(5):768-778.

Benowitz, L.I.; Routtenberg, A. GAP-43: an intrinsic determinant of neuronal development and plasticity. Trends Neurosci. 1997;20(2):84-91.

Bilak, M.M.; Becerra, S.P.; Vincent, A.M.; Moss, B.H.; Aymerich, M.S.; Kuncl, R.W. Identification of the neuroprotective molecular region of pigment epitheliumderived factor and its binding sites on motor neurons. $J$ Neurosci. 2002;22(21):9378-9386.

Bilak, M.M.; Corse, A.M.; Bilak, S.R.; Lehar, M.; Tombran-Tink, J.; Kuncl, R.W. Pigment epithelium-derived factor (PEDF) protects motor neurons from chronic glutamate-mediated neurodegeneration. $J$ Neuropathol Exp Neurol. 1999a;58(7):719-728.

Bilak, M.M.; Shifrin, D.A.; Corse, A.M.; Bilak, S.R.; Kuncl, R.W. Neuroprotective utility and neurotrophic action of neurturin in postnatal motor neurons: comparison with GDNF and persephin. Mol Cell Neurosci. 1999b;13(5):326-336.

Blottner, D.; Baumgarten, H.G. Neurotrophy and regeneration in vivo. Acta Anat (Basel). 1994;150(4):235-245.

Boquillon, M.; Boquillon, J.P.; Bralet, J. Photochemically induced, graded cerebral infarction in the mouse by laser irradiation evolution of brain edema. $J$ Pharmacol Toxicol Methods. 1992;27(1):1-6.

Bowden, M.G.; Embry, A.E.; Gregory, C.M. Physical therapy adjuvants to promote optimization of walking recovery after stroke. Stroke Res Treat. $2011 ; 2011: 601416$. 
Bradbury, E.J.; Moon, L.D.; Popat, R.J.; King, V.R.; Bennett, G.S.; Patel, P.N.; Fawcett, J.W.; McMahon, S.B. Chondroitinase ABC promotes functional recovery after spinal cord injury. Nature. 2002;416(6881):636-640.

Bradford, M.M. A rapid and sensitive method for the quantitation of microgram quantities of protein utilizing the principle of protein-dye binding. Anal Biochem. 1976;72:248-254.

Bradshaw, R.A.; Altin, J.G.; Blaber, M.; Cavanaugh, K.P.; Eveleth, D.D.; Kornblum, H.I.; Leslie, F.M.; Raffioni, S. Neurotrophic factors in the CNS: biosynthetic processing and functional responses. Prog Brain Res. 1990;86:157167.

Brustein, E.; Rossignol, S. Recovery of locomotion after ventral and ventrolateral spinal lesions in the cat. I. Deficits and adaptive mechanisms. J Neurophysiol. 1998;80(3):1245-1267.

Bundesen, L.Q.; Scheel, T.A.; Bregman, B.S.; Kromer, L.F. Ephrin-B2 and EphB2 regulation of astrocyte-meningeal fibroblast interactions in response to spinal cord lesions in adult rats. J Neurosci. 2003;23(21):7789-7800.

Bunge, M.B.; Holets, V.R.; Bates, M.L.; Clarke, T.S.; Watson, B.D. Characterization of photochemically induced spinal cord injury in the rat by light and electron microscopy. Exp Neurol. 1994;127(1):76-93.

Butt, S.J.; Harris-Warrick, R.M.; Kiehn, O. Firing properties of identified interneuron populations in the mammalian hindlimb central pattern generator. $J$ Neurosci. 2002;22(22):9961-9971.

Cafferty, W.B.; Duffy, P.; Huebner, E.; Strittmatter, S.M. MAG and OMgp synergize with Nogo-A to restrict axonal growth and neurological recovery after spinal cord trauma. J Neurosci. 2010;30(20):6825-6837.

Cafferty, W.B.; Yang, S.H.; Duffy, P.J.; Li, S.; Strittmatter, S.M. Functional axonal regeneration through astrocytic scar genetically modified to digest chondroitin sulfate proteoglycans. J Neurosci. 2007;27(9):2176-2185.

Calancie, B. Spinal myoclonus after spinal cord injury. J Spinal Cord Med. 2006;29(4):413-424.

Cazalets, J.R.; Borde, M.; Clarac, F. Localization and organization of the central pattern generator for hindlimb locomotion in newborn rat. J Neurosci. 1995;15(7 Pt 1):4943-4951.

Chadi, G.; Moller, A.; Rosen, L.; Janson, A.M.; Agnati, L.A.; Goldstein, M.; Ogren, S.O.; Pettersson, R.F.; Fuxe, K. Protective actions of human recombinant basic fibroblast growth factor on MPTP-lesioned nigrostriatal dopamine neurons after intraventricular infusion. Exp Brain Res. 1993a;97(1):145-158. 
Chadi, G.; Rosen, L.; Cintra, A.; Tinner, B.; Zoli, M.; Pettersson, R.F.; Fuxe, K. Corticosterone increases FGF-2 (bFGF) immunoreactivity in the substantia nigra of the rat. Neuroreport. 1993b;4(6):783-786.

Chadi, G.; Silva, C.; Maximino, J.R.; Fuxe, K.; da Silva, G.O. Adrenalectomy counteracts the local modulation of astroglial fibroblast growth factor system without interfering with the pattern of 6-OHDA-induced dopamine degeneration in regions of the ventral midbrain. Brain Res. 2008;1190:23-38.

Chen, Y.C.; Chen, Q.S.; Lei, J.L.; Wang, S.L. Physical training modifies the agerelated decrease of GAP-43 and synaptophysin in the hippocampal formation in C57BL/6J mouse. Brain Res. 1998;806(2):238-245.

Cheng, H.; Cao, Y.; Olson, L. Spinal cord repair in adult paraplegic rats: partial restoration of hind limb function. Science. 1996;273(5274):510-513.

Cheng, H.; Wu, J.P.; Tzeng, S.F. Neuroprotection of glial cell line-derived neurotrophic factor in damaged spinal cords following contusive injury. J Neurosci Res. 2002;69(3):397-405.

Cheshire, W.P.; Santos, C.C.; Massey, E.W.; Howard, J.F., Jr. Spinal cord infarction: etiology and outcome. Neurology. 1996;47(2):321-330.

Conrad, S.; Schluesener, H.J.; Trautmann, K.; Joannin, N.; Meyermann, R.; Schwab, J.M. Prolonged lesional expression of RhoA and RhoB following spinal cord injury. J Comp Neurol. 2005;487(2):166-175.

Coonan, J.R.; Bartlett, P.F.; Galea, M.P. Role of EphA4 in defining the position of a motoneuron pool within the spinal cord. J Comp Neurol. 2003;458(1):98-111.

Dawson, D.W.; Volpert, O.V.; Gillis, P.; Crawford, S.E.; Xu, H.; Benedict, W.; Bouck, N.P. Pigment epithelium-derived factor: a potent inhibitor of angiogenesis. Science. 1999;285(5425):245-248.

De la Barrera SS, B.B., Marqués AM, Velasco MEF, Dans MC, Sotillo AR. Spinal cord infarction: prognosis and recovery in a serie of 36 patients. Spinal Cord. 2001(39):520-525.

De Martino, C.; Zamboni, L. Silver methenamine stain for electron microscopy. J Ultrastruct Res. 1967;19(3):273-282.

DeCoster, M.A.; Schabelman, E.; Tombran-Tink, J.; Bazan, N.G. Neuroprotection by pigment epithelial-derived factor against glutamate toxicity in developing primary hippocampal neurons. J Neurosci Res. 1999;56(6):604-610.

Di Giovanni, S.; De Biase, A.; Yakovlev, A.; Finn, T.; Beers, J.; Hoffman, E.P.; Faden, A.I. In vivo and in vitro characterization of novel neuronal plasticity factors identified following spinal cord injury. J Biol Chem. 2005;280(3):2084-2091. 
Dietz, V.; Grillner, S.; Trepp, A.; Hubli, M.; Bolliger, M. Changes in spinal reflex and locomotor activity after a complete spinal cord injury: a common mechanism? Brain. 2009;132(Pt 8):2196-2205.

Dijkstra, J.R.; Meek, M.F.; Robinson, P.H.; Gramsbergen, A. Methods to evaluate functional nerve recovery in adult rats: walking track analysis, video analysis and the withdrawal reflex. J Neurosci Methods. 2000;96(2):89-96.

do Carmo Cunha, J.; de Freitas Azevedo Levy, B.; de Luca, B.A.; de Andrade, M.S.; Gomide, V.C.; Chadi, G. Responses of reactive astrocytes containing S100beta protein and fibroblast growth factor-2 in the border and in the adjacent preserved tissue after a contusion injury of the spinal cord in rats: implications for wound repair and neuroregeneration. Wound Repair Regen. 2007;15(1):134-146.

Duysens, J.; Van de Crommert, H.W. Neural control of locomotion; The central pattern generator from cats to humans. Gait Posture. 1998;7(2):131-141.

Ek, E.T.; Dass, C.R.; Choong, P.F. PEDF: a potential molecular therapeutic target with multiple anti-cancer activities. Trends Mol Med. 2006;12(10):497-502.

Erschbamer, M.K.; Hofstetter, C.P.; Olson, L. RhoA, RhoB, RhoC, Rac1, Cdc42, and Tc10 mRNA levels in spinal cord, sensory ganglia, and corticospinal tract neurons and long-lasting specific changes following spinal cord injury. J Comp Neurol. 2005;484(2):224-233.

Fabes, J.; Anderson, P.; Brennan, C.; Bolsover, S. Regeneration-enhancing effects of EphA4 blocking peptide following corticospinal tract injury in adult rat spinal cord. Eur J Neurosci. 2007;26(9):2496-2505.

Fahmy, G.H.; Moftah, M.Z. Fgf-2 in astroglial cells during vertebrate spinal cord recovery. Front Cell Neurosci. 2010;4:129.

Fawcett, J.W.; Asher, R.A. The glial scar and central nervous system repair. Brain Res Bull. 1999;49(6):377-391.

Figueroa, J.D.; Benton, R.L.; Velazquez, I.; Torrado, A.I.; Ortiz, C.M.; Hernandez, C.M.; Diaz, J.J.; Magnuson, D.S.; Whittemore, S.R.; Miranda, J.D. Inhibition of EphA7 up-regulation after spinal cord injury reduces apoptosis and promotes locomotor recovery. J Neurosci Res. 2006;84(7):1438-1451.

Gale, K.; Kerasidis, H.; Wrathall, J.R. Spinal cord contusion in the rat: behavioral analysis of functional neurologic impairment. Exp Neurol. 1985;88(1):123-134.

Garcia-Alias, G.; Valero-Cabre, A.; Lopez-Vales, R.; Fores, J.; Verdu, E.; Navarro, $X$. Differential motor and electrophysiological outcome in rats with mid-thoracic or high lumbar incomplete spinal cord injuries. Brain Res. 2006;1108(1):195-204. 
Gaviria, M.; Haton, H.; Sandillon, F.; Privat, A. A mouse model of acute ischemic spinal cord injury. J Neurotrauma. 2002;19(2):205-221.

Gerin, C.G.; Madueke, I.C.; Perkins, T.; Hill, S.; Smith, K.; Haley, B.; Allen, S.A.; Garcia, R.P.; Paunesku, T.; Woloschak, G. Combination strategies for repair, plasticity, and regeneration using regulation of gene expression during the chronic phase after spinal cord injury. Synapse. 2011;65(12):1255-1281.

Ginsberg, M.D.; Busto, R. Rodent models of cerebral ischemia. Stroke. 1989;20(12):1627-1642.

Goldshmit, Y.; Bourne, J. Upregulation of EphA4 on astrocytes potentially mediates astrocytic gliosis after cortical lesion in the marmoset monkey. $J$ Neurotrauma. 2010;27(7):1321-1332.

Goldshmit, Y.; Galea, M.P.; Wise, G.; Bartlett, P.F.; Turnley, A.M. Axonal regeneration and lack of astrocytic gliosis in EphA4-deficient mice. J Neurosci. 2004;24(45):10064-10073.

Goldshmit, Y.; Spanevello, M.D.; Tajouri, S.; Li, L.; Rogers, F.; Pearse, M.; Galea, M.; Bartlett, P.F.; Boyd, A.W.; Turnley, A.M. EphA4 Blockers Promote Axonal Regeneration and Functional Recovery Following Spinal Cord Injury in Mice. PLoS One. $2011 ; 6(9): \mathrm{e} 24636$.

Gomez-Pinilla, F.; Ying, Z.; Roy, R.R.; Hodgson, J.; Edgerton, V.R. Afferent input modulates neurotrophins and synaptic plasticity in the spinal cord. $J$ Neurophysiol. 2004;92(6):3423-3432.

Gomide, V.; Chadi, G. Glial bFGF and S100 immunoreactivities increase in ascending dopamine pathways following striatal 6-OHDA-induced partial lesion of the nigrostriatal system: a sterological analysis. Int J Neurosci. 2005;115(4):537555.

Grill, R.; Murai, K.; Blesch, A.; Gage, F.H.; Tuszynski, M.H. Cellular delivery of neurotrophin-3 promotes corticospinal axonal growth and partial functional recovery after spinal cord injury. J Neurosci. 1997;17(14):5560-5572.

Gulino, R.; Dimartino, M.; Casabona, A.; Lombardo, S.A.; Perciavalle, V. Synaptic plasticity modulates the spontaneous recovery of locomotion after spinal cord hemisection. Neurosci Res. 2007;57(1):148-156.

Guzen, F.P.; de Almeida Leme, R.J.; de Andrade, M.S.; de Luca, B.A.; Chadi, G. Glial cell line-derived neurotrophic factor added to a sciatic nerve fragment grafted in a spinal cord gap ameliorates motor impairments in rats and increases local axonal growth. Restor Neurol Neurosci. 2009;27(1):1-16.

Hale, C.F.; Dietz, K.C.; Varela, J.A.; Wood, C.B.; Zirlin, B.C.; Leverich, L.S.; Greene, R.W.; Cowan, C.W. Essential role for vav Guanine nucleotide exchange 
factors in brain-derived neurotrophic factor-induced dendritic spine growth and synapse plasticity. J Neurosci. 2011;31(35):12426-12436.

Halegoua, S.; Armstrong, R.C.; Kremer, N.E. Dissecting the mode of action of a neuronal growth factor. Curr Top Microbiol Immunol. 1991;165:119-170.

Hao, J.X.; Herregodts, P.; Lind, G.; Meyerson, B.; Seiger, A.; Wiesenfeld-Hallin, Z. Photochemically induced spinal cord ischaemia in rats: assessment of blood flow by laser Doppler flowmetry. Acta Physiol Scand. 1994;151(2):209-215.

Hockenbery, D.; Nunez, G.; Milliman, C.; Schreiber, R.D.; Korsmeyer, S.J. Bcl-2 is an inner mitochondrial membrane protein that blocks programmed cell death. Nature. 1990;348(6299):334-336.

Hollis, E.R., 2nd; Tuszynski, M.H. Neurotrophins: potential therapeutic tools for the treatment of spinal cord injury. Neurotherapeutics. 2011;8(4):694-703.

Houenou, L.J.; D'Costa, A.P.; Li, L.; Turgeon, V.L.; Enyadike, C.; Alberdi, E.; Becerra, S.P. Pigment epithelium-derived factor promotes the survival and differentiation of developing spinal motor neurons. $J$ Comp Neurol. 1999;412(3):506-514.

Hubli, M.; Dietz, V.; Bolliger, M. Spinal Reflex Activity: A Marker for Neuronal Functionality After Spinal Cord Injury. Neurorehabil Neural Repair. 2011.

Hunter, A.J.; Green, A.R.; Cross, A.J. Animal models of acute ischaemic stroke: can they predict clinically successful neuroprotective drugs? Trends Pharmacol Sci. 1995;16(4):123-128.

Iannotti, C.; Li, H.; Yan, P.; Lu, X.; Wirthlin, L.; Xu, X.M. Glial cell line-derived neurotrophic factor-enriched bridging transplants promote propriospinal axonal regeneration and enhance myelination after spinal cord injury. Exp Neurol. 2003;183(2):379-393.

Irizarry-Ramirez, M.; Willson, C.A.; Cruz-Orengo, L.; Figueroa, J.; Velazquez, I.; Jones, H.; Foster, R.D.; Whittemore, S.R.; Miranda, J.D. Upregulation of EphA3 receptor after spinal cord injury. J Neurotrauma. 2005;22(8):929-935.

Jacobson, M.D.; Burne, J.F.; King, M.P.; Miyashita, T.; Reed, J.C.; Raff, M.C. Bcl2 blocks apoptosis in cells lacking mitochondrial DNA. Nature. 1993;361(6410):365-369.

Jahn, R.; Schiebler, W.; Ouimet, C.; Greengard, P. A 38,000-dalton membrane protein (p38) present in synaptic vesicles. Proc Natl Acad Sci $U S A$. 1985;82(12):4137-4141.

Kamei, N.; Tanaka, N.; Oishi, Y.; Hamasaki, T.; Nakanishi, K.; Sakai, N.; Ochi, M. BDNF, NT-3, and NGF released from transplanted neural progenitor cells promote 
corticospinal axon growth in organotypic cocultures. Spine (Phila Pa 1976). 2007;32(12):1272-1278.

Kasahara, K.; Nakagawa, T.; Kubota, T. Neuronal loss and expression of neurotrophic factors in a model of rat chronic compressive spinal cord injury. Spine (Phila Pa 1976). 2006;31(18):2059-2066.

Kiehn, O.; Butt, S.J. Physiological, anatomical and genetic identification of CPG neurons in the developing mammalian spinal cord. Prog Neurobiol. 2003;70(4):347-361.

Klapdor, K.; Dulfer, B.G.; Hammann, A.; Van der Staay, F.J. A low-cost method to analyse footprint patterns. J Neurosci Methods. 1997;75(1):49-54.

Klein, R. Bidirectional modulation of synaptic functions by Eph/ephrin signaling. Nat Neurosci. 2009;12(1):15-20.

Krassioukov, A.V.; Weaver, L.C. Morphological changes in sympathetic preganglionic neurons after spinal cord injury in rats. Neuroscience. 1996;70(1):211-225.

Kullander, K.; Butt, S.J.; Lebret, J.M.; Lundfald, L.; Restrepo, C.E.; Rydstrom, A.; Klein, R.; Kiehn, O. Role of EphA4 and EphrinB3 in local neuronal circuits that control walking. Science. 2003;299(5614):1889-1892.

Kuncl, R.W.; Bilak, M.M.; Bilak, S.R.; Corse, A.M.; Royal, W.; Becerra, S.P. Pigment epithelium-derived factor is elevated in CSF of patients with amyotrophic lateral sclerosis. J Neurochem. 2002;81(1):178-184.

Lee, J.K.; Park, M.S.; Kim, Y.S.; Moon, K.S.; Joo, S.P.; Kim, T.S.; Kim, J.H.; Kim, S.H. Photochemically induced cerebral ischemia in a mouse model. Surg Neurol. 2007;67(6):620-625; discussion 625.

Lemons, M.L.; Howland, D.R.; Anderson, D.K. Chondroitin sulfate proteoglycan immunoreactivity increases following spinal cord injury and transplantation. Exp Neurol. 1999;160(1):51-65.

Li, G.L.; Farooque, M.; Isaksson, J.; Olsson, Y. Changes in synapses and axons demonstrated by synaptophysin immunohistochemistry following spinal cord compression trauma in the rat and mouse. Biomed Environ Sci. 2004;17(3):281290.

Lin, L.F.; Doherty, D.H.; Lile, J.D.; Bektesh, S.; Collins, F. GDNF: a glial cell linederived neurotrophic factor for midbrain dopaminergic neurons. Science. 1993;260(5111):1130-1132.

Lippoldt, A.; Andbjer, B.; Rosen, L.; Richter, E.; Ganten, D.; Cao, Y.; Pettersson, R.F.; Fuxe, K. Photochemically induced focal cerebral ischemia in rat: time 
dependent and global increase in expression of basic fibroblast growth factor mRNA. Brain Res. 1993;625(1):45-56.

Liu, Y.; Himes, B.T.; Murray, M.; Tessler, A.; Fischer, I. Grafts of BDNF-producing fibroblasts rescue axotomized rubrospinal neurons and prevent their atrophy. Exp Neurol. 2002;178(2):150-164.

Livak, K.J.; Schmittgen, T.D. Analysis of relative gene expression data using realtime quantitative PCR and the 2(-Delta Delta $\mathrm{C}(\mathrm{T})$ ) Method. Methods. $2001 ; 25(4): 402-408$.

Lu, K.W.; Chen, Z.Y.; Jin, D.D.; Hou, T.S.; Cao, L.; Fu, Q. Cationic liposomemediated GDNF gene transfer after spinal cord injury. $J$ Neurotrauma. 2002;19(9):1081-1090.

Maeda, T.; Hori, S.; Sasaki, S.; Maruo, S. Effects of tension at the site of coaptation on recovery of sciatic nerve function after neurorrhaphy: evaluation by walking-track measurement, electrophysiology, histomorphometry, and electron probe X-ray microanalysis. Microsurgery. 1999;19(4):200-207.

Maisonpierre, P.C.; Belluscio, L.; Squinto, S.; Ip, N.Y.; Furth, M.E.; Lindsay, R.M.; Yancopoulos, G.D. Neurotrophin-3: a neurotrophic factor related to NGF and BDNF. Science. 1990;247(4949 Pt 1):1446-1451.

Martinez, A.; Otal, R.; Soriano Garcia, E. [Ephrins, neuronal development and plasticity]. Rev Neurol. 2004;38(7):647-655.

Meek, M.F.; Den Dunnen, W.F.; Schakenraad, J.M.; Robinson, P.H. Long-term evaluation of functional nerve recovery after reconstruction with a thin-walled biodegradable poly (DL-lactide-epsilon-caprolactone) nerve guide, using walking track analysis and electrostimulation tests. Microsurgery. 1999;19(5):247-253.

Mendell, L.M. Neurotrophins and sensory neurons: role in development, maintenance and injury. A thematic summary. Philos Trans $R$ Soc Lond B Biol Sci. 1996;351(1338):463-467.

Mitsumoto, H.; Tsuzaka, K. Neurotrophic factors and neuromuscular disease: I. General comments, the neurotrophin family, and neuropoietic cytokines. Muscle Nerve. 1999;22(8):983-999.

Mocchetti, I.; Rabin, S.J.; Colangelo, A.M.; Whittemore, S.R.; Wrathall, J.R. Increased basic fibroblast growth factor expression following contusive spinal cord injury. Exp Neurol. 1996;141(1):154-164.

Navone, F.; Jahn, R.; Di Gioia, G.; Stukenbrok, H.; Greengard, P.; De Camilli, P. Protein p38: an integral membrane protein specific for small vesicles of neurons and neuroendocrine cells. J Cell Biol. 1986;103(6 Pt 1):2511-2527. 
Negishi, M.; Katoh, H. Rho family GTPases and dendrite plasticity. Neuroscientist. 2005;11(3):187-191.

Niclou, S.P.; Ehlert, E.M.; Verhaagen, J. Chemorepellent axon guidance molecules in spinal cord injury. J Neurotrauma. 2006;23(3-4):409-421.

Novy, J.; Carruzzo, A.; Maeder, P.; Bogousslavsky, J. Spinal cord ischemia: clinical and imaging patterns, pathogenesis, and outcomes in 27 patients. Arch Neurol. 2006;63(8):1113-1120.

Oppenheim, R.W.; Houenou, L.J.; Johnson, J.E.; Lin, L.F.; Li, L.; Lo, A.C.; Newsome, A.L.; Prevette, D.M.; Wang, S. Developing motor neurons rescued from programmed and axotomy-induced cell death by GDNF. Nature. 1995;373(6512):344-346.

Oudega, M.; Hagg, T. Neurotrophins promote regeneration of sensory axons in the adult rat spinal cord. Brain Res. 1999;818(2):431-438.

Pevsner, P.H.; Eichenbaum, J.W.; Miller, D.C.; Pivawer, G.; Eichenbaum, K.D.; Stern, A.; Zakian, K.L.; Koutcher, J.A. A photothrombotic model of small early ischemic infarcts in the rat brain with histologic and MRI correlation. J Pharmacol Toxicol Methods. 2001;45(3):227-233.

Pinter, M.M.; Dimitrijevic, M.R. Gait after spinal cord injury and the central pattern generator for locomotion. Spinal Cord. 1999;37(8):531-537.

Prado, R.; Dietrich, W.D.; Watson, B.D.; Ginsberg, M.D.; Green, B.A. Photochemically induced graded spinal cord infarction. Behavioral, electrophysiological, and morphological correlates. J Neurosurg. 1987;67(5):745753.

Reichardt, L.F. Neurotrophin-regulated signalling pathways. Philos Trans $R$ Soc Lond B Biol Sci. 2006;361(1473):1545-1564.

Richardson, P.M.; McGuinness, U.M.; Aguayo, A.J. Axons from CNS neurons regenerate into PNS grafts. Nature. 1980;284(5753):264-265.

Rivlin, A.S.; Tator, C.H. Objective clinical assessment of motor function after experimental spinal cord injury in the rat. J Neurosurg. 1977;47(4):577-581.

Rodrigues, R.W.; Gomide, V.C.; Chadi, G. Astroglial and microglial reaction after a partial nigrostriatal degeneration induced by the striatal injection of different doses of 6-hydroxydopamine. Int J Neurosci. 2001;109(1-2):91-126.

Rossignol, S.; Barriere, G.; Alluin, O.; Frigon, A. Re-expression of locomotor function after partial spinal cord injury. Physiology (Bethesda). 2009;24:127-139. 
Rossignol, S.; Frigon, A. Recovery of locomotion after spinal cord injury: some facts and mechanisms. Annu Rev Neurosci. 2011;34:413-440.

Rybak, I.A.; Shevtsova, N.A.; Lafreniere-Roula, M.; McCrea, D.A. Modelling spinal circuitry involved in locomotor pattern generation: insights from deletions during fictive locomotion. J Physiol. 2006;577(Pt 2):617-639.

Sanchez Martin, C.; Diaz-Nido, J.; Avila, J. Regulation of a site-specific phosphorylation of the microtubule-associated protein 2 during the development of cultured neurons. Neuroscience. 1998;87(4):861-870.

Sasaki, M.; Radtke, C.; Tan, A.M.; Zhao, P.; Hamada, H.; Houkin, K.; Honmou, O.; Kocsis, J.D. BDNF-hypersecreting human mesenchymal stem cells promote functional recovery, axonal sprouting, and protection of corticospinal neurons after spinal cord injury. J Neurosci. 2009;29(47):14932-14941.

Scarisbrick, I.A.; Isackson, P.J.; Windebank, A.J. Differential expression of brainderived neurotrophic factor, neurotrophin-3, and neurotrophin-4/5 in the adult rat spinal cord: regulation by the glutamate receptor agonist kainic acid. J Neurosci. 1999;19(18):7757-7769.

Scheff, S.W.; Saucier, D.A.; Cain, M.E. A statistical method for analyzing rating scale data: the BBB locomotor score. J Neurotrauma. 2002;19(10):1251-1260.

Schroeter, M.; Jander, S.; Stoll, G. Non-invasive induction of focal cerebral ischemia in mice by photothrombosis of cortical microvessels: characterization of inflammatory responses. J Neurosci Methods. 2002;117(1):43-49.

Scully, J.L.; Otten, U. NGF: not just for neurons. Cell Biol Int. 1995;19(5):459-469.

Sentman, C.L.; Shutter, J.R.; Hockenbery, D.; Kanagawa, O.; Korsmeyer, S.J. bcl2 inhibits multiple forms of apoptosis but not negative selection in thymocytes. Cell. 1991;67(5):879-888.

Shao, Y.; McCarthy, K.D. Plasticity of astrocytes. Glia. 1994;11(2):147-155.

Siebert, J.R.; Osterhout, D.J. The inhibitory effects of chondroitin sulfate proteoglycans on oligodendrocytes. J Neurochem. 2011;119(1):176-188.

Smith, P.F.; Darlington, C.L.; Curthoys, I.S. The effect of visual deprivation on vestibular compensation in the guinea pig. Brain Res. 1986;364(1):195-198.

Song, X.J.; Zheng, J.H.; Cao, J.L.; Liu, W.T.; Song, X.S.; Huang, Z.J. EphrinBEphB receptor signaling contributes to neuropathic pain by regulating neural excitability and spinal synaptic plasticity in rats. Pain. 2008;139(1):168-180. 
Spangenberg, E.M.; Augustsson, H.; Dahlborn, K.; Essen-Gustavsson, B.; Cvek, $\mathrm{K}$. Housing-related activity in rats: effects on body weight, urinary corticosterone levels, muscle properties and performance. Lab Anim. 2005;39(1):45-57.

Stahnisch, F.W.; Nitsch, R. Santiago Ramon y Cajal's concept of neuronal plasticity: the ambiguity lives on. Trends Neurosci. 2002;25(11):589-591.

Steele, F.R.; Chader, G.J.; Johnson, L.V.; Tombran-Tink, J. Pigment epitheliumderived factor: neurotrophic activity and identification as a member of the serine protease inhibitor gene family. Proc Natl Acad Sci U S A. 1993;90(4):1526-1530.

Stellmach, V.; Crawford, S.E.; Zhou, W.; Bouck, N. Prevention of ischemiainduced retinopathy by the natural ocular antiangiogenic agent pigment epitheliumderived factor. Proc Natl Acad Sci U S A. 2001;98(5):2593-2597.

Sung, J.K.; Miao, L.; Calvert, J.W.; Huang, L.; Louis Harkey, H.; Zhang, J.H. A possible role of RhoA/Rho-kinase in experimental spinal cord injury in rat. Brain Res. 2003;959(1):29-38.

Szebenyi, G.; Fallon, J.F. Fibroblast growth factors as multifunctional signaling factors. Int Rev Cytol. 1999;185:45-106.

Takamatsu, H.; Tsukada, H.; Kakiuchi, T.; Tatsumi, M.; Umemura, K. Changes in local cerebral blood flow in photochemically induced thrombotic occlusion model in rats. Eur J Pharmacol. 2000;398(3):375-379.

Taniwaki, T.; Hirashima, N.; Becerra, S.P.; Chader, G.J.; Etcheberrigaray, R.; Schwartz, J.P. Pigment epithelium-derived factor protects cultured cerebellar granule cells against glutamate-induced neurotoxicity. $J$ Neurochem. 1997;68(1):26-32.

Tazerart, S.; Vinay, L.; Brocard, F. The persistent sodium current generates pacemaker activities in the central pattern generator for locomotion and regulates the locomotor rhythm. J Neurosci. 2008;28(34):8577-8589.

Temporin, K.; Tanaka, H.; Kuroda, Y.; Okada, K.; Yachi, K.; Moritomo, H.; Murase, T.; Yoshikawa, H. IL-1beta promotes neurite outgrowth by deactivating RhoA via p38 MAPK pathway. Biochem Biophys Res Commun. 2008;365(2):375-380.

Terenghi, G. Peripheral nerve regeneration and neurotrophic factors. $J$ Anat. 1999;194 ( Pt 1):1-14.

The national spinal cord injury statistical center. Facts and figures at a glance. Birminghan: University of Alabama. 2011.

Tombran-Tink, J.; Barnstable, C.J. PEDF: a multifaceted neurotrophic factor. Nat Rev Neurosci. 2003;4(8):628-636. 
Tombran-Tink, J.; Johnson, L.V. Neuronal differentiation of retinoblastoma cells induced by medium conditioned by human RPE cells. Invest Ophthalmol Vis Sci. 1989;30(8):1700-1707.

Tombran-Tink, J.; Mazuruk, K.; Rodriguez, I.R.; Chung, D.; Linker, T.; Englander, E.; Chader, G.J. Organization, evolutionary conservation, expression and unusual Alu density of the human gene for pigment epithelium-derived factor, a unique neurotrophic serpin. Mol Vis. 1996;2:11.

Traystman, R.J. Animal models of focal and global cerebral ischemia. ILAR J. 2003;44(2):85-95.

Tripathi, R.B.; McTigue, D.M. Chronically increased ciliary neurotrophic factor and fibroblast growth factor-2 expression after spinal contusion in rats. J Comp Neurol. 2008;510(2):129-144.

Tuszynski, M.H.; Grill, R.; Jones, L.L.; Brant, A.; Blesch, A.; Low, K.; Lacroix, S.; Lu, P. NT-3 gene delivery elicits growth of chronically injured corticospinal axons and modestly improves functional deficits after chronic scar resection. Exp Neurol. 2003;181(1):47-56.

Varejão, A.S.; Meek, M.F.; Ferreira, A.J.; Patricio, J.A.; Cabrita, A.M. Functional evaluation of peripheral nerve regeneration in the rat: walking track analysis. $J$ Neurosci Methods. 2001;108(1):1-9.

Wang, J.M.; Zeng, Y.S.; Wu, J.L.; Li, Y.; Teng, Y.D. Cograft of neural stem cells and schwann cells overexpressing TrkC and neurotrophin-3 respectively after rat spinal cord transection. Biomaterials. 2011;32(30):7454-7468.

Watson, B.D.; Prado, R.; Dietrich, W.D.; Ginsberg, M.D.; Green, B.A. Photochemically induced spinal cord injury in the rat. Brain Res. 1986;367(12):296-300.

Watson BD, H.V., Prado R. Laser-driven photochemical induction of spinal cord injury in the rat: Methodology, histopathology, and aplications. Neuroprotocols. 1993(3):3-15.

Whittaker, M.T.; Zai, L.J.; Lee, H.J.; Pajoohesh-Ganji, A.; Wu, J.; Sharp, A.; Wyse, R.; Wrathall, J.R. GGF2 (Nrg1-beta3) treatment enhances NG2(+) cell response and improves functional recovery after spinal cord injury. Glia. 2011.

Wilkinson, D.G. Multiple roles of EPH receptors and ephrins in neural development. Nat Rev Neurosci. 2001;2(3):155-164.

Willson, C.A.; Miranda, J.D.; Foster, R.D.; Onifer, S.M.; Whittemore, S.R. Transection of the adult rat spinal cord upregulates EphB3 receptor and ligand expression. Cell Transplant. 2003;12(3):279-290. 
Yabe, T.; Herbert, J.T.; Takanohashi, A.; Schwartz, J.P. Treatment of cerebellar granule cell neurons with the neurotrophic factor pigment epithelium-derived factor in vitro enhances expression of other neurotrophic factors as well as cytokines and chemokines. J Neurosci Res. 2004;77(5):642-652.

Yabe, T.; Wilson, D.; Schwartz, J.P. NFkappaB activation is required for the neuroprotective effects of pigment epithelium-derived factor (PEDF) on cerebellar granule neurons. J Biol Chem. 2001;276(46):43313-43319.

Zanon BB, B.L., Batista CM, Ivo MMAA, Cecatto RB, Chadi G. Caracterization of photochemically induced low thoracic rat spinal cord injury and the neuroplasticity responses in lumbar anterior horn. Behavioral, cellular and biochemical evaluations. Em submissão.

Zhang, Y.J.; Zhang, W.; Lin, C.G.; Ding, Y.; Huang, S.F.; Wu, J.L.; Li, Y.; Dong, H.; Zeng, Y.S. Neurotrophin-3 gene modified mesenchymal stem cells promote remyelination and functional recovery in the demyelinated spinal cord of rats. $J$ Neurol Sci. 2011.

Zhao, J.; Yuan, G.; Cendan, C.M.; Nassar, M.A.; Lagerstrom, M.C.; Kullander, K.; Gavazzi, I.; Wood, J.N. Nociceptor-expressed ephrin-B2 regulates inflammatory and neuropathic pain. Mol Pain. 2010;6:77.

Zoli, M.; Zini, I.; Agnati, L.F.; Guidolin, D.; Ferraguti, F.; Fuxe, K. Aspects of neural plasticity in the central nervous system-I. Computer-assisted image analysis methods. Neurochem Int. 1990;16(4):383-418.

Zong, S.; Zeng, G.; Wei, B.; Xiong, C.; Zhao, Y. Beneficial Effect of Interleukin-1 Receptor Antagonist Protein on Spinal Cord Injury Recovery in the Rat. Inflammation. 2011. 